\title{
Tendencia de la Mortalidad por Causas Violentas en la Población General y Entre los Adolescentes y Jóvenes de la Región de las Américas
}

\author{
Trends in Mortality Due to Violent Causes in the Overall Population and \\ Among Adolescents and Young People in the Americas
}

\author{
João Yunes ${ }^{1}$ \\ Danuta Rajs ${ }^{2}$
}

YUNES, J. \& RAJS, D. Trends in Mortality Due to Violent Causes in the Overall Population and Among Adolescents and Young People in the Americas. Cad. Saúde Públ., Rio de Janeiro, 10 (supplement 1): 88-125, 1994.

This article analyzes the trend in mortality by external causes and by groups of causes in 15 countries, from 1979 to 1990. It demonstrates that in nine countries (Argentina, Canada, Chile, Costa Rica, Mexico, Surinam, Trinidad and Tobago, USA, and Venezuela) there is a downward trend in all of the age brackets studied and that in three, for the overall population (Uruguay), or the 10-24-year bracket (Panama and Puerto Rico), there is also a downward trend. Only three countries (Brazil, Colombia, and Cuba) displayed clear upward trends for all age groups, while the same was true for the population as a whole in two (Panama and Puerto Rico) and in one (Uruguay) for the 10-24-year bracket.

Mortality due to external causes by age bracket is frequently concentrated in adolescents and young people, and although males predominate, gender differences in mortality have tended to decrease. In terms of magnitude of mortality by rate, there are three major groups of countries: high mortality rates (Colombia, Cuba, Chile, Mexico, and Surinam), medium (Brazil, Canada, USA, Puerto Rico, and Venezuela) and moderate (Argentina, Costa Rica, Panama, Trinidad and Tobago, and Uruguay). As for groups of external causes, it was obvious that despite downward trends, traffic mortality is still a serious problem in Brazil, Canada, the USA, and Venezuela. Mortality due to suicide is still a major concern in Canada, USA, Surinam, Trinidad and Tobago, Argentina, and Uruguay.

Mortality due to homicide is particularly alarming in Brazil, Colombia, Mexico, Panama, Puerto Rico, and Venezuela, above all among adolescents and young people. For the three groups of external causes (traffic accidents, suicide, and homicide) there has been an unmistakable downward trend in the majority of the countries in the Americas in terms of traffic accidents, while mortality due to homicide and suicide has tended to increase in some, particularly affecting adolescents and young people, above all the 15-19-year bracket. The study also proposes a role for the health sector in preventing mortality due to violent causes.

Key words: Violence; Mortality; Adolescents; Epidemiology

${ }^{I}$ Programa Especial de Salud MaternoInfantil y Población, Organización Panamericana de La Salud. 525 Twenty Third Street N.W., Washington, D.C. 20037, U.S.A.

${ }^{2}$ Coordinación de Planificación y Desarrollo Técnico del Servicio Médico Legal de Chile. Av. La Paz 1012, Santiago, Chile.

\section{INTRODUCCION}

Por primera vez en los Cuerpos Directivos de la Organización Panamericana de la Salud (OPS), Oficina Regional de la Organización Mundial de la Salud (OMS), se discute el problema de la violencia y salud. 
En la $111^{a}$ Reunión del Comite Ejecutivo, realizada en Washington entre los días 28 de junio y 1 de julio de 1993, fue presentado y discutido este tema, donde se afirma que "las conductas violentas en la Región de las Américas constituyen un gran problema de salud pública y son causa de deterioro de la calidad de vida. Sus consecuencias para la salud y el bienestar de las colectividades, su equilibrio social y su estabilidad económica reviste proporciones alarmantes" (OPS, 1993).

Recientemente, Yunes (1993) publicó la "Mortalidad por causas violentas en la Región de las Américas", donde analiza el comportamiento de estas causas en la población general y, en particular, aquella menor de 24 años.

Tambien Yunes \& Rajs, (s/d) analizaron la mortalidad por causas violentas entre los adolescentes y los jóvenes de la Región de las Américas, con el objetivo de intentar interpretar el comportamiento de la mortalidad por causas externas en la población de todas las edades y en la población de 10 a 24 años.

La Organización Mundial de la Salud definió como tema oficial para la conmemoración del Día Mundial de la Salud (en 1993) el tema de la violencia, con el objetivo de concientizar y debatir esta problemática en todo nuestro universo durante el período de 1993-1994.

Esta problemática se reviste de la mayor importancia cuando se analizan algunos datos.

En los EE.UU. de Norteamérica, por ejemplo, se estimaba a mediados de la década pasada que sólo los accidentes de vehículos a motor generaban pérdidas del orden de los 75 billones de dólares estadounidenses anuales, dando lugar a unas 45.000 defunciones por año, de las cuales más del $60 \%$ correspondía a personas menores de 35 años de edad. Se constataba, además, que estos accidentes constituían la principal causa de lesiones cerebrales y de la médula espinal (U.S. Department of Health \& Human Services, 1991). A su vez, el costo anual total de los accidentes del trabajo fue estimado en ese país en unos 48 billones de dólares estadounidenses a fines del decenio anterior, ocasionando entre 7.000 y 11.000 defunciones, 85.000 hospitalizaciones, 2 millones de casos de discapacidad debida a las lesiones, 75 millones de días laborales perdidos y 250.000 años de vida potencial perdidos (OPS, 1990).

Se dispone de pocos estudios acerca de las relaciones entre la violencia y las condiciones de la salud colectiva de la población de la Región. Difícil es, por lo tanto, encontrar elementos teóricos suficientes para abordar el análisis de esta problemática. Entre los trabajos más recientes destacan los de AnzolaPérez \& Bangdiwala (1991), Aalund et al. (1990), Danielsen et al. (1989), Mello Jorge \& Bernardes Marques (1985), Franco (1990), Híjar Medina (1986), Minayo (1990), U.S. Department of Health \& Human Services (1991), Yunes (1993), Rajs \& Sandoval (1992) y Sáez \& Rajs (1992).

En las Américas, las actuales condiciones socioeconómicas y políticas están vinculadas al proceso de profundas transformaciones acaecido, en la economía capitalista mundial desde finales de los años 70, proceso que ha repercutido en un deterioro de la calidad de vida tanto en los países centrales como en los de la periferia del sistema económico (OPS, 1990). La producción se orientó prioritariamente a la exportación, según pautas de política económica que privilegián la acumulación y la inversión en infraestructura industrial, mientras asignan la responsabilidad de solucionar los problemas sociales al ámbito privado, más que a las funciones públicas, postergando el legado de derechos sociales que muchas de estas sociedades habían construído al menos desde la Segunda Postguerra (OPS, 1990).

En la esfera de lo social, la década pasada, denominada por la Comisión Económica para América Latina y el Caribe (CEPALC) (1989 y 1990) la "década perdida" para los países de América Latina y del Caribe, se caracterizó por la profundización del desempleo tecnológico, debido a la persistencia de la falta de calificación de la fuerza de trabajo y por la consecuente ampliación de los grupos poblacionales marginados del desarrollo y del acceso a servicios básicos de vivienda, salud y educación.

Las agudas crisis financieras e industriales 
determinaron, a su vez, el empobrecimiento de vastos sectores de las capas medias. La reorientación de las modalidades de la organización productiva dio origen a nuevas formas de relación entre la fuerza de trabajo y las empresas, elevándose la desocupación y surgiendo la economía informal (CEPALC, 1991), lícita e ilícita, en algunos casos convertida en el sector más dinámico, pero, a la vez, conflictivo y desestabilizador (Cano, 1989). El proceso de modernización se dio de modo desigual, concentrándose en algunas ramas de la producción y en las instancias de dirección de los grandes consorcios empresariales e induciendo la aparición paradójica de versiones inéditas de subempleo y/o de empleo temporal (García, 1992), [ha estimado en um $53 \%$ la proporción de la fuerza de trabajo ocupada en microempresas y en los sectores de empleo informal en América Latina y en el Caribe alrededor de 1990 (Tokman, 1992)] caracterizado por el uso de tecnología rudimentaria, no exenta en ocasiones de la utilización de objetos riesgosos para la vida y para la salud y por el nulo resguardo de las condiciones de trabajo.

Las transformaciones de las estructuras productivas se manifestaron en el desarrollo de nuevos sectores exportadores, como el agroindustrial, lo cual incidió en la modificación de los flujos migratorios urbano-rurales. Las ciudades profundizaron su deterioro por el contínuo crecimiento de cinturones marginales y por la velocidad del proceso de urbanización. En 1950, sólo 6 países de América Latina tenían más de un 50\% de población urbana, en tanto que en 1990, 12 de estas naciones contaban con más del $70 \%$ de su población asentada en ciudades (OPS, 1990).

La debilidad del contrato social vigente desde hace mucho tiempo en gran parte de los países de esta Región y el retroceso de los ordenamientos juridicos relativos a los derechos civiles, económicos y sociales en otros, favorecieron la irrupción de graves conflictos, que llegaron a expresarse en una generalización de la violencia de distintos órdenes (Cano, 1989), cuyos efectos sobre la calidad de vida se hacen notar cada vez más.

En nuestras sociedades es necesario, por lo tanto, entender el proceso de la violencia en todas sus facetas, distinguiendo sus diferentes causalidades (políticas, económicas, culturales, religiosas, étnicas, de género, etarias y otras), sus diversas expresiones concretas (causas externas de las defunciones y de las enfermedades y discapacidades físicas y psicológicas), su distribución según los grupos poblacionales afectados en tanto víctimas (trabajadores, niños, adolescentes, jóvenes, mujeres, etnias, minorías) y como victimarios, las distintas circunstancias de ocurrencia de las lesiones y enfermedades (condiciones peligrosas y actos inseguros), los agentes productores de las mismas (físicos, químicos, biológicos, mecánicos, ergonómicos, psicosociales y otros) y la naturaleza y la gravedad de los daños producidos al organismo humano.

En otros términos, la comprensión de la compleja red de determinaciones y de manifestaciones específicas y diferenciadas de la violencia puede permitir buscar en la propria sociedad las raíces del cambio (Minayo, 1990), con el objeto de eliminar definitivamente esta amenaza para la vida y para la salud de la población.

El objetivo del presente trabajo es abordar la descripción de las tendencias y de algunas distribuciones de la mortalidad por causas externas en las Américas, enfatizando en la situación particular de los adolescentes y de los jóvenes, como grupo etario preponderantemente afectado por la violencia. Esto permitirá aportar algunos criterios para la adopción de políticas de promoción de la salud y de prevención de los daños en esta esfera. Sin embargo, la complejidad del problema aconseja desarrollar y promover ampliamente la investigación interdisciplinaria de todos los aspectos antes señalados, con miras al logro de precisión en la formulación de políticas y estrategias destinadas al control y a la eliminación de la violencia en nuestras sociedades.

\section{MATERIAL Y METODO}

El presente estudio describe e intenta interpretar la tendencia y el comportamiento 
de la mortalidad por causas externas en la población general (para todas las edades) y en adolescentes y jóvenes de 10 a 24 años de edad en las Américas, como aproximación al conocimiento de la dinámica de estos problemas en esos grupos poblacionales.

El grupo de 10 a 24 años de edad ha sido elegido como foco del estudio, debido a que se trata de un segmento poblacional de baja mortalidad general, en el que las causas externas adquieren su máxima expresión como causas de muerte.

Se entiende como causa externa o violenta de defunción a toda causa incluída en la "Clasificación Suplementaria de Traumatismos y Envenenamientos" de la IX Revisión de la Clasificación Internacional de Enfermedades, Traumatismos y Causas de Defunción (CIEIX).

Para fines de presentación de los datos, se realizó una agrupación de las causas externas, tomando como base los grupos que incluyen el Banco de Datos de la OPS (confeccionado con base en informes anuales de mortalidad remitidos por los países de la región), obteniéndose los siguientes rubros:

Todas las Causas Externas (E800-E999); Accidentes de Tráfico de Vehículos de Motor (E810-E819);

Suicidios y Lesiones Autoinfligidas (E950E959);

Homicidios y Lesiones Intencionales y Lesiones Resultantes de Operaciones de Guerra o por Intervención Legal (E960E969; E970-E978; E990-E999).

En el texto y en las tablas, siempre que nos referíamos a homicidios se incluyen las demás "Lesiones Intencionales y Lesiones Resultantes de Operaciones de Guerra y por Intervención Legal":

Caídas Accidentales (E880-E888);

Lesiones en que se Ignora si Fueron Accidental o Intencionalmente Infligidas (E980-E989);

Otras Causas Externas (E800-E807; E820E879; E890-E949).
Los agrupamientos de las causas externas permite subdividirlos segun tres características:

Lesiones y Enfermedades de Origen Intencional (E950-E959; E960-E969; E970-E978 y E990-E999);

Lesiones y Enfermedades de Origen No Intencional o Accidental (E800-E949); Lesiones y Enfermedades en que se Ignora si Fueron Accidental o Intencionalmente Infligidas (E980-E989).

Franco (1990) afirma que "rigurosamente, no todo accidente es un acto de violencia, pero muchos realmente lo son, o sirven para ocultar formas larvadas o mediatas de violencia. Sin duda, buena parte de los diagnósticos que aparecen bajo el rubro 'Lesiones en que se Ignora si Fueron Accidental o Intencionalmente Infligidas' debe corresponder en realidad a homicidios, a suicidios y a operaciones de guerra".

Para establecer un patrón de comparación de la magnitud con que las causas externas contribuyen a la mortalidad global en la Región, se comparó sus valores en la población general con las del grupo de 10 a 24 años de edad.

\section{Ámbito Geográfico y Período del Estudio}

El área geográfica de estudio comprende la Región de las Américas y solo fueron incluídos en el análisis los países de cada subregión para los cuales se dispuso de información en el Banco de Datos de la OPS, aplicándose tambien el criterio de tamaño de la población de cada país e intentando conservar aquellos de mayor volúmen poblacional. Asimismo se consideró la disponibilidad de información para cada año de la serie y la calidad de sus estadísticas vitales, medida por la proporción de muertes por causas externas atribuídas a lesiones en que se ignora si fueron accidentales o intencionalmente infligidas.

La descripción de las tendencias de la mortalidad por causas externas en la Región 
solo es posible para algunos países, cuya información al respecto cubre la totalidad o la mayor parte del periodo analizado y cuenta además con el detalle de los grupos de causas externas.

Los países que acataron los criterios anteriormente establecidos en las ocho subregiones, según la clasificación utilizada por la OPS, fueron: Costa Rica y Panamá (América Central); Canadá y Estados Unidos de Norteamérica (América del Norte); Colombia y Venezuela (Área Andina); Brasil; México; Cuba y Puerto Rico (Caribe Latino); Suriname y Trinidad \& Tobago (caribe Inglés); Argentina, Chile y Uruguay (Cono Sur).

La investigación comprende el lapso que media entre 1979 y 1990. Sólo se incluyó aquéllos que tenían información completa o incompleta sobre defunciones por causas externas, durante al menos 5 años seguidos en el período.

\section{Distribuciones por Sexo y Edad}

Para todos los países cuya información incluía especificaciones por sexo y edad se distribuyó la mortalidad por todas las causas externas según sexo y los siguientes grupos de edad: todas las edades; de 10 a 14 años; de 15 a 19 años; de 20 a 24 años; y de 10 a 24 años, constituyéndose este último grupo de edad en el centro del análisis (adolescentes y jóvenes).

Para establecer un patrón de comparación de la magnitud con que las causas externas y sus grupos de causas contribuyen a la mortalidad global en la Región, se comparó sus valores en la población general con la del grupo de 10 a 24 años de edad.

\section{Calidad de la Información}

En los países que informan cierta proporción de defunciones de edad y sexo ignorados (Argentina, Brasil y México), se decidió excluír esos decesos, realizándose los cálculos sólo con los datos de edad y sexo confirmados.

Otros países debieron ser excluídos en esta fase, por no contar con información detallada para los grupos de edad escogidos para esta investigación.

Aparte de lo verificado respecto de la ausencia de información para los grupos de edad y sexo requeridos, de las inconsistencias de las cifras absolutas debidas a la presencia de defunciones de edad y/o de sexo ignorados en los listados (se habla de listados y no de consolidados, ya que la información estadística de defunciones que actualmente entrega el Banco de la OPS consiste en listados anuales de número de causas por grupos de edad y sexo y en listados anuales de estimaciones de población de cada país, debiendo realizar el investigador todas las etapas del proceso de consolidación de los dados, hasta la obtención de las salidas requeridas para los propósitos del estudio) y de la existencia de años sin información o con información parcial, la distribución de los grupos de causas en algunos países sugiere importantes deficiencias de la calidad de la certificación de la causa de muerte.

En países como Bahamas, Brasil, Chile, Guatemala, Islas Caimán, Panamá, Suriname y República Dominicana, la proporción de defunciones por causas externas atribuída a "Lesiones en que se Ignora si Fueron Accidental o Intencionalmente Infligidas" es superior al $10 \%$, en tanto que la proporción regional observada alcanza al $6 \%$, destacando los casos de Bahamas, Chile y Guatemala, países donde esta proporción supera al $20 \%$. A su vez, en El Salvador, la citada proporción es nula, lo cual sugiere también una escasa confiabilidad del registro de la causa externa de defunción en ese país, o la exclusión de algunas defunciones por causas externas de los consolidados de causas de muerte.

Por último, Cuba y Honduras no informan grupos detallados de causas externas, razón por la cual resulta desconocida la magnitud de las proporciones mencionadas para esos países.

A su vez, en Chile y El Salvador no se consigna defunciones debidas a "Operaciones de Guerra o a Intervención Legal” en el período, en circunstancias de que se trata precisamente de países afectados por graves conflictos políticos y sociales en esa etapa. En otros países, como Colombia, Guatemala y 
Perú, igualmente protagonistas de conmociones sociales durante la década anterior, las proporciones de muertes debidas a este grupo de causas externas son ínfimas, sugiriendo la existencia de sub-registro de las mismas.

Por su parte, en Panamá se aprecia el registro de defunciones por "Operaciones de Guerra e Intervención Legal”, especialmente en el último año de la serie, en correspondencia con el conflicto bélico vivido en ese país.

Aunque en varios países de la Región hay sub-registro de defunciones, se reconoce que, debido a disposiciones legales, las defunciones por causas externas son aquellas que presentan el menor sub-registro. O sea, la calidad de esta información, en términos cuantitativos, puede ser considerada como satisfactoria. Lo mismo no ocurre con el tipo de accidente o violencia, no siempre informado correctamente.

Todo lo anterior revela que, a diferencia de lo que ocurre con la certificación de otras causas de muerte, las deficiencias del registro de las causas externas obedecen también a factores de orden jurídico-político y legal.

\section{RESULTADOS}

Tendencias de la Mortalidad por Causas Externas por Grupos de Edad y Sexo

\section{A. Países de América Central: Costa Rica y Panamá (Tabla 1)}

En Costa Rica, las tendencias de la mortalidad por causas externas para la población general y para el grupo de 10 a 24 años de edad son descendentes. Comparando los valores iniciales y finales de la serie, se aprecia una caída de la mortalidad por causas externas de un $18 \%$ que alcanza a un $20 \%$ entre los hombres y sólo a un $10 \%$ entre las mujeres. Esta evolución de las tasas se verifica también en el grupo de adolescentes y jóvenes, entre los que la reducción de la mortalidad por causas externas en el período llega a un $41 \%$ (46 entre los hombres y $11 \%$ entre las mujeres). De aquí que al final del período se observe una reducción de la diferencia relativa entre las magnitudes de las tasas masculinas y femeninas de mortalidad por causas externas, que disminuye especialmente en el grupo de 10 a 24 años de edad de 5,9 a 3,6. El grupo de 10 a 24 años muestran un comportamiento similar, excepto el de 20 a 24 años, donde la importante caída de un $49 \%$ de la tasa de mortalidad por causas externas se distribuye entre un $54 \%$ de decremento de la tasa masculina y un $1,4 \%$ de incremento de la tasa femenina.

En Panamá, las tendencias de la serie se ven afectadas por el brusco aumento del conjunto de la mortalidad por causas externas verificado en 1989 entre los hombres, en ocasión del conflicto bélico externo sufrido por ese país. El incremento de la mortalidad por causas externas en Panamá entre los dos años extremos de la serie es de un $14 \%$, el cual se distribuye entre un $26 \%$ de aumento para los hombres y una caída de un $24 \%$ para las mujeres. Entre los adolescentes y los jóvenes, esta elevación del indicador es de sólo un 5\%, concentrado también en el sexo masculino. Las variaciones más relevantes se aprecian en el subgrupo de 20 a 24 años de edad, en el que la mortalidad masculina por causas externas crece en un $12 \%$ entre 1979 y 1989.

En ambos países llaman la atención las marcadas diferencias de la magnitud de la mortalidad por causas externas entre los grupos de edad del conjunto de los adolescentes y jóvenes, donde especialmente la mortalidad masculina del subgrupo de 20 a 24 años de edad llega a cuadruplicar y hasta a sextuplicar a la del subgrupo de 10 a 14 años de edad.

\section{B . Países de América del Norte: Canadá y EE.UU. de Norteamérica (Tabla 2)}

Las tendencias de la mortalidad por causas externas en Canadá son homogéneamente descendentes entre 1979 y 1989. Las diferencias entre los años extremos de la serie muestran una reducción del orden del $24 \%$ para la población general (27\% para los hombres y $19 \%$, para las mujeres) y de un $32 \%$ para el grupo de 10 a 24 años de edad 
TABLA 1. Mortalidad* por Causas Externas, para Todas las Edades y en el Grupo de 10 a 24 Años de Edad, por Grupos de Edad y Sexo. Costa Rica y Panamá, 1979-1989

\begin{tabular}{|c|c|c|c|c|c|c|c|c|c|c|}
\hline \multirow[b]{3}{*}{ Año y Sexo } & \multicolumn{10}{|c|}{ Grupos de Edad (años) } \\
\hline & \multicolumn{2}{|c|}{ Todas las Edades } & \multicolumn{2}{|c|}{$10-24$} & \multicolumn{2}{|c|}{$10-14$} & \multicolumn{2}{|c|}{$15-19$} & \multicolumn{2}{|c|}{$20-24$} \\
\hline & Costa Rica & Panamá & Costa Rica & Panamá & Costa Rica & Panamá & Costa Rica & Panamá & Costa Rica & Panamá \\
\hline \multicolumn{11}{|l|}{1979} \\
\hline AMBos os SeXos & $\ldots$ & 50.8 & $\ldots$ & 3.7 & $\ldots$ & 24.2 & $\ldots$ & 41.7 & $\ldots$ & 72.9 \\
\hline HOMBRES & $\ldots$ & 76.2 & $\ldots$ & 68.6 & $\ldots$ & 33.9 & $\ldots$ & 63.6 & $\ldots$ & 122.0 \\
\hline MUJERES & $\ldots$ & 24.4 & $\ldots$ & 17.7 & $\ldots$ & 14.2 & $\ldots$ & 19.2 & $\ldots$ & 20.9 \\
\hline \multicolumn{11}{|l|}{1980} \\
\hline Ambos SEXos & 54.2 & 52.9 & 45.8 & 2.8 & 23.9 & 14.8 & 42.2 & 48.4 & 76.2 & 74.3 \\
\hline HOMBRES & 85.5 & 81.9 & 77.4 & 68.6 & 38.6 & 22.0 & 66.7 & 80.0 & 136.4 & 118.1 \\
\hline MUJERES & 22.2 & 22.7 & 13.2 & 16.0 & 8.6 & 7.3 & 16.9 & 15.9 & 14.4 & 28.1 \\
\hline \multicolumn{11}{|l|}{1981} \\
\hline AMBOS SEXOS & 41.6 & 47.5 & 31.9 & 39.8 & 13.7 & 16.9 & 31.1 & 38.8 & 53.6 & 71.6 \\
\hline HOMBRES & 64.6 & 72.6 & 50.2 & 64.1 & 18.6 & 25.6 & 48.6 & 59.6 & 88.2 & 120.6 \\
\hline MUJERES & 18.2 & 21.3 & 13.0 & 14.6 & 8.6 & 8.0 & 12.9 & 17.3 & 17.9 & 20.4 \\
\hline \multicolumn{11}{|l|}{1982} \\
\hline Ambos Sexos & 40.0 & 49.6 & 28.6 & 38.5 & 11.7 & 18.1 & 29.6 & 39.6 & 45.7 & 64.3 \\
\hline HOMBRES & 63.7 & 76.0 & 45.5 & 61.3 & 17.5 & 25.8 & 44.5 & 57.3 & 77.1 & 113.0 \\
\hline MUJERES & 15.8 & 22.0 & 11.1 & 14.9 & 5.8 & 10.2 & 14.2 & 21.2 & 13.4 & 13.5 \\
\hline \multicolumn{11}{|l|}{1983} \\
\hline AMBos SEXos & 35.2 & 48.4 & 25.6 & 38.1 & 9.0 & 17.9 & 27.0 & 35.6 & 41.4 & 67.3 \\
\hline HOMBRES & 54.9 & 72.0 & 40.9 & 58.5 & 10.6 & 26.1 & 42.2 & 53.3 & 71.3 & 106.8 \\
\hline MUJERES & 15.1 & 23.8 & 9.7 & 16.9 & 7.3 & 9.3 & 11.3 & 17.2 & 10.6 & 26.3 \\
\hline \multicolumn{11}{|l|}{1984} \\
\hline AMBos SEXos & 40.5 & 49.1 & 29.3 & 35.5 & 11.9 & 17.4 & 24.1 & 34.9 & 52.4 & 59.4 \\
\hline HOMBRES & 62.9 & 75.8 & 45.1 & 54.7 & 16.2 & 22.2 & 37.2 & 51.6 & 82.9 & 100.0 \\
\hline MUJERES & 17.5 & 21.3 & 12.8 & 15.7 & 7.4 & 12.3 & 10.6 & 17.6 & 20.7 & 17.6 \\
\hline \multicolumn{11}{|l|}{1985} \\
\hline AMBOS SEXos & 43.5 & 49.2 & 34.5 & 37.9 & 13.6 & 14.6 & 33.4 & 36.8 & 56.6 & 68.2 \\
\hline HOMBRES & 69.4 & 75.9 & 58.8 & 60.7 & 21.0 & 17.6 & 52.0 & 59.2 & 103.5 & 116.7 \\
\hline MUJERES & 16.9 & 21.4 & 9.4 & 14.5 & 5.8 & 11.5 & 14.1 & 13.9 & 8.0 & 18.9 \\
\hline \multicolumn{11}{|l|}{1986} \\
\hline AMBos SEXos & 40.1 & 48.9 & 27.3 & 34.5 & 15.0 & 13.0 & 25.3 & 44.2 & 41.5 & 49.5 \\
\hline HOMBRES & 63.2 & 75.8 & 41.0 & 54.9 & 20.5 & 18.2 & 37.4 & 69.3 & 65.1 & 83.8 \\
\hline MUJERES & 16.4 & 20.9 & 13.0 & 13.4 & 9.2 & 7.6 & 12.8 & 18.5 & 17.0 & 14.7 \\
\hline \multicolumn{11}{|l|}{1987} \\
\hline AMBOS SEXOS & 43.2 & 50.9 & 31.8 & 39.0 & 17.2 & 14.1 & 27.3 & 42.6 & 51.2 & 64.6 \\
\hline HOMBRES & 67.2 & 80.0 & 51.1 & 64.3 & 19.9 & 19.0 & 47.3 & 70.0 & 87.1 & 112.3 \\
\hline MUJERES & 18.7 & 20.7 & 11.7 & 13.0 & 14.5 & 9.1 & 6.4 & 14.3 & 14.1 & 16.1 \\
\hline \multicolumn{11}{|l|}{1988} \\
\hline Ambos SEXos & 42.5 & 47.7 & 27.2 & 38.0 & 8.4 & 17.5 & 30.1 & 44.6 & 44.2 & 54.3 \\
\hline HOMBRES & 64.4 & 74.6 & 43.6 & 59.6 & 12.1 & 21.9 & 46.5 & 67.4 & 73.8 & 94.9 \\
\hline MUJERES & 20.3 & 19.7 & 10.2 & 15.7 & 4.6 & 12.9 & 13.0 & 21.1 & 13.3 & 13.0 \\
\hline \multicolumn{11}{|l|}{1989} \\
\hline AMBos SEXos & 44.5 & 57.9 & 27.2 & 43.9 & 14.1 & 13.4 & 29.4 & 44.7 & 39.2 & 77.3 \\
\hline HOMBRES & 68.4 & 95.9 & 41.9 & 72.1 & 20.2 & 20.4 & 44.4 & 66.9 & 63.1 & 136.7 \\
\hline MUJERES & 20.0 & 18.6 & 11.8 & 14.8 & 7.6 & 6.1 & 13.8 & 21.7 & 14.6 & 16.9 \\
\hline
\end{tabular}

* Tasas por 100.000 personas de cada grupo de edad y sexo.

... Datos no disponibles.

Fuente: Sistema de Información Técnica de la OPS. 
TABLA 2. Mortalidad* por Causas Externas, para Todas las Edades y en el Grupo de 10 a 24 Años de Edad, por Grupos de Edad y Sexo. Canadá y Estados Unidos, 1979-1989

\begin{tabular}{|c|c|c|c|c|c|c|c|c|c|c|}
\hline \multirow[b]{3}{*}{ Año y Sexo } & \multicolumn{10}{|c|}{ Grupos de Edad (años) } \\
\hline & \multicolumn{2}{|c|}{ Todas las Edades } & \multicolumn{2}{|c|}{$10-24$} & \multicolumn{2}{|c|}{$10-14$} & \multicolumn{2}{|c|}{$15-19$} & \multicolumn{2}{|c|}{$20-24$} \\
\hline & Canadá & EE.UU. & Canadá & EE.UU. & Canadá & EE.UU. & Canadá & EE.UU. & Canadá & EE.UU. \\
\hline \multicolumn{11}{|l|}{1979} \\
\hline AMBOS SEXOS & 69.6 & 70.5 & 69.0 & 68.7 & 20.9 & 18.4 & 81.0 & 79.1 & 99.4 & 102.3 \\
\hline HOMBRES & 99.9 & 104.8 & 108.2 & 106.1 & 30.1 & 25.5 & 122.8 & 119.8 & 164.0 & 163.9 \\
\hline MUJERES & 39.8 & 38.0 & 28.7 & 30.0 & 11.3 & 11.0 & 37.6 & 37.0 & 34.6 & 39.6 \\
\hline \multicolumn{11}{|l|}{1980} \\
\hline AMBOS SEXOS & 65.5 & 70.5 & 63.7 & 68.9 & 18.4 & 17.7 & 75.4 & 78.3 & 89.9 & 103.0 \\
\hline HOMBRES & 93.5 & 105.0 & 97.7 & 107.0 & 25.6 & 24.4 & 113.6 & 118.7 & 143.6 & 166.0 \\
\hline MUJERES & 37.9 & 37.8 & 28.5 & 29.7 & 10.9 & 10.8 & 35.7 & 36.3 & 35.9 & 39.0 \\
\hline \multicolumn{11}{|l|}{1981} \\
\hline AMBOS SEXOS & 63.9 & 67.6 & 63.1 & 64.1 & 19.4 & 17.4 & 75.7 & 70.4 & 86.1 & 96.5 \\
\hline HOMBRES & 92.0 & 100.7 & 99.5 & 99.0 & 27.4 & 24.1 & 118.2 & 106.2 & 140.5 & 154.5 \\
\hline MUJERES & 36.2 & 36.2 & 25.4 & 28.1 & 10.9 & 10.4 & 31.4 & 33.3 & 31.2 & 37.4 \\
\hline \multicolumn{11}{|l|}{1982} \\
\hline AMBOS SEXOS & 57.6 & 63.6 & 52.9 & 59.5 & 17.8 & 16.4 & 62.5 & 65.3 & 71.4 & 89.0 \\
\hline HOMBRES & 82.4 & 94.5 & 83.6 & 92.2 & 24.2 & 22.4 & 97.6 & 99.4 & 117.6 & 142.6 \\
\hline MUJERES & 33.2 & 34.3 & 21.1 & 25.7 & 11.1 & 10.0 & 25.8 & 29.9 & 24.4 & 34.5 \\
\hline \multicolumn{11}{|l|}{1983} \\
\hline AMBOS SEXOS & 56.7 & 61.4 & 52.3 & 56.1 & 15.3 & 16.0 & 58.2 & 61.3 & 75.4 & 83.4 \\
\hline HOMBRES & 81.0 & 90.4 & 82.4 & 85.9 & 21.7 & 22.2 & 88.9 & 92.1 & 123.9 & 132.0 \\
\hline MUJERES & 32.7 & 33.8 & 21.0 & 25.3 & 8.7 & 9.6 & 26.2 & 29.4 & 25.8 & 34.0 \\
\hline \multicolumn{11}{|l|}{1984} \\
\hline AMBOS SEXOS & 55.7 & 61.2 & 49.8 & 57.0 & 14.6 & 16.4 & 58.3 & 62.2 & 69.3 & 85.0 \\
\hline HOMBRES & 79.1 & 90.0 & 78.7 & 86.7 & 19.8 & 22.2 & 92.8 & 92.3 & 111.9 & 134.1 \\
\hline MUJERES & 32.7 & 33.8 & 19.6 & 26.4 & 9.0 & 10.3 & 22.3 & 31.0 & 25.4 & 35.0 \\
\hline \multicolumn{11}{|l|}{1985} \\
\hline AMBOS SEXOS & 52.9 & 63.1 & 48.3 & 59.5 & 14.7 & 16.2 & 54.4 & 69.4 & 69.0 & 85.8 \\
\hline HOMBRES & 74.8 & 93.2 & 74.2 & 91.3 & 19.4 & 22.7 & 79.9 & 103.2 & 111.8 & 136.9 \\
\hline MUJERES & 31.3 & 34.6 & 21.2 & 26.6 & 9.7 & 9.5 & 27.6 & 34.1 & 24.7 & 33.6 \\
\hline \multicolumn{11}{|l|}{1986} \\
\hline AMBOS SEXOS & 53.6 & 62.6 & 47.9 & 60.5 & 12.6 & 16.3 & 58.3 & 70.9 & 66.8 & 87.4 \\
\hline HOMBRES & 75.1 & 92.3 & 73.6 & 92.7 & 16.0 & 22.8 & 87.5 & 105.5 & 107.5 & 139.4 \\
\hline MUJERES & 32.6 & 34.3 & 20.9 & 27.0 & 8.9 & 9.5 & 27.6 & 34.9 & 24.7 & 34.3 \\
\hline \multicolumn{11}{|l|}{1987} \\
\hline AMBOS SEXOS & 55.0 & 61.6 & 49.2 & 58.2 & 15.1 & 15.9 & 60.4 & 69.5 & 67.3 & 83.6 \\
\hline HOMBRES & 77.2 & 90.3 & 76.6 & 88.8 & 21.4 & 22.7 & 91.9 & 102.4 & 108.9 & 132.4 \\
\hline MUJERES & 33.1 & 34.3 & 20.4 & 26.5 & 8.4 & 8.8 & 27.3 & 35.2 & 24.2 & 33.6 \\
\hline \multicolumn{11}{|l|}{1988} \\
\hline AMBOS SEXOS & 52.2 & 62.2 & 47.2 & 59.6 & 13.3 & 15.9 & 57.3 & 72.9 & 67.3 & 85.0 \\
\hline HOMBRES & 73.7 & 90.9 & 74.1 & 91.1 & 18.4 & 21.3 & 89.4 & 108.3 & 108.3 & 135.6 \\
\hline MUJERES & 31.2 & 34.8 & 19.1 & 26.9 & 7.8 & 10.2 & 23.5 & 35.8 & 24.7 & 33.1 \\
\hline \multicolumn{11}{|l|}{1989} \\
\hline AMBOS SEXOS & 52.5 & 61.0 & 46.6 & 57.5 & 11.9 & 15.6 & 58.7 & 71.5 & 66.7 & 81.4 \\
\hline HOMBRES & 73.1 & 89.2 & 70.2 & 87.7 & 15.6 & 21.11 & 89.5 & 105.8 & 101.8 & 130.2 \\
\hline MUJERES & 32.4 & 34.1 & 21.8 & 25.9 & 8.0 & 9.8 & 26.2 & 35.6 & 30.0 & 31.2 \\
\hline
\end{tabular}

* Tasas por 100.000 personas de cada grupo de edad y sexo.

... Datos no disponibles.

Fuente: Sistema de Información Técnica de la OPS. 
(35\% para los hombres y $24 \%$ para las mujeres). El menor descenso observado es el de la tasa de mortalidad de las mujeres de 20 a 24 años de edad, que alcanza sin embargo a un $13 \%$.

El caso de los EE.UU. de Norteamérica difiere ligeramente del anterior. La mortalidad por causas externas para la población general cayó en el período en un 13\% (15\% para los hombres y $10 \%$ para las mujeres), mientras la del grupo de adolescentes y jóvenes se redujo en un $16 \%$ (17\% para los hombres y $14 \%$ para las mujeres). Las menores reducciones de la tasa de mortalidad por causas externas en este país, inferiores al $10 \%$, se verifican en el grupo de 15 a 19 años de edad, especialmente entre las mujeres, la magnitud de cuya tasa permanece prácticamente estable.

Al igual que en el caso de los países de América Central, en los dos países del Norte de las Américas llama la atención el notable incremento de la tasa de mortalidad por causas externas que acompaña a la edad, en los grupos del conjunto de los adolescentes y jóvenes, fenómeno que nuevamente se concentra en la mortalidad masculina.

\section{Países del Area Andina: Colombia y Venezuela (Tabla 3)}

La información disponible se refiere sólo a Colombia y Venezuela, dado que sólo se informa de 4 años para Perú y de 6 años discontínuos para Ecuador.

En Colombia, el conjunto de la mortalidad por causas externas se incrementa notablemente en el período 1984-1990, salvo en el subgrupo de 10 a 14 años, donde se aprecia un muy ligero descenso, inferior al $10 \%$ en ambos sexos. Para la población general, el aumento de la mortalidad por en ese breve lapso fue de un $37 \%$, concentrándose éste principalmente en el sexo masculino, el ascenso de cuya tasa de mortalidad llega a un $43 \%$, en tanto el de la tasa femenina es de un 5\%. Variaciones aún más marcadas se manifiestan en el grupo de los adolescentes y jóvenes, con un $58 \%$ de incremento de la tasa de mortalidad (64\% entre los hombres y $22 \%$ entre las mujeres). Entre los grupos de edad del grupo de 10 a
24 años de edad, destaca el incremento de la mortalidad de la población de 15 a 19 años, de un $110 \%$ para los hombres, de un $35 \%$ para las mujeres y de un $96 \%$ para ambos sexos.

En Venezuela, la mortalidad por causas externas para la población general disminuyó entre 1979 y 1987 en un 19\% (en casi $20 \%$ para los hombres y en $16 \%$ para las mujeres), en tanto que la caída de este indicador para los adolescentes y jóvenes alcanzó a un 28\%, con valores similares para ambos sexos. Llama la atención el hecho de que el menor decremento observado se da entre los hombres de 10 a 14 años y que la reducción de la tasa femenina de mortalidad para el grupo de 20 a 24 años de edad sea inferior a la caída de la tasa masculina correspondiente, siendo ambas tasas bastante elevadas.

Las diferencias entre los valores de las tasas al interior del grupo de adolescentes y jóvenes son espectaculares en Colombia, de modo que las magnitudes del indicador para el subgrupo de 15 a 19 años más que sextuplican a las del subgrupo de 10 a 14 años, en tanto las del grupo de 20 a 24 años llegan a decuplicar a las de aquél, especialmente al final del período. En cambio, en Venezuela se observa proporcionalidades similares a las verificadas en los países de América Central y de América de Norte, con diferencias relativas entre las tasas del subgrupo de 15 a 19 años del orden de 3 y 4 , respecto del subgrupo de 10 a 14 años de edad, las cuales ascienden a 6 y 7, cuando se compara la mortalidad por causas externas del subgrupo de 20 a 24 años con la del subgrupo de 10 a 14 años de edad.

D. Brasil (Tabla 4)

En Brasil, obsérvase un incremento sostenido de este indicador para todos los grupos de edad y sexo presentados. Estos aumentos alcanzan al $26 \%$ para la población general (30\% para los hombres y $12 \%$ para las mujeres), mientras se empinan al $36 \%$ para la población de adolescentes y jóvenes (42\% para los hombres y $14 \%$ para las mujeres).

$\mathrm{Al}$ igual que en el caso de Colombia, en Brasil los incrementos más relevantes dieron en el subgrupo de 15 a 19 años de edad, con 
un aumento de un $52 \%$ para los hombres, de un $22 \%$ para las mujeres y de un $46 \%$ para ambos sexos.

Las diferencias relativas entre las magnitudes de las tasas de los grupo de edad del conjunto de los adolescentes y jóvenes son ligeramente inferiores en Brasil a las observadas en los países anteriormente mencionados, hecho que se explica más por los valores más moderados de estos indicadores en los grupo de 15 a 19 años de edad y de 20 a 24 años de edad, que por una mayor magnitud de la mortalidad por causas externas en el subgrupo de 10 a 14 años de edad.

\section{E. México (Tabla 4)}

A pesar de la escasa información reportada por ese país a la OPS (periodos 1981-1983 y 1985-1986), México ha sido incluído en esta fase del estudio por las magnitudes de su población y de sus tasas de mortalidad por causas externas. Así, la caída de la mortalidad por causas externas es de un $20 \%$ para la población general (18\% para los hombres y $23 \%$ para las mujeres) y de un $27 \%$ para los adolescentes y jóvenes (25\% para los hombres y $32 \%$ para las mujeres). Las variaciones en los grupos de edad del conjunto de los adolescentes y jóvenes fluctúan entre el $26 \%$ y el $30 \%$, destacándose las reducciones del componente femenino, todas superiores al $30 \%$.

En México llaman la atención las elevadas magnitudes de las tasas entre los hombres, que se asemejan a las observadas en Brasil, Colombia y Chile.

\section{F. Países del Caribe Latino: Cuba y Puerto Rico (Tabla 5)}

En Cuba se aprecia claramente el crecimiento del indicador, del orden de un $21 \%$ para la población general $(25 \%$ para los hombres y $23 \%$ para las mujeres). Sin embargo, cabe señalar que los incrementos verificados no afectan particularmente al grupo de 10 a 24 años de edad, que presenta un ascenso, cercano al 9\%, que se acompaña de una caída de un $12 \%$ de la mortalidad femenina por estas causas (con una elevación del 23\% para la tasa masculina). Los dos primeros grupo de edad del conjunto de los adolescentes y jóvenes muestran evoluciones más bien estables, con pequeños incrementos en el componente masculino (10\% para el subgrupo de 10 a 14 años de edad y $12 \%$ para el subgrupo de 15 a 19 años de edad) y francos descensos del componente femenino (12\% y $18 \%$, respectivamente, en los dos grupos de edad mencionados). En el subgrupo de 20 a 24 años, si bien hay una caída moderada, del orden de $11 \%$, ésta se acompaña de un fuerte decremento de la tasa femenina, superior al $27 \%$, mientras la tasa masculina crece ligeramente, en un $8 \%$. En suma, las tendencias crecientes de la mortalidad por causas externas en Cuba se concentran prioritariamente en otros grupos de edad y no en el de adolescentes y jóvenes.

El caso de Puerto Rico es completamente distinto del anterior, si bien prácticamente todas las tendencias observadas son crecientes o estables. La mortalidad por causas externas se incrementa levemente, en un $8 \%$, para la población general entre 1979 y 1989 , pero su componente femenino lo hace francamente, alcanzando un ascenso de un 54\%, mientras la mortalidad masculina por estas causas se conserva prácticamente sin variaciones $(+2 \%)$. Por su parte, entre los adolescentes y jóvenes la mortalidad varía escasamente entre 1979 y 1986 (+1\%), aumentando también abiertamente la tasa femenina, en un $28 \%$. Al interior de los grupos de edad del conjunto de los adolescentes y jóvenes, la evolución de estos indicadores es aún más llamativa. Así, por ejemplo, el mayor incremento aparece en el subgrupo de 10 a 14 años de edad, con un $18 \%$ de ascenso, en el cual se incluye un $114 \%$ de incremento de la tasa femenina. En el subgrupo de 15 a 19 años de edad, cuya mortalidad por causas externas crece sólo en un $7 \%$ entre 1979 y 1986 , se aprecia un $80 \%$ de ascenso para las mujeres, reduciéndose la tasa masculina en un $18 \%$. Por último, en el subgrupo de 20 a 24 años de edad son también las mujeres las que aportan la mayor cuota de incremento (63\%), mientras la tasa masculina desciende ligeramente $(7 \%)$, manteniéndose estable los valores del indicador para ambos sexos. 
TABLA 3. Mortalidad* por Causas Externas, para Todas las edades y en el Grupo de 10 a 24 Años de Edades, por Grupos de Edad y Sexo. Colombia y Venezuela 1979-1990

\begin{tabular}{|c|c|c|c|c|c|c|c|c|c|c|}
\hline \multirow[b]{2}{*}{ Año y Sexo } & \multicolumn{10}{|c|}{ "Grupos de Edad (años) } \\
\hline & \multicolumn{2}{|c|}{$\begin{array}{c}\text { Todas las Edades } \\
\text { Colombia Venezuela } \\
\end{array}$} & \multicolumn{2}{|c|}{$\begin{array}{c}10-24 \\
\text { Colombia Venezuela } \\
\end{array}$} & \multicolumn{2}{|c|}{$\begin{array}{c}10-14 \\
\text { Colombia Venezuela } \\
\end{array}$} & \multicolumn{2}{|c|}{$\begin{array}{c}15-19 \\
\text { Colombia Venezuela } \\
\end{array}$} & \multicolumn{2}{|c|}{$\begin{array}{c}20-24 \\
\text { Colombia Venezuela } \\
\end{array}$} \\
\hline 1979 & & & & & & & & & & \\
\hline AMBOS SEXOS & $\ldots$ & 73.8 & $\ldots$ & 73.1 & $\ldots$ & 23.9 & $\ldots 80.5$ & & $\ldots$ & 129.9 \\
\hline HOMBRES & $\ldots$ & 117.4 & $\ldots$ & 121.0 & $\ldots$ & 32.0 & ... 131.0 & & $\ldots$ & 227.6 \\
\hline MUJERES & $\cdots$ & 29.1 & $\ldots$ & 23.6 & $\ldots$ & 15.4 & ... 28.1 & & $\ldots$ & 29.0 \\
\hline \multicolumn{11}{|l|}{1980} \\
\hline AMBOS SEXOS & $\ldots$ & 77.3 & $\ldots$ & 76.4 & $\ldots$ & 25.6 & .. 82.9 & & $\ldots$ & 134.9 \\
\hline HOMBRES & $\ldots$ & 24.9 & $\ldots$ & 129.1 & $\ldots$ & 37.0 & .. 137.9 & & $\ldots$ & 239.0 \\
\hline MUJERES & $\ldots$ & 28.5 & $\ldots$ & 21.8 & $\ldots$ & 13.8 & ... 26.0 & & $\ldots$ & 27.3 \\
\hline \multicolumn{11}{|l|}{1981} \\
\hline AMBOS SEXOS & $\ldots$ & 74.7 & $\ldots$ & 72.1 & $\ldots$ & 24.6 & ... 78.2 & & $\ldots$ & 125.9 \\
\hline HOMBRES & $\ldots$ & 118.8 & $\ldots$ & 118.0 & $\ldots$ & 33.7 & $\ldots$ & 123.8 & $\ldots$ & 219.3 \\
\hline MUJERES & $\ldots$ & 29.5 & $\ldots$ & 24.6 & $\ldots$ & 15.1 & ... 31.1 & & $\ldots$ & 29.4 \\
\hline \multicolumn{11}{|l|}{1982} \\
\hline AMBOS SEXOS & $\ldots$ & 73.8 & $\ldots$ & 71.4 & $\ldots$ & 23.1 & .. 72.9 & & $\ldots$ & 130.2 \\
\hline HOMBRES & $\ldots$ & 117.7 & $\ldots$ & 119.0 & $\ldots$ & 33.4 & .. 115.9 & & $\ldots$ & 230.1 \\
\hline MUJERES & $\ldots$ & 28.9 & $\ldots$ & 22.2 & $\ldots$ & 12.4 & $\ldots 28.5$ & & $\ldots$ & 27.2 \\
\hline \multicolumn{11}{|l|}{1983} \\
\hline AMBOS SEXOS & $\ldots$ & 71.3 & $\ldots$ & 68.3 & $\ldots$ & 22.6 & .. 69.1 & & $\ldots$ & 123.6 \\
\hline HOMBRES & $\ldots$ & 14.5 & $\ldots$ & 114.4 & $\ldots$ & 32.2 & .. 112.9 & & $\ldots$ & 217.2 \\
\hline MUJERES & $\ldots$ & 7.2 & ... 20.6 & & $\ldots$ & 12.7 & ... 23.7 & & $\ldots$ & 26.9 \\
\hline \multicolumn{11}{|l|}{1984} \\
\hline AMBOS SEXOS & 83.5 & $\ldots$ & 66.4 & $\ldots$ & 22.2 & $\ldots$ & 57.7 & $\ldots$ & 127.6 & $\ldots$ \\
\hline HOMBRES & 139.8 & $\ldots$ & 111.5 & $\ldots$ & 32.5 & $\ldots$ & 92.6 & $\ldots$ & 225.9 & $\ldots$ \\
\hline MUJERES & 28.0 & $\ldots$ & 20.6 & $\ldots$ & 11.6 & $\ldots$ & 22.0 & $\ldots$ & 29.3 & $\ldots$ \\
\hline \multicolumn{11}{|l|}{1985} \\
\hline AMBOS SEXOS & 97.8 & 60.9 & 79.0 & 52.5 & 22.2 & 20.4 & 71.1 & 52.5 & 151.5 & 90.8 \\
\hline HOMBRES & 165.7 & 5.8 & 133.7 & 86.3 & 31.8 & 28.6 & 115.9 & 86.1 & 269.8 & 155.8 \\
\hline MUJERES & 30.7 & 25.4 & 23.3 & 17.5 & 12.3 & 12.0 & 25.5 & 17.7 & 33.1 & 23.8 \\
\hline \multicolumn{11}{|l|}{1986} \\
\hline AMBOS SEXOS & 99.1 & 60.0 & 82.4 & 54.3 & 21.3 & 20.7 & 74.5 & 57.2 & 158.1 & 90.8 \\
\hline HOMBRES & 171.5 & 95.0 & 141.7 & 89.5 & 31.3 & 29.3 & 123.5 & 93.6 & 284.7 & 156.8 \\
\hline MUJERES & 27.7 & 24.3 & 22.1 & 17.8 & 11.1 & 11.8 & 24.6 & 19.7 & 31.3 & 22.9 \\
\hline \multicolumn{11}{|l|}{1987} \\
\hline AMBOS SEXOS & 103.5 & 59.7 & 85.7 & 53.0 & 21.7 & 20.8 & 80.6 & 56.6 & 160.6 & 87.5 \\
\hline HOMBRES & 178.9 & 94.4 & 146.8 & 88.0 & 30.3 & 29.9 & 133.8 & 93.2 & 288.9 & 151.8 \\
\hline MUJERES & 29.0 & 24.4 & 23.5 & 16.9 & 12.8 & 11.5 & 26.3 & 18.9 & 32.1 & 21.3 \\
\hline \multicolumn{11}{|l|}{1988} \\
\hline AMBOS SEXOS & 110.7 & $\ldots$ & 92.9 & $\ldots$ & 22.6 & $\ldots$ & 88.4 & $\ldots$ & 173.8 & $\ldots$ \\
\hline HOMBRES & 193.5 & $\ldots$ & 161.6 & $\ldots$ & 31.0 & $\ldots$ & 149.7 & $\ldots$ & 317.6 & $\ldots$ \\
\hline MUJERES & 28.9 & $\ldots$ & 23.0 & $\ldots$ & 13.9 & $\ldots$ & 25.9 & $\ldots$ & 29.9 & $\ldots$ \\
\hline \multicolumn{11}{|l|}{1989} \\
\hline AMBOS SEXOS & 112.0 & $\ldots$ & 98.4 & $\ldots$ & 21.4 & $\ldots$ & 101.3 & $\ldots$ & 179.4 & $\ldots$ \\
\hline HOMBRES & 196.4 & $\ldots$ & 171.6 & $\ldots$ & 30.6 & $\ldots$ & 172.0 & $\ldots$ & 327.2 & $\ldots$ \\
\hline MUJERES & 28.8 & $\ldots$ & 23.9 & $\ldots$ & 11.9 & $\ldots$ & 29.4 & $\ldots$ & 31.4 & $\ldots$ \\
\hline \multicolumn{11}{|l|}{1990} \\
\hline AMBOS SEXOS & 114.4 & $\ldots$ & 104.7 & $\ldots$ & 20.7 & $\ldots$ & 113.0 & $\ldots$ & 188.9 & $\ldots$ \\
\hline HOMBRES & 200.5 & $\ldots$ & 183.0 & $\ldots$ & 29.6 & $\ldots$ & 194.6 & $\ldots$ & 342.4 & $\ldots$ \\
\hline MUJERES & 29.5 & $\ldots$ & 25.1 & $\ldots$ & 11.4 & $\ldots$ & 29.8 & $\ldots$ & 35.2 & $\ldots$ \\
\hline
\end{tabular}

* Tasas por 100.000 personas de cada grupo de edad y sexo... Datos no disponibles.

Fuente: Sistema de Información Técnica de la OPS. 
TABLA 4. Mortalidad* por Causas Externas, para Todas las Edades y en el Grupo de 10 a 24 Años de Edad, por Grupos de Edad y Sexo. Brasil y Mexico, 1979-1986

\begin{tabular}{|c|c|c|c|c|c|c|c|c|c|c|}
\hline \multirow[b]{3}{*}{ Año y Sexo } & \multicolumn{10}{|c|}{ Grupos de Edad (años) } \\
\hline & \multicolumn{2}{|c|}{ Todas las Edades } & \multicolumn{2}{|c|}{$10-24$} & \multicolumn{2}{|c|}{$10-14$} & \multicolumn{2}{|c|}{$15-19$} & \multicolumn{2}{|c|}{$20-24$} \\
\hline & Brasil & Mexico & Brasil & Mexico & Brasil & Mexico & Brasil & Mexico & Brasil & Mexico \\
\hline \multicolumn{11}{|l|}{1979} \\
\hline AMBOS SEXOS & 55.0 & $\ldots$ & 46.5 & $\ldots$ & 20.2 & $\ldots$ & 47.2 & $\ldots$ & 77.9 & $\ldots$ \\
\hline HOMBRES & 86.9 & $\ldots$ & 74.1 & $\ldots$ & 28.0 & $\ldots$ & 73.7 & $\ldots$ & 131.1 & $\ldots$ \\
\hline MUJERES & 23.0 & $\ldots$ & 18.7 & $\ldots$ & 12.2 & $\ldots$ & 20.4 & $\ldots$ & 24.4 & $\ldots$ \\
\hline \multicolumn{11}{|l|}{1980} \\
\hline AMBOS SEXOS & 57.9 & $\ldots$ & 50.3 & $\ldots$ & 21.5 & $\ldots$ & 52.1 & $\ldots$ & 82.5 & $\ldots$ \\
\hline HOMBRES & 92.2 & $\ldots$ & 81.1 & $\ldots$ & 30.1 & $\ldots$ & 81.2 & $\ldots$ & 141.5 & $\ldots$ \\
\hline MUJERES & 23.5 & $\ldots$ & 19.3 & $\ldots$ & 12.7 & $\ldots$ & 22.7 & $\ldots$ & 23.2 & $\ldots$ \\
\hline \multicolumn{11}{|l|}{1981} \\
\hline AMBOS SEXOS & 57.9 & 96.4 & 51.2 & 77.4 & 21.2 & 31.8 & 53.4 & 80.9 & 83.4 & 139.9 \\
\hline HOMBRES & 92.7 & 154.5 & 82.5 & 127.3 & 29.8 & 45.4 & 83.3 & 132.1 & 142.5 & 242.0 \\
\hline MUJERES & 23.0 & 36.4 & 19.6 & 24.9 & 12.5 & 17.1 & 23.1 & 26.5 & 24.0 & 34.3 \\
\hline \multicolumn{11}{|l|}{1982} \\
\hline AMBOS SEXOS & 57.9 & 92.3 & 50.3 & 72.8 & 20.4 & 29.5 & 51.9 & 75.2 & 82.4 & 132.8 \\
\hline HOMBRES & 93.0 & 149.4 & 81.4 & 120.2 & 28.4 & 42.8 & 82.0 & 123.2 & 140.7 & 230.5 \\
\hline MUJERES & 22.7 & 33.1 & 19.0 & 22.7 & 12.3 & 15.2 & 21.4 & 24.6 & 23.8 & 31.3 \\
\hline \multicolumn{11}{|l|}{1983} \\
\hline AMBOS SEXOS & 60.1 & 79.2 & 52.4 & 58.8 & 20.6 & 23.2 & 55.0 & 59.7 & 84.8 & 109.4 \\
\hline HOMBRES & 97.4 & 129.4 & 85.5 & 98.0 & 28.7 & 33.9 & 87.9 & 98.4 & 146.0 & 191.2 \\
\hline MUJERES & 22.9 & 28.9 & 19.0 & 18.5 & 12.5 & 12.0 & 21.8 & 19.7 & 23.3 & 26.3 \\
\hline \multicolumn{11}{|l|}{1984} \\
\hline AMBOS SEXOS & 62.1 & $\ldots$ & 55.1 & $\ldots$ & 19.9 & $\ldots$ & 58.6 & $\ldots$ & 90.2 & $\ldots$ \\
\hline HOMBRES & 101.5 & $\ldots$ & 91.5 & $\ldots$ & 28.3 & $\ldots$ & 95.3 & $\ldots$ & 156.7 & $\ldots$ \\
\hline MUJERES & 22.6 & $\ldots$ & 18.5 & $\ldots$ & 11.4 & $\ldots$ & 21.5 & $\ldots$ & 23.1 & $\ldots$ \\
\hline \multicolumn{11}{|l|}{1985} \\
\hline AMBOS SEXOS & 63.3 & 80.2 & 57.4 & 59.2 & 21.8 & 24.0 & 62.3 & 61.7 & 91.4 & 105.6 \\
\hline HOMBRES & 103.3 & 128.1 & 95.3 & 96.4 & 31.2 & 35.1 & 101.6 & 98.7 & 158.9 & 180.4 \\
\hline MUJERES & 23.4 & 32.4 & 19.3 & 21.0 & 12.4 & 12.5 & 22.6 & 23.5 & 23.5 & 29.7 \\
\hline \multicolumn{11}{|l|}{1986} \\
\hline AMBOS SEXOS & 69.3 & 77.0 & 63.4 & 56.6 & 23.1 & 23.2 & 69.0 & 59.5 & 102.0 & 98.5 \\
\hline HOMBRES & 112.8 & 126.2 & 105.2 & 95.3 & 32.8 & 34.6 & 112.7 & 99.2 & 177.2 & 173.4 \\
\hline MUJERES & 25.8 & 28.0 & 21.3 & 17.0 & 13.5 & 11.5 & 24.9 & 18.5 & 26.4 & 22.5 \\
\hline
\end{tabular}

* Tasas por 100.000 personas de cada grupo de edad y sexo.

... Datos no disponibles.

Fuente: Sistema de Información Técnica de la OPS. 
TABLA 5. Mortalidad* por Causas Externas, para Todas las Edades y en el Grupo de 10 a 24 Años de Edad, por Grupos de Edad y Sexo. Cuba y Puerto Rico, 1979-1989

\begin{tabular}{|c|c|c|c|c|c|c|c|c|c|c|}
\hline \multirow[b]{3}{*}{ Año y Sexo } & \multicolumn{10}{|c|}{ Grupos de Edad (años) } \\
\hline & \multicolumn{2}{|c|}{ Todas las Edades } & \multicolumn{2}{|r|}{$10-24$} & \multicolumn{2}{|c|}{$10-14$} & \multicolumn{2}{|r|}{$15-19$} & \multicolumn{2}{|r|}{$20-24$} \\
\hline & Cuba & Puerto Rico & Cuba & Puerto Rico & Cuba & Puerto Rico & Cuba & Puerto rico & Cuba & Puerto Rico \\
\hline \multicolumn{11}{|l|}{1979} \\
\hline AMBOS SEXOS & 65.1 & 60.3 & 55.1 & 49.4 & 24.7 & 13.3 & 64.0 & 55.6 & 99.2 & 85.7 \\
\hline HOMBRES & 84.6 & 106.9 & 62.3 & 90.1 & 28.8 & 22.7 & 67.3 & 101.8 & 111.8 & 162.4 \\
\hline MUJERES & 45.1 & 16.0 & 47.7 & 9.3 & 20.4 & 3.6 & 60.7 & 9.5 & 72.7 & 15.8 \\
\hline \multicolumn{11}{|l|}{1980} \\
\hline AMBOS SEXOS & 66.5 & 60.5 & 55.5 & 50.8 & 24.8 & 13.0 & 66.0 & 59.8 & 88.5 & 86.5 \\
\hline HOMBRES & 85.3 & 103.5 & 60.3 & 87.9 & 27.1 & 22.0 & 65.6 & 101.8 & 106.8 & 157.7 \\
\hline MUJERES & 47.2 & 19.8 & 50.5 & 14.2 & 22.5 & 3.6 & 66.4 & 17.8 & 70.4 & 22.2 \\
\hline \multicolumn{11}{|l|}{1981} \\
\hline AMBOS SEXOS & 67.1 & 59.3 & 54.2 & 47.7 & 24.2 & 13.9 & 64.3 & 53.7 & 84.2 & 82.6 \\
\hline HOMBRES & 87.1 & 101.5 & 58.0 & 82.8 & 27.3 & 17.9 & 62.4 & 93.5 & 98.2 & 156.3 \\
\hline MUJERES & 46.6 & 19.3 & 50.4 & 13.0 & 21.0 & 9.7 & 66.2 & 13.6 & 70.1 & 16.2 \\
\hline \multicolumn{11}{|l|}{1982} \\
\hline AMBOS SEXOS & 68.3 & 56.1 & 55.4 & 46.2 & 25.3 & 14.3 & 65.5 & 48.5 & 82.5 & 83.3 \\
\hline HOMBRES & 87.3 & 95.9 & 60.7 & 80.5 & 30.1 & 22.0 & 67.2 & 86.0 & 94.5 & 152.8 \\
\hline MUJERES & 48.9 & 18.5 & 49.9 & 12.2 & 20.3 & 6.1 & 63.8 & 10.7 & 70.6 & 21.1 \\
\hline \multicolumn{11}{|l|}{1983} \\
\hline AMBOS SEXOS & 66.9 & 55.1 & 47.9 & 41.9 & 18.1 & 13.8 & 57.9 & 35.2 & 71.9 & 84.9 \\
\hline HOMBRES & 86.6 & 94.0 & 54.4 & 68.6 & 22.0 & 18.5 & 61.7 & 57.2 & 85.9 & 151.6 \\
\hline MUJERES & 46.9 & 18.3 & 41.1 & 15.0 & 14.1 & 8.7 & 54.1 & 12.5 & 57.8 & 25.2 \\
\hline \multicolumn{11}{|l|}{1984} \\
\hline AMBOS SEXOS & 67.6 & 58.1 & 52.5 & 43.1 & 22.1 & 12.4 & 59.3 & 48.2 & 78.6 & 73.8 \\
\hline HOMBRES & 89.1 & 97.7 & 61.9 & 69.7 & 26.9 & 17.4 & 64.5 & 75.4 & 98.5 & 130.5 \\
\hline MUJERES & 45.7 & 20.8 & 42.8 & 16.2 & 17.0 & 6.9 & 53.9 & 19.8 & 58.6 & 22.2 \\
\hline \multicolumn{11}{|l|}{1985} \\
\hline AMBOS SEXOS & 71.5 & 64.7 & 53.8 & 48.2 & 22.8 & 19.2 & 58.2 & 50.3 & 80.6 & 79.4 \\
\hline HOMBRES & 93.5 & 107.2 & 62.8 & 79.7 & 27.8 & 26.9 & 61.9 & 80.1 & 99.5 & 145.6 \\
\hline MUJERES & 49.2 & 24.2 & 44.6 & 15.8 & 17.6 & 10.8 & 54.2 & 18.7 & 61.6 & 17.8 \\
\hline \multicolumn{11}{|l|}{1986} \\
\hline AMBOS SEXOS & 73.4 & 68.2 & 57.5 & 50.0 & 23.6 & 15.7 & 63.2 & 51.5 & 82.9 & 86.3 \\
\hline HOMBRES & 97.2 & 113.6 & 68.3 & 82.2 & 29.6 & 23.1 & 67.5 & 83.5 & 105.0 & 150.3 \\
\hline MUJERES & 49.3 & 25.5 & 46.4 & 16.6 & 17.3 & 7.7 & 58.7 & 17.1 & 60.4 & 25.3 \\
\hline \multicolumn{11}{|l|}{1987} \\
\hline AMBOS SEXOS & 74.0 & 64.7 & 60.1 & $\ldots$ & 25.8 & $\ldots$ & 61.3 & $\ldots$ & 87.4 & $\ldots$ \\
\hline HOMBRES & 98.0 & 108.7 & 74.0 & $\ldots$ & 35.6 & $\ldots$ & 68.2 & $\ldots$ & 112.2 & $\ldots$ \\
\hline MUJERES & 49.8 & 23.2 & 45.7 & $\ldots$ & 15.6 & $\ldots$ & 54.2 & $\ldots$ & 62.0 & $\ldots$ \\
\hline \multicolumn{11}{|l|}{1988} \\
\hline AMBOS SEXOS & 79.7 & 68.4 & 61.7 & $\ldots$ & 28.5 & $\ldots$ & 67.0 & $\ldots$ & 81.6 & $\ldots$ \\
\hline HOMBRES & 106.4 & 115.9 & 78.8 & $\ldots$ & 39.9 & $\ldots$ & 79.4 & $\ldots$ & 107.9 & $\ldots$ \\
\hline MUJERES & 52.6 & 23.8 & 43.9 & $\cdots$ & 16.7 & $\ldots$ & 54.0 & $\cdots$ & 54.5 & $\ldots$ \\
\hline \multicolumn{11}{|l|}{1989} \\
\hline AMBOS SEXOS & 79.1 & 65.4 & 59.9 & $\ldots$ & 24.3 & $\ldots$ & 62.6 & $\ldots$ & 81.9 & $\ldots$ \\
\hline HOMBRES & 106.0 & 108.7 & 76.9 & $\ldots$ & 31.6 & $\ldots$ & 75.6 & $\ldots$ & 109.8 & $\ldots$ \\
\hline MUJERES & 51.8 & 24.6 & 42.1 & $\ldots$ & 16.8 & $\ldots$ & 49.0 & $\ldots$ & 52.8 & $\ldots$ \\
\hline
\end{tabular}

* Tasas por 100.000 personas de cada grupo de edad y sexo.

... Datos no disponibles.

Fuente: Sistema de Información Técnica de la OPS. 
Tanto en Cuba como en Puerto Rico se puede apreciar el incremento de la mortalidad por causas externas que acompaña a la edad, en el grupo de los adolescentes y jóvenes, siendo éste más marcado en Puerto Rico, donde las tasas de mortalidad por estas causas en el subgrupo de 20 a 24 años de edad llegan a superar en 6 veces a las del subgrupo de 10 a 14 años de edad. En Cuba, en cambio, las diferencias relativas observadas alcanzan a casi 4 , debido a que sus tasas en el subgrupo de 10 a 14 años de edad son más elevadas que en Puerto Rico, asemejándose a las observadas en Colombia y en Brasil.

\section{G. Países del Caribe Inglés: Suriname y Trinidad \& Tobago (Tabla 6)}

En Suriname, la mortalidad por causas externas muestra un descenso muy irregular entre 1979 y 1987. De hecho, salvo en los dos últimos años de la serie, la mortalidad por estas causas se mantiene elevada, especialmente en 1980, año en el que el brusco incremento observado expresa al conflicto político militar vivido en ese país a principios de la década. Se puede observar incluso que la pronunciada aceleración del ritmo de descenso en los años 1986 y 1987 sugiere el posible efecto de alguna modificación en el registro de las defunciones por causas externas, o bien, en la integridad de los datos remitidos por el país a la OPS.

Por otra parte, las variaciones de las tasas en Suriname son muy diversas para cada grupo de edad y sexo. Si bien en la población general se aprecia un descenso del indicador del 16\% (14\% para los hombres y $22 \%$ para las mujeres) y lo propio ocurre con la mortalidad de los adolescentes y jóvenes, que cae en un $21 \%$ (11\% para los hombres y $39 \%$ para las mujeres), no ocurre lo mismo al interior de los grupos de edad de este último conjunto. Así, por ejemplo, mientras en el subgrupo de 10 a 14 años las tasas decrecen en un $66 \%$ durante el período estudiado, en el de 20 a 24 años de edad lo hacen en un 17\%, en cuya distribución por sexo se incluye un incremento de un $21 \%$ de la tasa masculina. A su vez, en el subgrupo de 15 a 19 años de edad, la reducción de un $33 \%$ se acompaña de un aumento de un $17 \%$ de la tasa femenina, si bien esta variación debe ser analizada con cautela, ya que los valores calculados derivan de un exiguo número de defunciones, inferior a 10, tanto para hombres como para mujeres.

En Trinidad \& Tobago, la mortalidad por causas externas se ha mantenido más bien estable, especialmente en el grupo de adolescentes y jóvenes. Si bien la tasa de la población general muestra un decremento de un $13 \%$, concentrado especialmente en las mujeres (-29\%), la caída del indicador para el grupo de 10 a 24 años de edad se acerca sólo al $5 \%$, incluyendo un incremento del $3 \%$ para el sexo femenino. Igualmente exigua es la reducción de la mortalidad por causas externas para el subgrupo de 10 a 14 años de edad, que incluye un llamativo incremento de un $83 \%$ de su componente femenino. A su vez, en el subgrupo de 15 a 19 años se observa un ascenso de un $15 \%$ en la mortalidad por estas causas, que alcanza a un $30 \%$ entre los hombres. Por último, en el subgrupo de 20 a 24 años, aunque la caída es de un $19 \%$, ésta llega sólo al 5\% en la tasa femenina.

\section{H. Países del Cono Sur: Argentina, Chile y Uruguay (Tabla 7)}

En Argentina, las tendencias de los indicadores correspondientes son más bien estables, mostrando variaciones inferiores al $10 \%$ en casi todos los grupos de edad y sexo considerados. Así, para la población general se aprecia un ligero descenso, del orden del $7 \%$ (8\% para los hombres y $4 \%$ para las mujeres), en tanto que para el grupo de adolescentes y jóvenes, las reducciones del indicador son también modestas, excepto para las mujeres, donde se verifica una caída de un 19\%. En todo caso, las disminuciones más notables aparecen en el subgrupo de 10 a 14 años de edad (19\% para ambos sexos y para los hombres y $17 \%$ para las mujeres). El subgrupo de 15 a 19 años de edad es el único que presenta un ligero aumento de la mortalidad en el período, cercano al $3 \%$ y concentrado en el componente masculino.

En Chile, los indicadores de todos los grupos de edad y sexo presentados muestran 
TABLA 6. Mortalidad* por Causas Externas, para Todas las Edades y en el Grupo de 10 a 24 Años de Edad, por Grupos de Edad y Sexo. Suriname y Trinidad \& Tobago, 1979-1989

\begin{tabular}{|c|c|c|c|c|c|c|c|c|c|c|}
\hline \multirow[b]{3}{*}{ Año y Sexo } & \multicolumn{10}{|c|}{ Grupos de Edad (años) } \\
\hline & \multicolumn{2}{|c|}{ Todas las Edades } & \multicolumn{2}{|c|}{$10-24$} & \multicolumn{2}{|c|}{$10-14$} & \multicolumn{2}{|c|}{$15-19$} & \multicolumn{2}{|c|}{$20-24$} \\
\hline & SUR & TRT & SUR & TRT & SUR & TRT & SUR & TRT & SUR & TRT \\
\hline \multicolumn{11}{|l|}{1979} \\
\hline AMBOS SEXOS & 57.8 & 58.1 & 46.1 & 45.4 & 20.0 & 19.4 & 52.2 & 40.6 & 78.1 & 80.7 \\
\hline HOMBRES & 80.5 & 86.3 & 59.4 & 67.4 & 28.0 & 30.6 & 65.2 & 53.7 & 100.0 & 125.5 \\
\hline MUJERES & 35.6 & 30.0 & 32.8 & 23.1 & 12.0 & 8.1 & 39.1 & 27.3 & 56.3 & 35.2 \\
\hline \multicolumn{11}{|l|}{1980} \\
\hline AMBOS SEXOS & 125.0 & 58.1 & 104.9 & 43.9 & 28.1 & 11.5 & 116.3 & 48.5 & 120.6 & 73.5 \\
\hline HOMBRES & 191.9 & 90.6 & 158.0 & 71.4 & 32.1 & 16.4 & 166.6 & 75.6 & 194.1 & 122.8 \\
\hline MUJERES & 59.9 & 25.7 & 51.3 & 16.3 & 24.1 & 6.6 & 62.7 & 15.9 & 47.1 & 23.2 \\
\hline \multicolumn{11}{|l|}{1981} \\
\hline AMBOS SEXOS & 63.0 & 54.3 & 41.4 & 40.5 & 10.2 & 10.8 & 58.3 & 51.9 & 61.1 & 58.1 \\
\hline HOMBRES & 86.3 & 83.1 & 58.2 & 62.4 & 12.0 & 16.7 & 79.2 & 80.6 & 94.4 & 88.1 \\
\hline MUJERES & 40.2 & 25.6 & 24.2 & 18.5 & 8.3 & 5.0 & 37.5 & 22.7 & 27.8 & 27.6 \\
\hline \multicolumn{11}{|l|}{1982} \\
\hline AMBOS SEXOS & 76.7 & 65.4 & 55.1 & 45.7 & 28.6 & 11.8 & 52.1 & 63.1 & 92.3 & 60.3 \\
\hline HOMBRES & 113.5 & 101.6 & 76.5 & 70.4 & 40.0 & 20.0 & 75.0 & 96.9 & 126.3 & 91.8 \\
\hline MUJERES & 40.7 & 29.3 & 33.8 & 20.7 & 16.7 & 3.4 & 29.2 & 29.2 & 60.0 & 28.3 \\
\hline \multicolumn{11}{|l|}{1983} \\
\hline AMBOS SEXOS & 76.0 & 59.4 & 53.2 & 52.8 & 22.4 & 26.1 & 68.8 & 54.8 & 71.4 & 76.2 \\
\hline HOMBRES & 108.2 & 89.4 & 78.6 & 83.9 & 36.0 & 35.0 & 104.2 & 88.9 & 100.0 & 125.4 \\
\hline MUJERES & 44.3 & 29.5 & 27.5 & 21.6 & 8.3 & 16.9 & 33.3 & 20.6 & 42.9 & 27.0 \\
\hline \multicolumn{11}{|l|}{1984} \\
\hline AMBOS SEXOS & 78.7 & 59.0 & 48.6 & 54.6 & 25.0 & 24.4 & 45.8 & 56.6 & 77.3 & 80.6 \\
\hline HOMBRES & 111.8 & 90.0 & 67.1 & 86.6 & 33.3 & 36.7 & 58.3 & 80.3 & 113.6 & 138.5 \\
\hline MUJERES & 46.0 & 28.1 & 30.0 & 22.3 & 16.7 & 11.9 & 33.3 & 32.8 & 40.9 & 21.9 \\
\hline \multicolumn{11}{|l|}{1985} \\
\hline AMBOS SEXOS & 69.5 & 59.4 & 41.8 & 41.1 & 25.5 & 8.3 & 45.8 & 48.3 & 54.3 & 64.6 \\
\hline HOMBRES & 102.6 & 90.8 & 64.8 & 66.7 & 37.5 & 13.1 & 58.3 & 76.7 & 100.0 & 107.7 \\
\hline MUJERES & 36.8 & 28.3 & 18.6 & 15.2 & 13.0 & 3.4 & 33.3 & 20.0 & 8.7 & 21.5 \\
\hline \multicolumn{11}{|l|}{1986} \\
\hline AMBOS SEXOS & 47.7 & 56.8 & 37.3 & 40.7 & 10.9 & 9.1 & 43.8 & 39.8 & 56.3 & 70.8 \\
\hline HOMBRES & 73.6 & 86.3 & 56.3 & 62.2 & 4.3 & 11.5 & 62.5 & 57.6 & 100.0 & 113.8 \\
\hline MUJERES & 22.3 & 27.6 & 18.3 & 19.0 & 17.4 & 6.7 & 25.0 & 22.0 & 12.5 & 27.7 \\
\hline \multicolumn{11}{|l|}{1987} \\
\hline AMBOS SEXOS & 48.5 & 57.0 & 36.4 & 44.0 & 6.8 & 9.1 & 35.4 & 38.5 & 64.6 & 82.5 \\
\hline HOMBRES & 69.5 & 89.8 & 52.9 & 72.7 & 9.1 & 14.8 & 25.0 & 66.1 & 120.8 & 134.9 \\
\hline MUJERES & 27.9 & 24.3 & 20.0 & 14.9 & 4.5 & 3.3 & 45.8 & 10.3 & 8.3 & 30.2 \\
\hline \multicolumn{11}{|l|}{1988} \\
\hline AMBOS SEXOS & $\ldots$ & 51.3 & $\ldots$ & 40.3 & $\ldots$ & 16.4 & $\ldots$ & 42.7 & $\ldots$ & 61.8 \\
\hline HOMBRES & $\ldots$ & 76.5 & $\ldots$ & 64.3 & $\ldots$ & 19.4 & $\ldots$ & 71.2 & $\ldots$ & 103.3 \\
\hline MUJERES & $\ldots$ & 26.3 & $\ldots$ & 16.1 & $\ldots$ & 13.3 & $\ldots$ & 13.8 & $\ldots$ & 21.0 \\
\hline \multicolumn{11}{|l|}{1989} \\
\hline AMBOS SEXOS & $\ldots$ & 50.4 & $\ldots$ & 43.2 & $\ldots$ & 18.5 & $\ldots$ & 46.6 & $\ldots$ & 65.5 \\
\hline HOMBRES & $\ldots$ & 79.1 & $\ldots$ & 62.4 & $\ldots$ & 22.2 & $\ldots$ & 69.5 & $\ldots$ & 98.3 \\
\hline MUJERES & $\ldots$ & 21.9 & $\ldots$ & 23.9 & $\ldots$ & 14.8 & $\ldots$ & 23.7 & $\ldots$ & 33.3 \\
\hline
\end{tabular}

* Tasas por 100.000 personas de cada grupo de edad y sexo

... Datos no disponibles.

Fuente: Sistema de Información Técnica de la OPS. 
TABLA 7. Mortalidad* por Causas Externas, para Todas las Edades y en el Grupo de 10 a 24 Años de Edad, por Grupos de Edad y Sexo. Argentina, Chile y Uruguay, 1979-1990

\begin{tabular}{|c|c|c|c|c|c|c|c|c|c|c|c|c|c|c|c|}
\hline \multirow[b]{3}{*}{ Año y Sexo } & \multicolumn{15}{|c|}{ Grupos de Edad (años) } \\
\hline & \multirow{2}{*}{\multicolumn{3}{|c|}{$\begin{array}{l}\text { Todas las Edades } \\
\text { ARG CHI URU }\end{array}$}} & \multirow{2}{*}{\multicolumn{3}{|c|}{$\begin{array}{c}10-24 \\
\text { ARG CHI URL }\end{array}$}} & \multirow{2}{*}{\multicolumn{3}{|c|}{$\begin{array}{c}10-14 \\
\text { ARG CHI URU } \\
\end{array}$}} & \multicolumn{3}{|c|}{$15-19$} & \multicolumn{3}{|c|}{$20-24$} \\
\hline & & & & & & & & & & & $\mathrm{G} \mathrm{Cl}$ & HI URU & & ARG & CHI URI \\
\hline \multicolumn{16}{|l|}{1979} \\
\hline AMBOS SEXOS & 59.0 & $\ldots$ & $\ldots$ & 41.0 & $\ldots$ & $\ldots$ & 20.1 & $\ldots$ & $\ldots$ & 44.9 & $\ldots$ & $\ldots$ & 59.5 & F. & $\ldots$ \\
\hline HOMBRES & 85.9 & $\ldots$ & $\ldots$ & 61.1 & $\ldots$ & $\ldots$ & 28.2 & $\ldots$ & $\ldots$ & 66.0 & $\ldots$ & $\ldots$ & 91.2 & $2 \ldots$ & $\ldots$ \\
\hline MUJERES & 32.4 & $\ldots$ & $\ldots$ & 20.5 & $\ldots$ & $\ldots$ & 11.8 & $\ldots$ & $\ldots$ & 23.1 & $\ldots$ & $\ldots$ & 26.9 & $\ldots$ & $\ldots$ \\
\hline \multicolumn{16}{|l|}{1980} \\
\hline AMBOS SEXOS & 58.1 & 78.4 & 62.8 & 39.3 & 46. & $.8 \quad 42.9$ & 18.9 & 20.8 & 17.0 & 44.4 & 45.9 & 50.8 & 56.3 & 77.7 & 62.2 \\
\hline HOMBRES & 84.9 & 123.3 & 93.0 & 58.2 & 74. & 870.0 & 25.1 & 28.5 & 24.4 & 64.1 & 72.5 & 79.8 & 88.1 & 130.9 & 9110.0 \\
\hline MUJERES & 31.6 & 34.7 & 33.6 & 19.9 & 18. & $4 \quad 15.3$ & 12.6 & 13.0 & 9.3 & 24.1 & 18.8 & 21.3 & 23.6 & 523.9 & 15.2 \\
\hline \multicolumn{16}{|l|}{1981} \\
\hline AMBOS SEXOS & 58.5 & 78.0 & 61.6 & 39.5 & 46. & $\begin{array}{ll}4 & 39.2\end{array}$ & 20.5 & 20.9 & 15.6 & 42.5 & 45.6 & 41.0 & 57.1 & 75.6 & 62.7 \\
\hline HOMBRES & 85.3 & 122.0 & 89.3 & 59.9 & 74. & $.1 \quad 59.8$ & 29.3 & 28.6 & 21.0 & 62.3 & 72.0 & 62.6 & 90.9 & 127.2 & 2100.0 \\
\hline MUJERES & 32.0 & 35.2 & 34.9 & 18.5 & 18. & $\begin{array}{ll}.2 & 18.4\end{array}$ & 11.4 & 13.0 & 10.1 & 22.2 & 18.7 & 19.0 & 22.5 & 23.3 & 26.3 \\
\hline \multicolumn{16}{|l|}{1982} \\
\hline AMBOS SEXOS & 53.5 & 73.6 & 65.4 & 35.1 & 42. & $\begin{array}{ll}.8 & 38.8\end{array}$ & 16.4 & 18.7 & 15.9 & 39.8 & 42.4 & 43.8 & 51.1 & 69.1 & 58.3 \\
\hline HOMBRES & 79.2 & 116.9 & 96.4 & 53.6 & 69. & 663.3 & 23.4 & 28.3 & 26.2 & 59.6 & 66.6 & 73.6 & 81.3 & 117.7 & 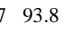 \\
\hline MUJERES & 27.9 & 31.4 & 35.7 & 16.0 & 15. & $\begin{array}{ll}.4 & 13.8\end{array}$ & 9.2 & 8.9 & 5.0 & 19.3 & 17.6 & 13.4 & 20.1 & 19.9 & 23.5 \\
\hline \multicolumn{16}{|l|}{1983} \\
\hline AMBOS SEXOS & 54.4 & 78.6 & 58.4 & 36.1 & 47. & $6 \quad 29.4$ & 18.8 & 25.7 & 10.3 & 39.7 & 43.3 & 36.4 & 52.1 & 75.0 & 43.0 \\
\hline HOMBRES & 79.1 & 125.7 & $\begin{array}{ll}7 & 83.5\end{array}$ & 55.7 & 73. & $.3 \quad 47.8$ & 26.6 & 26.3 & 16.3 & 61.4 & 67.2 & 58.0 & 83.1 & 129.0 & 072.8 \\
\hline MUJERES & 29.8 & 32.8 & 34.3 & 15.8 & 21. & $\begin{array}{ll}.4 & 10.7\end{array}$ & 10.6 & 25.4 & 4.1 & 17.3 & 18.8 & 14.5 & 20.2 & 20.2 & 13.8 \\
\hline \multicolumn{16}{|l|}{1984} \\
\hline AMBOS SEXOS & 53.9 & 77.4 & 53.0 & 35.6 & 42. & $\begin{array}{ll}4 & 29.7\end{array}$ & 17.7 & 15.9 & 14.0 & 40.8 & 39.6 & 30.8 & 51.1 & 72.5 & 546.3 \\
\hline HOMBRES & 78.2 & 124.4 & $\begin{array}{ll}4 & 76.4\end{array}$ & 54.8 & 69. & .246 .6 & 25.5 & 22.6 & $6 \quad 15.9$ & 61.6 & 61.7 & 48.3 & 82.0 & 124.8 & $\begin{array}{ll}8 & 80.0\end{array}$ \\
\hline MUJERES & 29.6 & 31.6 & 30.5 & 15.8 & 15. & $.2 \quad 12.6$ & 9.6 & 9.1 & 11.9 & 19.4 & 17.0 & 12.9 & 19.4 & +19.4 & $4 \quad 12.9$ \\
\hline \multicolumn{16}{|l|}{1985} \\
\hline AMBOS SEXOS & 49.0 & 74.3 & 50.8 & 33.7 & 43. & .231 .6 & 16.1 & 17.4 & $4 \quad 21.2$ & 37.4 & 40.7 & 29.9 & 50.8 & 31.4 & $4 \quad 45.0$ \\
\hline HOMBRES & 70.3 & 118.1 & $1 \quad 75.4$ & 52.3 & 70. & $.9 \quad 50.5$ & 22.6 & 24.8 & 31.9 & 58.0 & 65.2 & 46.6 & 81.8 & 123.0 & $0 \quad 76.5$ \\
\hline MUJERES & 26.5 & 31.7 & 27.3 & 13.9 & 14. & $\begin{array}{ll}.9 & 12.2\end{array}$ & 9.3 & 9.9 & 10.1 & 15.5 & 15.7 & 12.9 & 17.9 & 19.1 & 13.8 \\
\hline \multicolumn{16}{|l|}{1986} \\
\hline AMBOS SEXOS & 54.2 & 71.4 & 56.3 & 37.2 & 42. & $.7 \quad 33.0$ & 17.7 & 16.2 & $2 \quad 17.5$ & 42.5 & 42.6 & 34.2 & 55.6 & 68.6 & $5 \quad 49.8$ \\
\hline HOMBRES & 78.3 & 112.1 & 181.0 & 56.4 & 70. & $\begin{array}{l}.0 \\
\end{array} 50.0$ & 24.3 & 22.8 & $3 \quad 24.1$ & 65.3 & 66.2 & 50.0 & 86.5 & 120.4 & $\begin{array}{ll}4 & 80.9\end{array}$ \\
\hline MUJERES & 29.3 & 31.7 & 32.7 & 16.9 & 14. & $\begin{array}{ll}.7 & 15.7\end{array}$ & 10.5 & 9.6 & 10.7 & 18.3 & 18.5 & 17.9 & 23.1 & 16.1 & 19.0 \\
\hline \multicolumn{16}{|l|}{1987} \\
\hline AMBOS SEXOS & 53.8 & 67.0 & 60.2 & 35.8 & 40. & $.7 \quad 36.3$ & 15.4 & 16.1 & $1 \quad 19.0$ & 43.8 & 37.6 & 38.0 & 52.9 & 67.4 & 455.3 \\
\hline HOMBRES & 76.6 & 105.5 & $\begin{array}{ll}5 & 85.2\end{array}$ & 53.8 & 66. & $.3 \quad 53.6$ & 21.4 & 24.2 & $2 \quad 24.3$ & 64.4 & 59.4 & 55.3 & 83.6 & 5114.4 & $\begin{array}{ll}4 & 87.7\end{array}$ \\
\hline MUJERES & 29.7 & 29.5 & 36.4 & 16.4 & 14. & $.4 \quad 18.5$ & 8.8 & 7.8 & 13.4 & 21.4 & 15.4 & 20.2 & 20.4 & 19.6 & 522.8 \\
\hline 1988 & & & & & & & & & & & & & & & \\
\hline AMBOS SEXOS & 54.8 & $\ldots$ & 58.0 & 36.4 & $\ldots$ & 38.3 & 15.9 & $\ldots$ & 16.6 & 44.9 & $\ldots$ & 44.0 & 53.6 & $5 \quad \ldots 5$ & 58.8 \\
\hline HOMBRES & 78.6 & $\ldots$ & 83.9 & 55.4 & $\ldots$ & 58.4 & 22.1 & $\ldots$ & 20.6 & 66.8 & $\ldots$ & 67.5 & 86.0 & ) & 95.6 \\
\hline MUJERES & 29.8 & $\ldots$ & 33.2 & 16.0 & $\ldots$ & 17.8 & 8.9 & $\ldots$ & 12.5 & 21.4 & $\ldots$ & 19.7 & 19.3 & $3 \quad \ldots 2$ & 22.1 \\
\hline 1989 & & & & & & & & & & & & & & & \\
\hline AMBOS SEXOS & 54.7 & $\ldots$ & 64.3 & 37.9 & $\ldots$ & 45.4 & 16.3 & $\ldots$ & 17.9 & 46.2 & $\ldots$ & 58.0 & 56.9 & ... & 65.0 \\
\hline HOMBRES & 78.8 & $\ldots$. & 94.4 & 58.6 & $\ldots$ & 70.1 & 22.7 & $\ldots$ & 26.8 & 71.0 & $\ldots$ & 83.8 & 92.0 & f. 1 & 108.8 \\
\hline MUJERES & 31.1 & $\ldots$ & 35.6 & 16.6 & $\ldots$ & 20.0 & 9.8 & $\ldots$ & 8.8 & 20.7 & $\ldots$ & 31.2 & 20.8 & $3 \quad \ldots 2$ & 21.2 \\
\hline 1990 & & & & & & & & & & & & & & & \\
\hline AMBOS SEXOS & $\ldots$ & $\ldots$ & 61.8 & $\ldots$ & $\ldots$ & 37.9 & $\ldots$ & $\ldots \quad 1$ & 16.8 & $\ldots$ & ... 46 & 6.2 & $\ldots$ & ... 54 & 4.2 \\
\hline HOMBRES & $\ldots$ & $\ldots$ & 91.0 & $\ldots$ & $\ldots$ & 57.3 & $\ldots$ & ... 2 & 26.1 & $\ldots$ & ... 64 & 4.7 & $\ldots$ & $\ldots 87$ & 7.7 \\
\hline MUJERES & $\ldots$ & $\ldots$ & 33.8 & $\ldots$ & $\ldots$ & 17.8 & $\ldots$ & $\ldots 7$ & 7.3 & ... & $\ldots 26$ & 6.8 & $\ldots$ & $\ldots 20$ & 0.4 \\
\hline
\end{tabular}

* Tasas por 100.000 personas de cada grupo de edad y sexo.

... Datos no disponibles.

Fuente: Sistema de Información Técnica de la OPS. 
tendencias moderadamente descendentes, apreciándose caídas del orden del 12\% al $18 \%$ para la mayoría de ellos. La reducción más relevante se verifica en el subgrupo de 10 a 14 años, en el que la mortalidad femenina por causas externas decrece en un $40 \%$ en el lapso descrito, la masculina en un $15 \%$ y la de ambos sexos, en un $22 \%$. La disparidad entre las magnitudes de las tasas de hombres y mujeres es más acentuada en Chile que en los otros dos países del Cono Sur.

En Uruguay, la mortalidad por causas externas se mantiene más bien estable, decreciendo en un $2 \%$ para la población general, con un muy leve incremento del componente femenino, cercano al 1\%. Entre los adolescentes y jóvenes, la reducción del indicador es más apreciable, alcanzando a un $12 \%$, que incluye un incremento de un $16 \%$ de la tasa femenina para este grupo de edad. También crecen las tasas femeninas de los grupo de 15 a 19 años (23\%) y de 20 a 24 años (34\%), en tanto las masculinas decrecen en órdenes cercanos al $20 \%$ en ambos grupo de edad.

\section{Tendencias de la Mortalidad por Grupos de Causas Externas y Grupos de Edad}

\section{A. Países de América Central: Costa Rica y Panamá (Tabla 8)}

En Costa Rica, las relaciones entre las magnitudes de la mortalidad originada en los distintos grupos de causas externas demuestran que el componente principal del grupo está dado por los accidentes de tráfico durante la totalidad del período analizado, cuyas tasas triplican o cuadruplican a las correspondientes a los dos grupos de lesiones intencionales, que muestran, a su vez, valores bastante similares entre sí, si bien conviene destacar que, en la población general de Costa Rica, la segunda causa externa de defunción está representada por las caídas accidentales, mientras entre los adolescentes y jóvenes este lugar corresponde a los suicidios.

La comparación de los valores de las tasas en los años extremos de la serie denota una caída de la mortalidad por accidentes de tráfico en todos los grupos de edad (28\%, con un máximo de $49 \%$ en el subgrupo de 20 a 24 años); un ligero aumento de la mortalidad por suicidio en la población general (8\%), acompañado de un descenso de la misma entre los adolescentes y jóvenes (29\%); y una disminución de la mortalidad por homicidios (23\% en la población general y $58 \%$ entre los adolescentes y jóvenes).

En cuanto a la mortalidad por suicidio, ésta creció entre 1980 y 1989 con un ritmo de aproximadamente una defunción anual por millón de habitantes, pero se redujo en una defunción anual por millón de adolescentes y jóvenes, acentuándose el ritmo de descenso en el subgrupo de 20 a 24 años de edad.

La mortalidad por homicidio presentó tendencias muy ligeramente descendentes, algo inferiores a una defunción anual por millón de habitantes para la población general y de una muerte anual por millón de personas para el grupo de 10 a 24 años de edad. De aquí que se pueda concluír que la mortalidad por homicidio se mantuvo relativamente estable durante el lapso del estudio. La mortalidad por caídas accidentales decreció entre los adolescentes y jóvenes en el período, pero se incrementó en la población general.

En suma, la caída de la mortalidad por causas externas en Costa Rica se explica principalmente por los descensos de la mortalidad por accidentes de tráfico y por homicidios, descensos que pueden ser calificados como moderados.

En Panamá, la primera causa externa de mortalidad está representada por los accidentes de tráfico, excepto en el último año de la serie, cuando este lugar es ocupado por los homicidios y demás lesiones intencionales infligidas por otros. Las tasas de mortalidad por accidentes de tráfico comienzan octuplicando a las de mortalidad por homicidio, mientras éstas casi duplican a las de mortalidad por suicidio, pero en los últimos 5 años de la serie, la mortalidad por homicidio se acerca rápidamente a la mortalidad por accidentes de tráfico, llegando a constituír la mitad de aquélla, hasta sobrepasarla finalmente en el año del conflicto bélico. A su vez, la mortalidad por suicidio alcanza los niveles que tenía la 
mortalidad por homicidio al inicio del período, conservándose la razón entre ambas en órdenes de 2 a 1 . Estos hechos ocurren más o menos paralelamente en la población general y entre los adolescentes y jóvenes.

Comparando los valores de las tasas de mortalidad en los años extremos de la serie se observa un descenso moderado de la mortalidad por accidentes de tráfico (16\% para la población general y $24 \%$ para los adolescentes y jóvenes), incremento de la mortalidad por suicidio y sobre todo, de la mortalidad por homicidios $(632 \%$ en la población general y $836 \%$ entre los adolescentes y jóvenes), todo lo cual es atribuíble al conflicto bélico sufrido por este país.

De aquí se desprende que el moderado descenso de la mortalidad por causas externas en Panamá en el período del estudio se debe específicamente a la reducción de su principal componente en ese país, la mortalidad por accidentes de tráfico, ya que la mortalidad por las otras dos causas externas importantes mostró tendencias siempre crecientes en ese lapso, incluso si se excluye del análisis los valores alcanzados en el año del conflicto bélico.

\section{B. Países de América del Norte: Canadá y EE.UU. de Norteamérica (Tabla 9)}

El principal componente de la mortalidad por causas externas en Canadá está dado por la mortalidad debida a accidentes de tráfico, seguido por aquella causada por suicidio. Las elevadas tasas por suicidio determinan en este caso una razón inferior a 2 entre los valores de las respectivas tasas de mortalidad en la población general, y de entre 2 y 3 para las de los adolescentes y jóvenes. Por otra parte, la tercera causa externa de muerte en Canadá corresponde a las caídas accidentales, con tasas cuyos valores son del orden de la mitad de las de mortalidad por suicidio, salvo en el grupo de 10 a 24 años de edad, en el que la mortalidad por homicidio supera a la producida por caídas accidentales. La mortalidad por homicidio ocupa el cuarto lugar, con tasas que no llegan a superar a la quinta o sexta parte de las de mortalidad por suicidio.

La mortalidad por accidentes de tráfico se muestra decreciente en este lapso para todos los grupos de edad considerados, cayendo en un $34 \%$ para la población general y en un $38 \%$ para los adolescentes y jóvenes. Llama la atención observar que entre los adolescentes y jóvenes la reducción de la mortalidad por accidentes de tráfico se concentre en el subgrupo de 15 a 24 años (casi dos defunciones anuales por 100.000 personas).

En cambio, la mortalidad por suicidio, si bien se redujo ligeramente en la población general y en el grupo de 10 a 24 años de edad, en órdenes del $6 \%$ al $7 \%$, presenta incrementos en algunos grupos de edad del conjunto de los adolescentes y jóvenes, especialmente en el de 10 a 14 años, en el que aumenta en un $28 \%$, mientras en el de 15 a 19 años se eleva en un $6 \%$.

En lo que se refiere a homicidios, las tendencias observadas son moderadamente decrecientes, en órdenes del $15 \%$ en la población general y del $6 \%$ entre los adolescentes y jóvenes, excepto en el subgrupo de 15 a 19 años de edad, donde se aprecia un incremento de la mortalidad por estas causas del orden del $11 \%$. Los ritmos de descenso de la mortalidad por homicidios son, por lo tanto, mínimos en la población general (de cuatro defunciones anuales por millón de personas) y estacionarios, entre los adolescentes y jóvenes.

En Canadá fue también creciente la tendencia de la mortalidad por caídas accidentales, tanto en la población general como en el subgrupo de 15 a 19 años, hecho este último que llama la atención, ya que entre los adolescentes de otros países de la Región muchas caídas accidentales que producen la muerte son de origen laboral. En este país, suponiendo que no sea frecuente el desempeño laboral de personas de ese subgrupo de edad, cabría confirmar frente a estos casos el carácter accidental de las lesiones, ya que se trata de un subgrupo de edad en el que aumentan las muertes debidas a lesiones intencionales, tanto autoinfligidas como producidas por otros. 
TABLA 8. Mortalidad* por Causas Externas, para Todas las Edades y en el Grupo de 10 a 24 Años de Edad, Segun Grupos de Causas. Costa Rica y Panamá, 1979-1989

\begin{tabular}{|c|c|c|c|c|c|c|c|c|c|c|}
\hline \multirow[b]{3}{*}{ Grupos de Causas y Año } & \multicolumn{10}{|c|}{ Grupos de Edad (años) } \\
\hline & \multicolumn{2}{|c|}{ Todas las Edades } & \multicolumn{2}{|c|}{$10-24$} & \multicolumn{2}{|c|}{$10-14$} & \multicolumn{2}{|c|}{$15-19$} & & \\
\hline & $\mathrm{COR}$ & PAN & $\mathrm{COR}$ & PAN & $\mathrm{COR}$ & PAN & $\mathrm{COR}$ & PAN & $\mathrm{COR}$ & PAN \\
\hline 1979 & & & & & & & & & & \\
\hline ACCIDENTE DE TRAFICO (1) & $\ldots$ & 16.14 & $\ldots$ & 14.72 & $\ldots$ & 8.61 & $\ldots$ & 9.00 & $\ldots$ & 29.94 \\
\hline SUICIDIO (2) & $\ldots$ & 1.57 & $\ldots$ & 1.11 & $\ldots$ & 0.00 & $\ldots$ & 1.42 & $\ldots$ & 2.26 \\
\hline HOMICIDIO Y OTRAS (3) & $\ldots$ & 2.9 & $\ldots$ & 1.27 & $\ldots$ & 0.00 & $\ldots$ & 0.47 & $\ldots$ & 3.95 \\
\hline CAIDA ACCIDENTAL (4) & $\ldots$ & 2.30 & $\ldots$ & 0.63 & $\ldots$ & 0.41 & $\ldots$ & 0.95 & $\ldots$ & 0.56 \\
\hline LESIONES C. EXT. IGNORADA (5) & & 4.39 & & 6.01 & $\ldots$ & 0.41 & $\ldots$ & 7.11 & & 12.43 \\
\hline $\begin{array}{l}\text { RESTO CAUSAS EXTERNAS (6) } \\
1980\end{array}$ & $\ldots$ & 24.35 & $\ldots$ & 19.94 & $\ldots$ & 14.75 & $\ldots$ & 22.75 & $\ldots$ & 23.73 \\
\hline ACCIDENTE DE TRAFICO (1) & 18.35 & 17.94 & 16.60 & 14.46 & 8.07 & 2.40 & 14.44 & 17.05 & 29.29 & 27.87 \\
\hline SUICIDIO (2) & 5.34 & 1.99 & 6.12 & 1.85 & 1.05 & 0.80 & 4.69 & 1.84 & 13.81 & 3.28 \\
\hline HOMICIDIO Y OTRAS (3) & 5.69 & 2.10 & 6.12 & 1.85 & 2.11 & 0.40 & 7.22 & 2.30 & 9.62 & 3.28 \\
\hline CAIDA ACCIDENTAL (4) & 5.79 & 2.91 & 1.25 & 0.77 & 0.70 & 0.80 & 1.08 & 0.92 & 2.09 & 0.55 \\
\hline LESIONES C. EXT. IGNORADA (5) & 1.23 & 11.81 & 1.12 & 11.23 & 1.05 & 0.80 & 0.36 & 13.36 & 2.09 & 22.95 \\
\hline RESTO CAUSAS EXTERNAS (6) & 16.77 & 16.16 & 14.61 & 12.62 & 10.88 & 9.60 & 14.44 & 12.90 & 19.25 & 16.39 \\
\hline & & & & & & & & & & \\
\hline ACCIDENTE DE TRAFICO (1) & 12.41 & 17.36 & 10.77 & 14.7 & 4.23 & 5.91 & 8.83 & 14.29 & 20.40 & 24.74 \\
\hline SUICIDIO (2) & 4.12 & 1.85 & 4.77 & 1.50 & 1.06 & 0.79 & 4.59 & 1.34 & 9.20 & 2.63 \\
\hline HOMICIDIO Y OTRAS (3) & 4.50 & 2.40 & 3.06 & 2.84 & 0.00 & 0.00 & 3.53 & 3.13 & 6.00 & 6.32 \\
\hline CAIDA ACCIDENTAL (4) & 4.80 & 2.55 & 1.35 & 0.60 & 0.35 & 0.00 & 2.12 & 0.45 & 1.60 & 1.58 \\
\hline LESIONES C. EXT. IGNORADA (5) & 1.23 & 9.45 & 0.73 & 9.88 & 0.00 & 1.97 & 0.35 & 8.48 & 2.00 & 22.11 \\
\hline $\begin{array}{l}\text { RESTO CAUSAS EXTERNAS (6) } \\
1982\end{array}$ & 14.58 & 13.66 & 11.26 & 10.93 & 8.10 & 8.27 & 11.66 & 11.16 & 14.40 & 14.21 \\
\hline ACCIDENTE DE TRAFICO (1) & 11.76 & 18.45 & 9.93 & 12.85 & 4.27 & 9.27 & 9.41 & 13.04 & 16.67 & 17.35 \\
\hline SUICIDIO (2) & 3.71 & 1.71 & 2.66 & 1.31 & 0.00 & 0.00 & 1.74 & 1.74 & 6.59 & 2.55 \\
\hline HOMICIDIO Y OTRAS (3) & 4.13 & 2.64 & 2.91 & 3.21 & 1.07 & 0.00 & 2.44 & 2.17 & 5.43 & 8.67 \\
\hline CAIDA ACCIDENTAL (4) & 5.45 & 2.59 & 0.97 & 0.58 & 0.00 & 0.00 & 1.05 & 0.43 & 1.94 & 1.53 \\
\hline LESIONES C. EXT. IGNORADA (5) & 1.44 & 10.62 & 1.09 & 9.64 & 0.36 & 0.77 & 1.05 & 10.00 & 1.94 & 20.92 \\
\hline RESTO CAUSAS EXTERNAS (6) & 13.49 & 13.56 & 11.02 & 10.95 & 6.05 & 8.11 & 13.94 & 12.17 & 13.18 & 13.27 \\
\hline 1983 & & & & & & & & & & \\
\hline ACCIDENTE DE TRAFICO (1) & 8.01 & 16.85 & 6.10 & 15.12 & 2.15 & 5.70 & 5.19 & 14.83 & 11.19 & 27.72 \\
\hline SUICIDIO (2) & 5.29 & 1.87 & 4.78 & 2.28 & 0.36 & 0.76 & 5.19 & 1.27 & 8.96 & 5.45 \\
\hline HOMICIDIO Y OTRAS (3) & 3.77 & 2.39 & 3.47 & 1.85 & 0.00 & 0.00 & 4.50 & 2.54 & 5.97 & 3.47 \\
\hline CAIDA ACCIDENTAL (4) & 5.41 & 3.64 & 1.32 & 0.14 & 0.72 & 0.00 & 1.38 & 0.00 & 1.87 & 0.50 \\
\hline LESIONES C. EXT. IGNORADA (5) & 0.36 & 8.43 & 0.60 & 8.13 & 0.00 & 0.00 & 0.69 & 10.17 & 1.12 & 16.34 \\
\hline RESTO CAUSAS EXTERNAS (6) & 12.38 & 15.22 & 9.33 & 10.56 & 5.73 & 11.41 & 10.03 & 6.78 & 12.31 & 13.86 \\
\hline 1984 & & & & & & & & & & \\
\hline ACCIDENTE DE TRAFICO (1) & 12.11 & 16.21 & 8.66 & 11.78 & 2.52 & 6.04 & 8.97 & 10.37 & 14.55 & 20.77 \\
\hline SUICIDIO (2) & 4.40 & 1.36 & 2.85 & 1.26 & 0.72 & 0.38 & 2.76 & 2.07 & 5.09 & 1.45 \\
\hline HOMICIDIO Y OTRAS (3) & 4.52 & 2.76 & 4.15 & 2.38 & 1.08 & 0.75 & 2.07 & 2.90 & 9.45 & 3.86 \\
\hline CAIDA ACCIDENTAL (4) & 5.49 & 3.42 & 1.07 & 0.56 & 1.44 & 0.00 & 0.00 & 1.24 & 1.82 & 0.48 \\
\hline LESIONES C. EXT. IGNORADA (5) & 0.23 & 9.23 & 0.12 & 8.42 & 0.00 & 0.75 & 0.00 & 9.54 & 0.36 & 16.91 \\
\hline RESTO CAUSAS EXTERNAS (6) & 13.71 & 16.16 & 12.46 & 11.08 & 6.12 & 9.43 & 10.34 & 8.71 & 21.09 & 15.94 \\
\hline $\begin{array}{l}1985 \\
\text { ACCIDENTE DE TRAFICO (1) }\end{array}$ & 13.82 & 15.78 & 11.75 & 10.44 & 3.47 & 5.24 & 11.38 & 10.53 & 20.28 & 16.82 \\
\hline SUICIDIO (2) & 4.88 & 2.57 & 5.17 & 2.06 & 1.07 & 0.37 & 5.86 & 1.21 & 8.54 & 5.14 \\
\hline HOMICIDIO Y OTRAS (3) & 4.81 & 5.50 & 4.47 & 5.77 & 0.00 & 0.00 & 3.10 & 5.26 & 10.32 & 13.55 \\
\hline CAIDA ACCIDENTAL (4) & 6.89 & 2.66 & 0.71 & 0.14 & 0.36 & 0.00 & 0.69 & 0.40 & 1.07 & 0.00 \\
\hline LESIONES C. EXT. IGNORADA (5) & 1.06 & 5.37 & 1.29 & 5.91 & 0.71 & 1.50 & 1.38 & 6.88 & 1.78 & 10.28 \\
\hline RESTO CAUSAS EXTERNAS (6) & 12.00 & 17.29 & 11.16 & 13.60 & 7.86 & 7.49 & 11.03 & 12.55 & 14.59 & 22.43 \\
\hline 1986 & & & & & & & & & & \\
\hline ACCIDENTE DE TRAFICO (1) & 12.66 & 16.52 & 9.63 & 10.81 & 5.23 & 3.35 & 6.94 & 11.95 & 16.72 & 18.64 \\
\hline SUICIDIO (2) & 4.82 & 3.73 & 3.36 & 3.78 & 0.70 & 1.12 & 3.82 & 5.98 & 5.57 & 4.55 \\
\hline HOMICIDIO Y OTRAS (3) & 4.01 & 5.84 & 3.94 & 5.68 & 1.74 & 1.12 & 3.82 & 6.77 & 6.27 & 10.00 \\
\hline CAIDA ACCIDENTAL (4) & 4.82 & 3.01 & 0.46 & 0.27 & 0.00 & 0.00 & 0.35 & 0.40 & 1.05 & 0.45 \\
\hline LESIONES C. EXT. IGNORADA (5) & 0.92 & 4.31 & 0.70 & 2.70 & 0.70 & 0.37 & 0.69 & 1.99 & 0.70 & 6.36 \\
\hline $\begin{array}{l}\text { RESTO CAUSAS EXTERNAS (6) } \\
1987\end{array}$ & 12.85 & 15.45 & 9.16 & 11.22 & 6.62 & 7.06 & 9.72 & 17.13 & 11.15 & 9.55 \\
\hline ACCIDENTE DE TRAFICO (1) & 14.01 & 17.06 & 11.37 & 13.05 & 6.76 & 4.46 & 8.74 & 15.63 & 18.69 & 20.35 \\
\hline SUICIDIO (2) & 4.30 & 3.78 & 3.56 & 3.60 & 0.68 & 1.12 & 2.45 & 3.13 & 7.61 & 7.08 \\
\hline HOMICIDIO Y OTRAS (3) & 4.69 & 7.48 & 4.02 & 7.19 & 2.36 & 1.49 & 3.50 & 7.81 & 6.23 & 13.27 \\
\hline CAIDA ACCIDENTAL (4) & 5.84 & 2.77 & 0.57 & 0.53 & 0.00 & 0.00 & 0.70 & 0.78 & 1.04 & 0.88 \\
\hline LESIONES C. EXT. IGNORADA (5) & 1.07 & 5.32 & 1.03 & 3.99 & 1.35 & 1.12 & 0.70 & 3.91 & 1.04 & 7.52 \\
\hline RESTO CAUSAS EXTERNAS (6) & 13.29 & 14.47 & 11.25 & 10.65 & 6.08 & 5.95 & 11.19 & 11.33 & 16.61 & 15.49 \\
\hline 1988 & & & & & & & & & & \\
\hline ACCIDENTE DE TRAFICO (1) & 12.99 & 13.65 & 8.05 & 11.96 & 3.25 & 6.32 & 9.93 & 13.46 & 11.30 & 16.81 \\
\hline SUICIDIO (2) & 4.99 & 3.75 & 3.40 & 4.07 & 0.00 & 1.12 & 2.84 & 5.77 & 7.53 & 5.60 \\
\hline HOMICIDIO Y OTRAS (3) & 4.01 & 7.58 & 3.74 & 6.96 & 0.00 & 0.37 & 2.84 & 8.46 & 8.56 & 12.93 \\
\hline CAIDA ACCIDENTAL (4) & 6.39 & 3.83 & 0.57 & 0.79 & 0.00 & 1.12 & 1.06 & 0.38 & 0.68 & 0.86 \\
\hline LESIONES C. EXT. IGNORADA (5) & 2.02 & 3.70 & 1.47 & 2.50 & 0.32 & 0.74 & 1.77 & 4.23 & 2.40 & 2.59 \\
\hline RESTO CAUSAS EXTERNAS (6) & 12.81 & 15.76 & 9.98 & 11.70 & 4.87 & 7.81 & 11.70 & 12.31 & 13.70 & 15.52 \\
\hline 1989 & & & & & & & & & & \\
\hline ACCIDENTE DE TRAFICO (1) & 13.23 & 13.50 & 9.61 & 11.20 & 5.31 & 3.36 & 8.87 & 15.65 & 15.02 & 15.13 \\
\hline SUICIDIO (2) & 5.78 & 2.95 & 4.36 & 2.86 & 1.25 & 0.37 & 4.61 & 2.67 & 7.51 & 5.88 \\
\hline HOMICIDIO Y OTRAS (3) & 4.39 & 15.32 & 2.57 & 11.85 & 0.94 & 0.37 & 2.13 & 12.21 & 4.78 & 24.37 \\
\hline CAIDA ACCIDENTAL (4) & 6.05 & 2.32 & 0.56 & 0.39 & 0.31 & 0.37 & 0.35 & 0.38 & 1.02 & 0.42 \\
\hline LESIONES C. EXT. IGNORADA (5) & 2.11 & 8.86 & 1.90 & 7.03 & 1.25 & 1.12 & 2.13 & 3.82 & 2.39 & 17.23 \\
\hline RESTO CAUSAS EXTERNAS (6) & 12.89 & 14.98 & 8.16 & 10.55 & 5.00 & 7.84 & 11.35 & 9.92 & 8.53 & 14.29 \\
\hline
\end{tabular}

* Tasas por 100.000 personas de cada grupo de edad

... Datos no disponibles.

Fuente: Sistema de Informacion Tecnica de la OPS.

(1) Códigos E810-E819, CIE IX; (2) Códigos E950-E959, CIE IX; (3) Códigos E960-969, E970-E978 Y E990-E999, CIE IX;

(4) Códigos E880-E888, CIE IX; (5) Códigos E980-E989, CIE IX; (6) Códigos E800-E807, E820-E879, E890-E949, CIE IX. 
TABLA 9. Mortalidad* por Causas Externas, para Todas las Edades y en el Grupo de 10 a 24 Años de Edad, Segun Grupos de Causas. Canadá y Estados Unidos, 1979-1989

\begin{tabular}{|c|c|c|c|c|c|c|c|c|c|c|}
\hline \multirow{4}{*}{$\begin{array}{l}\text { Grupos de Causas } \\
1979\end{array}$} & \multicolumn{10}{|c|}{$\begin{array}{l}\text { Grupos de Edad (años) } \\
\end{array}$} \\
\hline & \multirow{2}{*}{\multicolumn{2}{|c|}{$\begin{array}{l}\text { Todas las Edades } \\
\text { CANEE.UU. }\end{array}$}} & \multicolumn{2}{|c|}{$10-24$} & \multicolumn{2}{|c|}{$10-14$} & \multicolumn{2}{|c|}{$15-19$} & & -24 \\
\hline & & & CAN & EE.UU. & CAN & EE.UU. & CAN & EE.UU. & CAN & EE.UU. \\
\hline & & & & & & & & & & \\
\hline ACCIDENTE DE TRAFICO (1) & 24.4 & 23.18 & 37.14 & 33.43 & 10.94 & 7.77 & 48.74 & 43.73 & 48.57 & 45.59 \\
\hline SUICIDIO (2) & 14.12 & 12.07 & 12.38 & 8.79 & 1.08 & 0.81 & 12.89 & 8.35 & 21.95 & 16.22 \\
\hline HOMICIDIO Y OTRAS (3) & 2.52 & 10.01 & 2.48 & 10.39 & 0.94 & 1.22 & 2.59 & 10.23 & 3.75 & 18.60 \\
\hline CAIDA ACCIDENTAL (4) & 8.00 & 5.86 & 1.18 & 0.90 & 0.69 & 0.35 & 1.09 & 0.99 & 1.72 & 1.30 \\
\hline LESIONES C. EXT. IGNORADA (5) & 2.83 & 1.71 & 1.73 & 1.38 & 0.39 & 0.39 & 1.72 & 1.32 & 2.95 & 2.32 \\
\hline RESTO CAUSAS EXTERNAS (6) & 17.92 & 17.68 & 14.10 & 13.78 & 6.90 & 7.83 & 14.18 & 14.53 & 20.45 & 18.23 \\
\hline 1980 & & & & & & & & & & \\
\hline ACCIDENTE DE TRAFICO (1) & 22.45 & 22.80 & 34.94 & 33.07 & 9.01 & 7.73 & 46.12 & 42.30 & 45.45 & 45.43 \\
\hline SUICIDIO (2) & 13.97 & 11.80 & 11.15 & 8.82 & 1.08 & 0.76 & 11.78 & 8.49 & 19.04 & 15.95 \\
\hline HOMICIDIO Y OTRAS (3) & 2.10 & 10.67 & 1.48 & 11.33 & 0.26 & 1.44 & 1.19 & 10.65 & 2.82 & 20.36 \\
\hline CAIDA ACCIDENTAL (4) & 7.69 & 5.84 & 1.07 & 0.91 & 0.26 & 0.22 & 0.76 & 0.99 & 2.08 & 1.42 \\
\hline LESIONES C. EXT. IGNORADA (5) & 2.49 & 1.61 & 1.41 & 1.23 & 0.51 & 0.26 & 1.31 & 1.18 & 2.25 & 2.09 \\
\hline $\begin{array}{l}\text { RESTO CAUSAS EXTERNAS (6) } \\
\mathbf{1 9 8 1}\end{array}$ & 16.78 & 17.78 & 13.61 & 13.56 & 7.32 & 7.31 & 14.24 & 14.65 & 18.30 & 17.77 \\
\hline ACCIDENTE DE TRAFICO (1) & 21.78 & 21.81 & 32.85 & 30.53 & 8.92 & 7.38 & 42.60 & 37.71 & 42.68 & 42.73 \\
\hline SUICIDIO (2) & 14.00 & 11.99 & 12.04 & 8.82 & 1.80 & 0.91 & 12.76 & 8.53 & 19.65 & 15.61 \\
\hline HOMICIDIO Y OTRAS (3) & 2.34 & 10.28 & 2.33 & 10.70 & 1.06 & 1.59 & 2.05 & 9.98 & 3.64 & 18.87 \\
\hline CAIDA ACCIDENTAL (4) & 7.23 & 5.49 & 0.93 & 0.83 & 0.16 & 0.24 & 1.05 & 0.75 & 1.46 & 1.39 \\
\hline LESIONES C. EXT. IGNORADA (5) & 2.67 & 1.57 & 1.92 & 1.18 & 0.32 & 0.27 & 2.48 & 1.16 & 2.65 & 1.94 \\
\hline RESTO CAUSAS EXTERNAS (6) & 15.86 & 16.46 & 12.98 & 12.05 & 7.13 & 7.05 & 14.72 & 12.31 & 16.01 & 15.92 \\
\hline 等 & & & & & & & & & & \\
\hline ACCIDENTE DE TRAFICO (1) & 16.57 & 19.23 & 25.23 & 27.40 & 8.00 & 6.99 & 33.41 & 33.78 & 31.10 & 37.96 \\
\hline SUICIDIO (2) & 14.33 & 12.15 & 11.88 & 8.76 & 1.46 & 1.13 & 12.78 & 8.55 & 19.19 & 15.14 \\
\hline HOMICIDIO Y OTRAS (3) & 2.44 & 9.62 & 2.28 & 9.95 & 0.59 & 1.35 & 2.77 & 9.57 & 3.14 & 17.27 \\
\hline CAIDA ACCIDENTAL (4) & 7.40 & 5.19 & 1.04 & 0.86 & 0.38 & 0.33 & 0.86 & 0.89 & 1.74 & 1.25 \\
\hline LESIONES C. EXT. IGNORADA (5) & 2.24 & 1.38 & 1.65 & 1.00 & 0.43 & 0.23 & 1.68 & 0.92 & 2.58 & 1.71 \\
\hline $\begin{array}{l}\text { RESTO CAUSAS EXTERNAS (6) } \\
\mathbf{1 9 8 3}\end{array}$ & 14.63 & 16.04 & 10.80 & 11.53 & 6.97 & 6.36 & 10.97 & 11.60 & 13.64 & 15.65 \\
\hline ACCIDENTE DE TRAFICO (1) & 16.72 & 18.49 & 25.70 & 25.93 & 7.21 & 6.70 & 31.21 & 32.10 & 35.01 & 35.77 \\
\hline SUICIDIO (2) & 15.11 & 12.05 & 12.48 & 8.58 & 1.27 & 1.12 & 13.75 & 8.53 & 19.95 & 14.61 \\
\hline HOMICIDIO Y OTRAS (3) & 2.43 & 8.60 & 2.02 & 8.94 & 0.44 & 1.22 & 2.00 & 8.35 & 3.25 & 15.66 \\
\hline CAIDA ACCIDENTAL (4) & 7.13 & 5.12 & 0.72 & 0.76 & 0.39 & 0.24 & 0.52 & 0.73 & 1.14 & 1.21 \\
\hline LESIONES C. EXT. IGNORADA (5) & 1.77 & 1.32 & 1.16 & 0.95 & 0.39 & 0.28 & 1.00 & 0.83 & 1.90 & 1.60 \\
\hline $\begin{array}{l}\text { RESTO CAUSAS EXTERNAS (6) } \\
\mathbf{1 9 8 4}\end{array}$ & 13.52 & 15.77 & 10.22 & 10.91 & 5.67 & 6.47 & 9.75 & 10.80 & 14.13 & 14.57 \\
\hline ACCIDENTE DE TRAFICO (1) & 15.81 & 19.07 & 23.72 & 27.19 & 6.96 & 6.97 & 30.57 & 33.58 & 30.66 & 37.71 \\
\hline SUICIDIO (2) & 13.69 & 12.35 & 11.86 & 9.08 & 1.50 & 1.31 & 12.64 & 8.87 & 19.07 & 15.51 \\
\hline HOMICIDIO Y OTRAS (3) & 2.38 & 8.36 & 2.08 & 8.81 & 0.50 & 1.59 & 1.80 & 8.19 & 3.51 & 15.14 \\
\hline CAIDA ACCIDENTAL (4) & 7.22 & 5.03 & 0.70 & 0.76 & 0.11 & 0.24 & 0.90 & 0.76 & 0.97 & 1.18 \\
\hline LESIONES C. EXT. IGNORADA (5) & 2.16 & 1.26 & 1.41 & 0.94 & 0.33 & 0.29 & 1.40 & 0.81 & 2.24 & 1.59 \\
\hline RESTO CAUSAS EXTERNAS (6) & 14.46 & 15.09 & 10.01 & 10.24 & 5.18 & 6.03 & 11.04 & 10.01 & 12.81 & 13.83 \\
\hline 1985 & & & & & & & & & & \\
\hline ACCIDENTE DE TRAFICO (1) & 16.15 & 19.59 & 24.42 & 28.55 & 6.67 & 7.06 & 30.11 & 37.18 & 33.30 & 38.32 \\
\hline SUICIDIO (2) & 12.84 & 12.92 & 10.96 & 9.44 & 0.95 & 1.46 & 11.49 & 10.20 & 18.17 & 15.20 \\
\hline HOMICIDIO Y OTRAS (3) & 2.18 & 9.09 & 2.14 & 10.14 & 0.90 & 1.43 & 2.18 & 10.02 & 3.04 & 17.26 \\
\hline CAIDA ACCIDENTAL (4) & 7.21 & 4.78 & 0.84 & 0.76 & 0.28 & 0.19 & 1.04 & 0.81 & 1.11 & 1.17 \\
\hline LESIONES C. EXT. IGNORADA (5) & 1.42 & 1.30 & 0.78 & 0.88 & 0.11 & 0.22 & 0.88 & 0.80 & 1.20 & 1.49 \\
\hline $\begin{array}{l}\text { RESTO CAUSAS EXTERNAS (6) } \\
\mathbf{1 9 8 6}\end{array}$ & 13.07 & 15.45 & 9.16 & 9.74 & 5.78 & 5.86 & 8.68 & 10.37 & 12.13 & 12.31 \\
\hline ACCIDENTE DE TRAFICO (1) & 15.31 & 19.41 & 23.49 & 29.02 & 6.03 & 7.11 & 31.66 & 38.01 & 30.40 & 39.06 \\
\hline SUICIDIO (2) & 14.32 & 12.80 & 11.88 & 9.59 & 1.35 & 1.47 & 12.91 & 10.43 & 19.24 & 15.50 \\
\hline HOMICIDIO Y OTRAS (3) & 2.01 & 9.01 & 1.94 & 10.30 & 0.79 & 1.44 & 1.87 & 10.24 & 2.90 & 17.59 \\
\hline CAIDA ACCIDENTAL (4) & 7.85 & 4.74 & 0.73 & 0.77 & 0.17 & 0.19 & 0.80 & 0.82 & 1.10 & 1.20 \\
\hline LESIONES C. EXT. IGNORADA (5) & 1.79 & 1.29 & 1.06 & 0.90 & 0.17 & 0.22 & 1.23 & 0.82 & 1.63 & 1.52 \\
\hline RESTO CAUSAS EXTERNAS (6) & 12.34 & 15.31 & 8.75 & 9.90 & 4.06 & 5.90 & 9.80 & 10.60 & 11.56 & 12.55 \\
\hline 1987 & & & & & & & & & & \\
\hline ACCIDENTE DE TRAFICO (1) & 16.17 & 19.43 & 24.78 & 28.06 & 6.87 & 7.11 & 32.84 & 37.58 & 32.53 & 37.12 \\
\hline SUICIDIO (2) & 13.90 & 12.65 & 11.41 & 9.39 & 1.69 & 1.48 & 13.31 & 10.64 & 17.68 & 14.88 \\
\hline HOMICIDIO Y OTRAS (3) & 2.24 & 8.67 & 2.22 & 10.21 & 0.84 & 1.57 & 1.91 & 10.29 & 3.60 & 17.32 \\
\hline CAIDA ACCIDENTAL (4) & 7.37 & 4.82 & 0.84 & 0.62 & 0.45 & 0.19 & 0.93 & 0.52 & 1.09 & 1.08 \\
\hline LESIONES C. EXT. IGNORADA (5) & 2.10 & 1.24 & 1.05 & 0.83 & 0.11 & 0.25 & 1.09 & 0.83 & 1.78 & 1.31 \\
\hline RESTO CAUSAS EXTERNAS (6) & 13.17 & 14.78 & 8.87 & 9.13 & 5.12 & 5.30 & 10.37 & 9.63 & 10.66 & 11.87 \\
\hline 1988 & & & & & & & & & & \\
\hline ACCIDENTE DE TRAFICO (1) & 15.22 & 19.57 & 23.63 & 28.38 & 6.28 & 7.08 & 32.18 & 37.97 & 30.97 & 37.98 \\
\hline SUICIDIO (2) & 13.46 & 12.39 & 11.78 & 9.52 & 1.51 & 1.41 & 13.33 & 11.68 & 19.14 & 14.52 \\
\hline HOMICIDIO Y OTRAS (3) & 1.90 & 8.98 & 1.63 & 11.15 & 0.39 & 1.66 & 1.38 & 12.11 & 2.90 & 18.40 \\
\hline CAIDA ACCIDENTAL (4) & 8.05 & 4.93 & 0.84 & 0.65 & 0.28 & 0.18 & 1.05 & 0.58 & 1.14 & 1.11 \\
\hline LESIONES C. EXT. IGNORADA (5) & 1.80 & 1.23 & 0.98 & 0.92 & 0.28 & 0.30 & 0.88 & 0.89 & 1.66 & 1.48 \\
\hline $\begin{array}{l}\text { RESTO CAUSAS EXTERNAS (6) } \\
\mathbf{1 9 8 9}\end{array}$ & 11.81 & 15.07 & 8.36 & 8.98 & 4.54 & 5.27 & 8.48 & 9.65 & 11.50 & 11.56 \\
\hline ACCIDENTE DE TRAFICO (1) & 16.01 & 18.84 & 22.92 & 25.88 & 5.78 & 6.52 & 30.62 & 35.30 & 31.32 & 34.32 \\
\hline SUICIDIO (2) & 13.28 & 12.22 & 11.45 & 9.53 & 1.39 & 1.40 & 13.68 & 11.52 & 18.43 & 14.88 \\
\hline HOMICIDIO Y OTRAS (3) & 2.13 & 9.27 & 2.33 & 12.16 & 0.39 & 1.95 & 2.88 & 14.00 & 3.57 & 19.46 \\
\hline CAIDA ACCIDENTAL (4) & 7.58 & 4.91 & 0.87 & 0.51 & 0.22 & 0.19 & 1.22 & 0.54 & 1.14 & 0.75 \\
\hline LESIONES C. EXT. IGNORADA (5) & 1.24 & 1.09 & 0.82 & 0.72 & 0.17 & 0.25 & 0.94 & 0.72 & 1.29 & 1.14 \\
\hline RESTO CAUSAS EXTERNAS (6) & 12.29 & 14.67 & 8.18 & 8.66 & 3.95 & 5.29 & 9.36 & 9.45 & 10.90 & 10.89 \\
\hline
\end{tabular}

* Tasas por 100.000 personas de cada grupo de edad..

Datos no disponibles. Fuente: Sistema de Informacion Tecnica de la OPS (1) Códigos E810-E819, CIE IX; (2) Códigos E950-E959, CIE IX; (3) Códigos E960-969, E970-E978 Y E990-E999, CIE IX;

(4) Códigos E880-E888, CIE IX; (5) Códigos E980-E989, CIE IX; (6) Códigos E800-E807, E820-E879, E890-E949, CIE IX. 
De lo anterior se deduce que el descenso de la mortalidad verificado en Canadá entre 1979 y 1989 se debió principalmente a la caída de la mortalidad por accidentes de tráfico, y secundariamente, a las disminuciones de la mortalidad por las demás causas externas en la población general, disminuciones que son más pronunciadas que las verificadas en el grupo de 10 a 24 años de edad.

En los EE.UU. de Norteamérica, la principal causa externa de defunción está constituída por los accidentes de tráfico, con tasas cuyos valores son alrededor de dos veces superior a los de la segunda causa externa de muerte, los suicidios, excepto entre los adolescentes y jóvenes, grupo en el que la mortalidad por homicidio resulta ligeramente superior.

Se constata diferencias importantes con respecto a lo ocurrido en el otro país de la subregión. En primer lugar, la reducción de la mortalidad por accidentes de tráfico fue inferior a la del caso anterior, alcanzando al $19 \%$ en la población general y al $23 \%$ entre los adolescentes y jóvenes.

Por otra parte, la mortalidad por suicidio fue creciente en los EE.UU. en prácticamente todos los grupos de edad considerados, si bien las magnitudes de las variaciones observadas son disímiles. Entre 1979 y 1989, la mortalidad por suicidio aumentó en este país en un $1 \%$ para la población general y en un $8 \%$ para los adolescentes y jóvenes, con una distribución de este incremento marcadamente concentrada en los grupos de 10 a 14 años (73\% de aumento) y de 15 a 19 años (38\% de aumento)

La mortalidad por homicidio, si bien cayó en un $7 \%$ en la población general, mostró un incremento del $17 \%$ entre los adolescentes y jóvenes, concentrado en los grupos de 10 a 14 años (59\%) y de 15 a 19 años (37\%).

En suma, la moderada reducción de la mortalidad por causas externas en los EE.UU. debe ser atribuída principalnente a la caída de la mortalidad por accidentes de tráfico, ya que las tendencias de la mortalidad debida a los otros dos grupos importantes de causas externas fueron crecientes o estables en la población general y se elevaron francamente en la población de 10 a 24 años de edad y muy especialmente, en el grupo de 10 a 19 años.

\section{Países del Area Andina: Colombia y Venezuela (Tabla 10)}

En Colombia, en el breve lapso para el cual se dispone de información (entre 1984 y 1990), se aprecian variaciones muy marcadas y diversas para cada una de ellas.

La primera causa externa de defunción en Colombia es, sin lugar a dudas, el homicidio y las demás lesiones intencionales producidas por otros, seguida por los accidentes de tráfico. Las relaciones entre las magnitudes de las tasas de mortalidad originadas en estos dos grupos de causas muestran un gran incremento durante el período, debido al rápido crecimiento de la mortalidad por homicidio. Así, al inicio de la serie la mortalidad por homicidio duplica a la mortalidad por accidentes de tráfico, pero al final del mismo, es casi seis veces mayor. La tercera causa externa de defunción, el suicidio, muestra valores insignificantes en comparación con los anteriores, del orden de la tercera o cuarta parte de la mortalidad por accidentes de tráfico, pero al final del mismo, es casi seis veces mayor.

Las mortalidades por accidentes de tráfico y por suicidio son decrecientes en el período, reduciéndose la primera en un $16 \%$ y la segunda, en un $27 \%$. Las disminuciones señaladas son mayores entre los adolescentes y jóvenes (20\% y 29\%, respectivamente).

Muy distinto es, en cambio, el comportamiento de la mortalidad por homicidio, que creció en un $128 \%$ en la población general y en un $182 \%$ entre los adolescentes y jóvenes. Las velocidades de ascenso de la tasa de mortalidad por homicidio en Colombia resultan espectaculares, alcanzando a siete decesos anuales por 100.000 habitantes para la población general y a ocho muertes por 100.000 jóvenes y adolescentes al año.

Se puede concluír, por lo tanto, que el enorme aumento de la mortalidad por causas externas obedece casi exclusivamente al 
TABLA 10. Mortalidad* por Causas Externas para Todas las Edades y en el Grupo de 10 a 24 Años de Edad, Segun Grupos de Causas. Colombia y Venezuela, 1979-1990

\begin{tabular}{|c|c|c|c|c|c|c|c|c|c|c|}
\hline \multirow[b]{3}{*}{ Grupos de Causas y Año } & & & & & upos de & ad (años) & & & & \\
\hline & Todas & Edades & & & & 14 & & & & 24 \\
\hline & & EN & & VEN & & VEN & & & & JEN \\
\hline 1979 & & & & & & & & & & \\
\hline ACCIDENTE DE TRAFICO (1) & ... & 33.74 & $\ldots$ & 34.20 & $\ldots$ & 10.54 & $\ldots$ & 38.02 & ... & 61.11 \\
\hline SUICIDIO (2) & $\ldots$ & 4.05 & $\ldots$ & 4.84 & $\ldots$ & 0.76 & $\ldots$ & 6.02 & ... & 8.87 \\
\hline HOMICIDIO Y OTRAS (3) & $\ldots$ & 9.70 & $\ldots$ & 11.87 & $\ldots$ & 0.71 & $\ldots$ & 11.49 & ... & 27.13 \\
\hline CAIDA ACCIDENTAL (4) & $\ldots$ & 5.05 & $\ldots$ & 2.64 & $\ldots$ & 1.36 & $\ldots$ & 2.64 & ... & 4.33 \\
\hline LESIONES C. EXT. IGNORADA (5) & $\ldots$ & 0.07 & $\ldots$ & 0.06 & $\ldots$ & 0.00 & $\ldots$ & 0.06 & $\ldots$ & 0.14 \\
\hline $\begin{array}{l}\text { RESTO CAUSAS EXTERNAS (6) } \\
\mathbf{1 9 8 0}\end{array}$ & $\ldots$ & 21.23 & $\ldots$ & 19.51 & $\cdots$ & 10.49 & $\ldots$ & 22.24 & $\ldots$ & 28.28 \\
\hline ACCIDENTE DE TRAFICO (1) & $\ldots$ & 34.68 & $\ldots$ & 35.50 & $\ldots$ & 11.47 & $\ldots$ & 37.54 & $\ldots$ & 64.44 \\
\hline SUICIDIO (2) & $\ldots$ & 4.80 & $\ldots$ & 4.41 & ... & 0.69 & $\ldots$ & 5.06 & $\ldots$ & 8.49 \\
\hline HOMICIDIO Y OTRAS (3) & $\ldots$ & 11.79 & ... & 14.88 & $\ldots$ & 1.23 & ... & 14.81 & $\ldots$ & 32.78 \\
\hline CAIDA ACCIDENTAL (4) & $\ldots$ & 5.19 & $\ldots$ & 2.36 & $\ldots$ & 1.01 & ... & 2.50 & $\ldots$ & 3.97 \\
\hline LESIONES C. EXT. IGNORADA (5) & $\ldots$ & 0.07 & $\ldots$ & 0.04 & $\ldots$ & 0.05 & $\ldots$ & 0.06 & $\ldots$ & 0.00 \\
\hline RESTO CAUSAS EXTERNAS (6) & $\ldots$ & 20.74 & $\ldots$ & 19.17 & $\cdots$ & 11.15 & $\ldots$ & 22.96 & $\ldots$ & 25.19 \\
\hline 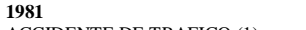 & & & & & & & & & & \\
\hline ACCIDENTE DE TRAFICO (1) & $\ldots$ & 32.48 & $\ldots$ & 34.04 & $\ldots$ & 11.19 & $\ldots$ & 35.55 & ... & 61.49 \\
\hline SUICIDIO (2) & $\ldots$ & 4.33 & $\ldots$ & 4.35 & $\ldots$ & 0.74 & $\ldots$ & 4.91 & $\ldots$ & 8.33 \\
\hline HOMICIDIO Y OTRAS (3) & $\ldots$ & 9.74 & $\ldots$ & 11.07 & $\ldots$ & 0.84 & $\ldots$ & 11.10 & $\ldots$ & 24.26 \\
\hline CAIDA ACCIDENTAL (4) & $\ldots$ & 5.19 & $\ldots$ & 2.50 & $\ldots$ & 1.26 & $\ldots$ & 2.49 & ... & 4.10 \\
\hline LESIONES C. EXT. IGNORADA (5) & $\ldots$ & 0.02 & $\ldots$ & 0.02 & $\ldots$ & 0.00 & $\ldots$ & 0.00 & $\ldots$ & 0.07 \\
\hline RESTO CAUSAS EXTERNAS (6) & $\ldots$ & 22.90 & $\ldots$ & 20.11 & $\ldots$ & 10.56 & $\ldots$ & 24.16 & ... & 27.62 \\
\hline 1982 & & & & & & & & & & \\
\hline ACCIDENTE DE TRAFICO (1) & $\ldots$ & 31.77 & ... & 32.98 & $\ldots$ & 10.33 & $\ldots$ & 34.37 & $\ldots$ & 59.75 \\
\hline SUICIDIO (2) & $\ldots$ & 4.31 & $\ldots$ & 4.13 & $\ldots$ & 0.47 & $\ldots$ & 4.57 & $\ldots$ & 8.19 \\
\hline HOMICIDIO Y OTRAS (3) & $\ldots$ & 11.50 & $\ldots$ & 13.62 & $\ldots$ & 1.30 & $\ldots$ & 12.87 & $\ldots$ & 29.91 \\
\hline CAIDA ACCIDENTAL (4) & $\ldots$ & 4.56 & $\ldots$ & 2.33 & $\ldots$ & 1.25 & $\ldots$ & 1.75 & $\ldots$ & 4.36 \\
\hline LESIONES C. EXT. IGNORADA (5) & $\ldots$ & 0.01 & $\ldots$ & 0.00 & $\ldots$ & 0.00 & $\ldots$ & 0.00 & $\ldots$ & 0.00 \\
\hline RESTO CAUSAS EXTERNAS (6) & $\ldots$ & 21.68 & $\ldots$ & 18.37 & $\cdots$ & 9.76 & $\ldots$ & 19.36 & $\ldots$ & 28.02 \\
\hline 1983 & & & ${ }^{2}$ & & & & & & & \\
\hline ACCIDENTE DE TRAFICO (1) & $\ldots$ & 29.28 & ... & 29.90 & $\ldots$ & 10.57 & $\ldots$ & 30.96 & $\ldots$ & 52.43 \\
\hline SUICIDIO (2) & $\ldots$ & 4.80 & $\ldots$ & 4.47 & $\ldots$ & 0.62 & $\ldots$ & 5.25 & $\ldots$ & 8.32 \\
\hline HOMICIDIO Y OTRAS (3) & $\ldots$ & 12.95 & $\ldots$ & 14.63 & $\ldots$ & 1.08 & $\ldots$ & 13.88 & & 32.14 \\
\hline CAIDA ACCIDENTAL (4) & $\ldots$ & 4.45 & ... & 2.15 & ... & 1.18 & $\cdots$ & 1.71 & ... & 3.84 \\
\hline LESIONES C. EXT. IGNORADA (5) & $\ldots$ & 0.00 & $\ldots$ & 0.00 & $\ldots$ & 0.00 & $\ldots$ & 0.00 & $\ldots$ & 0.00 \\
\hline RESTO CAUSAS EXTERNAS (6) & $\ldots$ & 19.86 & $\ldots$ & 17.16 & $\ldots$ & 9.14 & $\ldots$ & 17.30 & $\ldots$ & 26.84 \\
\hline 1984 & & & & & & & & & & \\
\hline ACCIDENTE DE TRAFICO (1) & 15.76 & $\ldots$ & 12.22 & $\ldots$ & 6.74 & $\ldots$ & 10.59 & $\ldots$ & 20.44 & $\ldots$ \\
\hline SUICIDIO (2) & 3.66 & $\ldots$ & 4.37 & $\ldots$ & 0.80 & $\ldots$ & 4.50 & $\ldots$ & 8.33 & $\ldots$ \\
\hline HOMICIDIO Y OTRAS (3) & 31.97 & $\ldots$ & 26.44 & $\ldots$ & 2.44 & $\ldots$ & 21.29 & $\ldots$ & 60.15 & $\ldots$ \\
\hline CAIDA ACCIDENTAL (4) & 4.08 & $\ldots$ & 1.77 & $\ldots$ & 0.92 & $\ldots$ & 1.64 & $\ldots$ & 2.91 & $\ldots$ \\
\hline LESIONES C. EXT. IGNORADA (5) & 3.05 & $\ldots$ & 2.86 & $\ldots$ & 0.95 & $\ldots$ & 2.41 & $\ldots$ & 5.59 & $\ldots$ \\
\hline RESTO CAUSAS EXTERNAS (6) & 25.01 & $\ldots$ & 18.73 & $\ldots$ & 10.32 & $\ldots$ & 17.24 & & 30.16 & $\ldots$ \\
\hline 1985 & & & & & & & & & & \\
\hline ACCIDENTE DE TRAFICO (1) & 15.32 & 22.79 & 11.74 & 20.35 & 6.20 & 8.47 & 10.29 & 19.62 & 19.60 & 35.38 \\
\hline SUICIDIO (2) & 3.38 & 4.53 & 3.88 & 3.46 & 0.63 & 0.35 & 4.66 & 3.69 & 6.64 & 6.91 \\
\hline HOMICIDIO Y OTRAS (3) & 40.65 & 9.42 & 34.75 & 10.40 & 2.93 & 1.05 & 28.44 & 10.42 & 77.57 & 21.56 \\
\hline CAIDA ACCIDENTAL (4) & 3.49 & 4.83 & 1.30 & 1.82 & 0.57 & 1.15 & 1.46 & 1.76 & 1.92 & 2.68 \\
\hline LESIONES C. EXT. IGNORADA (5) & 7.92 & 0.41 & 6.55 & 0.31 & 1.23 & 0.10 & 5.30 & 0.27 & 14.24 & 0.60 \\
\hline RESTO CAUSAS EXTERNAS (6) & 27.02 & 18.94 & 20.64 & 16.14 & 10.61 & 9.32 & 20.95 & 16.73 & 31.50 & 23.65 \\
\hline (1) & & & & & & & & & & \\
\hline ACCIDENTE DE TRAFICO (1) & 13.48 & 24.41 & 10.15 & 22.53 & 5.45 & 8.49 & 9.38 & 23.19 & 16.16 & 38.50 \\
\hline SUICIDIO (2) & 3.20 & 4.59 & 3.89 & 4.36 & 0.57 & 0.83 & 4.55 & 3.90 & 6.82 & 9.06 \\
\hline HOMICIDIO Y OTRAS (3) & 47.20 & 8.11 & 40.76 & 9.26 & 2.84 & 0.63 & 33.49 & 10.44 & 90.44 & 18.23 \\
\hline CAIDA ACCIDENTAL (4) & 3.14 & 4.40 & 1.35 & 1.96 & 0.88 & 1.17 & 1.26 & 2.16 & 1.96 & 2.67 \\
\hline LESIONES C. EXT. IGNORADA (5) & 6.53 & 0.64 & 5.71 & 0.65 & 1.08 & 0.10 & 5.08 & 0.63 & 11.49 & 1.34 \\
\hline RESTO CAUSAS EXTERNAS (6) & 25.54 & 17.88 & 20.52 & 15.49 & 10.52 & 9.52 & 20.77 & 16.92 & 31.20 & 21.02 \\
\hline $\begin{array}{l}1987 \\
\text { ACCIDENTE DE TRAFICO (1) }\end{array}$ & 13.66 & 23.92 & 10.26 & 21.19 & 5.26 & 8.67 & 9.70 & 22.09 & 16.30 & 35.11 \\
\hline SUICIDIO (2) & 3.10 & 4.10 & 4.26 & 3.94 & 0.70 & 0.38 & 4.79 & 4.74 & 7.56 & 7.32 \\
\hline HOMICIDIO Y OTRAS (3) & 50.24 & 7.96 & 43.29 & 9.07 & 2.78 & 0.71 & 37.63 & 9.48 & 93.55 & 18.55 \\
\hline CAIDA ACCIDENTAL (4) & 2.82 & 4.33 & 1.21 & 2.30 & 0.75 & 1.76 & 1.11 & 1.98 & 1.81 & 3.29 \\
\hline LESIONES C. EXT. IGNORADA (5) & 6.94 & 2.82 & 5.64 & 2.84 & 0.70 & 0.71 & 5.39 & 3.39 & 11.28 & 4.76 \\
\hline RESTO CAUSAS EXTERNAS (6) & 26.70 & 16.61 & 21.00 & 13.70 & 11.49 & 8.58 & 21.95 & 14.96 & 30.33 & 18.43 \\
\hline 1988 & & & & & & & & & & \\
\hline ACCIDENTE DE TRAFICO (1) & 13.36 & $\ldots$ & 9.93 & $\ldots$ & 5.43 & $\ldots$ & 9.43 & $\ldots$ & 15.33 & $\ldots$ \\
\hline SUICIDIO (2) & 2.92 & $\ldots$ & 3.32 & $\ldots$ & 0.60 & $\ldots$ & 3.59 & $\ldots$ & 5.98 & $\ldots$ \\
\hline HOMICIDIO Y OTRAS (3) & 59.64 & $\ldots$ & 53.82 & $\ldots$ & 4.29 & $\ldots$ & 50.20 & ... & 111.32 & $\ldots$ \\
\hline CAIDA ACCIDENTAL (4) & 3.21 & $\ldots$ & 1.08 & $\ldots$ & 0.41 & $\ldots$ & 1.04 & $\ldots$ & 1.86 & $\ldots$ \\
\hline LESIONES C. EXT. IGNORADA (5) & 5.57 & $\ldots$ & 4.96 & $\ldots$ & 0.84 & $\ldots$ & 4.77 & $\ldots$ & 9.61 & $\ldots$ \\
\hline RESTO CAUSAS EXTERNAS (6) & 25.98 & $\ldots$ & 19.77 & $\ldots$ & 11.02 & $\ldots$ & 19.32 & $\ldots$ & 29.72 & $\ldots$ \\
\hline 1989 & & & & & & & & & & \\
\hline ACCIDENTE DE TRAFICO (1) & 12.97 & $\ldots$ & 9.64 & $\ldots$ & 5.17 & $\ldots$ & 9.26 & $\ldots$ & 14.88 & $\ldots$ \\
\hline SUICIDIO (2) & 2.60 & $\ldots$ & 2.74 & $\ldots$ & 0.61 & $\ldots$ & 3.14 & $\ldots$ & 4.66 & $\ldots$ \\
\hline HOMICIDIO Y OTRAS (3) & 66.80 & $\ldots$ & 63.22 & $\ldots$ & 4.35 & $\ldots$ & 64.23 & $\ldots$ & 126.46 & $\ldots$ \\
\hline CAIDA ACCIDENTAL (4) & 3.13 & $\ldots$ & 1.31 & $\ldots$ & 0.82 & $\ldots$ & 1.34 & $\ldots$ & 1.82 & $\ldots$ \\
\hline LESIONES C. EXT. IGNORADA (5) & 5.02 & $\ldots$ & 4.81 & $\ldots$ & 0.61 & $\ldots$ & 5.02 & ... & 9.18 & $\ldots$ \\
\hline RESTO CAUSAS EXTERNAS (6) & 21.45 & $\ldots$ & 16.62 & & 9.82 & $\ldots$ & 18.32 & $\ldots$ & 22.35 & $\cdots$ \\
\hline 1990 & & & & & & & & & & \\
\hline ACCIDENTE DE TRAFICO (1) & 13.29 & $\ldots$ & 9.79 & $\ldots$ & 5.06 & $\ldots$ & 9.67 & $\ldots$ & 15.09 & $\ldots$ \\
\hline SUICIDIO (2) & 2.67 & $\ldots$ & 3.10 & $\ldots$ & 0.50 & $\ldots$ & 3.78 & $\ldots$ & 5.31 & $\ldots$ \\
\hline HOMICIDIO Y OTRAS (3) & 72.94 & & 74.55 & & 6.03 & & 81.52 & & 143.00 & $\ldots$ \\
\hline CAIDA ACCIDENTAL (4) & 2.91 & $\ldots$ & 1.12 & $\ldots$ & 0.57 & $\ldots$ & 1.10 & $\ldots$ & 1.75 & $\ldots$ \\
\hline LESIONES C. EXT. IGNORADA (5) & 2.30 & $\ldots$ & 1.99 & $\ldots$ & 0.31 & $\ldots$ & 2.18 & ... & 3.64 & $\ldots$ \\
\hline RESTO CAUSAS EXTERNAS (6) & 20.30 & $\ldots$ & 14.14 & $\ldots$ & 8.19 & $\ldots$ & 14.73 & $\ldots$ & 20.11 & $\ldots$ \\
\hline
\end{tabular}

* Tasas por 100.000 personas de cada grupo de edad...

Datos no disponibles. Fuente: Sistema de Informacion Tecnica de la OPS (1) Códigos E810-E819, CIE IX; (2) Códigos E950-E959, CIE IX; (3) Códigos E960-969, E970-E978 Y E990-E999, CIE IX;

(4) Códigos E880-E888, CIE IX; (5) Códigos E980-E989, CIE IX; (6) Códigos E800-E807, E820-E879, E890-E949, CIE IX. 
violento crecimiento de la mortalidad por homicidio y dado que las demás causas externas identificadas, incluídas las caídas accidentales, mostraron tendencias descendentes en ese período, tanto en la población general como entre los adolescentes y jóvenes.

El componente principal de la mortalidad por causas externas en Venezuela está representado por la mortalidad debida a accidentes de tráfico, los valores de cuyas tasas duplican o triplican a los de las medidas de la segunda causa externa de muerte, los homicidios. La mortalidad por suicidio es baja y estable en el tiempo, con valores cercanos a la mitad de la mortalidad por homicidio.

En relación a la evolución de la mortalidad generada por los tres principales grupos de causas externas se observa que la mortalidad por accidentes de tráfico se redujo en un $29 \%$ en la población general y en un $38 \%$ en el grupo de 10 a 24 años de edad.

La mortalidad por suicidio, si bien aumentó en un $1 \%$ para la población general, se redujo en un $18 \%$ entre los adolescentes y jóvenes.

Por su parte, la mortalidad por homicidio cayó notablemente durante el período, en un $18 \%$ para la población general y en un $24 \%$ para los adolescentes y jóvenes. La caída más veloz se observó en el subgrupo de 20 a 24 años, cuyo descenso se ciñó a un ritmo de un deceso anual por 100.000 personas.

En suma, se puede concluír que en Venezuela la acentuada caída de la mortalidad por causas externas se debe a la reducción de sus dos componentes principales, la mortalidad por accidentes de tráfico y la mortalidad por homicidio, a lo que se agrega la moderada disminución de la mortalidad por suicidio entre los adolescentes y jóvenes.

\section{Brasil (Tabla 11)}

En Brasil, las relaciones entre las magnitudes de las tasas de mortalidad originadas por los tres principales grupos de causas externas se caracterizan por la escasa distancia entre los valores de la primera causa externa de muerte, los accidentes de tráfico, y los de la segunda, los homicidios, cuyas razones fluctúan entre 1 y 2 , tendiendo a disminuír a 1 al final del período. Por su parte, la magnitud de la mortalidad por suicidio es estable y notablemente inferior a la de las otras dos tasas, que la superan en cuatro a seis veces.

Detectándose un incremento de la mortalidad por accidentes de tráfico de un $21 \%$ en la población general y de un $33 \%$ entre los adolescentes y jóvenes, aumento este último que se concentra en el subgrupo de 15 a 19 años de edad, cuya mortalidad por esta causa creció en un $47 \%$ en ese lapso.

La mortalidad por suicidio se mantuvo estable, tanto en la población general, donde muestra un leve incremento del 5\%, como entre los adolescentes y jóvenes, entre los cuales se verificó una pequeña caída del orden del $5 \%$.

La mortalidad por homicidio, en cambio, fue francamente creciente, incrementándose en un $56 \%$ para la población general y en un 90\% para los adolescentes y jóvenes, con un aumento máximo del $136 \%$ en el subgrupo de 15 a 19 años de edad.

En suma, se concluye que en Brasil el aumento notable de la mortalidad por causas externas entre 1979 y 1986 se debió principalmente a la elevación de las mortalidades por accidentes de tráfico y por homicidios, concentrándose además ambos incrementos en el grupo de los adolescentes y jóvenes y en especial, en el subgrupo de 15 a 24 años de edad.

\section{E. México (Tabla 11)}

El componente principal de la mortalidad por causas externas en México está constituído alternativamente por los accidentes de tráfico y por los homicidios en la población general, mientras entre los adolescentes y jóvenes lo configuran definitivamente estas últimas. La tercera causa externa de defunción, los suicidios, presenta tasas cuyos valores son hasta de un octavo de los observados para las dos primeras causas externas de muerte.

La mortalidad por accidentes de tráfico muestra reducciones considerables en todos 
los grupos de edad ( $37 \%$ en la población general y $43 \%$ en el grupo de 10 a 24 años de edad), mientras la mortalidad por suicidio se incrementó en el período en un $28 \%$ para la población general y en un $6 \%$ para los adolescentes y jóvenes, concentrándose este aumento en el subgrupo de 10 a 14 años ( $70 \%$ de crecimiento), si bien se trata siempre de tasas muy bajas, que fluctúan entre 0,3 y 4 por 100.000 mil. La mortalidad por homicidio muestra un aumento homogéneo de un $11 \%$ en ambos grupos de edad.

En resumen, la caída de la mortalidad por causas externas verificada en México entre 1981 y 1986 puede ser atribuída especialmente a la reducción de la mortalidad por accidentes de tráfico, ya que las demás causas externas de defunción, excepto las caídas accidentales que también disminuyen, tienden a crecer lentamente o a mantenerse invariables, especialmente en el grupo de los adolescentes y jóvenes.

\section{F. Países del Caribe Latino: Cuba y Puerto Rico (Tabla 11)}

La evolución de la mortalidad por causas externas en Cuba, entre 1979 y 1989, no podrá ser detallada por grupos de causas, debido a la ausencia de esta información en los reportes remitidos por este país a la OPS.

En Puerto Rico, los homicidios y los accidentes de tráfico comparten el primer lugar como causa externa de muerte en este país, con ligero predominio de los primeros. De aquí que las relaciones entre los valores de las correspondientes tasas de mortalidad denoten diferencias mínimas o nulas. A su vez, la mortalidad por suicidio, que aparece en tercer lugar en orden de magnitud, presenta tasas inferiores en un 50\% a las anteriores en la población general y cercanas a la cuarta parte de las de mortalidad por homicidio, para el caso de los adolescentes y jóvenes.

En el análisis de la evolución de los tres principales grupos de causas externas entre 1979 y 1986 se constata que la mortalidad por accidentes de tráfico se elevó en un $17 \%$ en el período para la población general y en un
$20 \%$, para el grupo de 10 a 24 años (109\% para el subgrupo de 10 a 14 años).

La mortalidad por suicidio, si bien creció ligeramente, en un 8\%, para la población general, se redujo notablemente entre los adolescentes y jóvenes en un $51 \%$.

La mortalidad por homicidio creció en un $41 \%$ para la población general y en un $23 \%$ para el grupo de 10 a 24 años de edad, concentrándose este último incremento en los grupos de 10 a $14(109 \%)$ y de 15 a 19 años (58\%). Para la interpretación de estas cifras, conviene señalar que sobre ellas pueden incidir las pequeñas magnitudes de las tasas del subgrupo de 10 a 14 años, las cuales, sin embargo, son bastante más elevadas que en otros países de la Región e, incluso, que las observadas en los otros países del Caribe.

En resumen, el crecimiento de la mortalidad por causas externas en Puerto Rico se puede explicar por el incremento combinado de la mortalidad por accidentes de tráfico, tanto en la población general como entre los adolescentes y jóvenes, y de la mortalidad por homicidio, aumentó este último que es más pronunciado en la población general que en el conjunto de los adolescentes y jóvenes.

\section{G. Países del Caribe Inglés: Suriname y Trinidad \& Tobago (Tabla 12)}

Comparando las magnitudes de las tasas de mortalidad debidas a los distintos grupos de causas externas, en Suriname se constata que el componente principal de este grupo está representado alternativamente por los accidentes de tráfico y por los suicidios en la población general, mientras entre los adolescentes y jóvenes el primer lugar corresponde casi invariablemente a los suicidios. Por lo tanto, las diferencias relativas entre los valores de las tasas de mortalidad por accidentes de tráfico y por suicidio son escasas, excepto para el grupo de 10 a 24 años de edad al final del período, donde se verifica un incremento de las diferencias entre la primera y la segunda causa externa de defunción, por reducción de la segunda.

En la evolución de la mortalidad producida 
por los tres principales grupos de causas externas en Suriname, tanto en la población general como en el grupo de 10 a 24 años de edad se observa que la mortalidad por accidentes de tráfico sufrió una importante caída, de un $48 \%$ en la población general y de un $31 \%$ entre los adolescentes y jóvenes, con un decremento máximo del $37 \%$ en el subgrupo de 10 a 14 años de edad.

La mortalidad por suicidio, si bien elevada, muestra también tendencias moderadamente decrecientes, disminuyendo en un $6 \%$ para la población general y en un $22 \%$ para el grupo de 10 a 24 años, aunque al interior de este último las importantes reducciones, del $43 \%$ y del $55 \%$, verificadas en los grupos de 10 a 14 y de 20 a 24 años de edad, se acompañan de una ligera elevación de la mortalidad por suicidio en el subgrupo de 15 a 19 años, del orden del $6 \%$.

La mortalidad por homicidio, de por sí bastante más baja que en otros países de la Región, muestra también tendencias al descenso en todos los grupos de edad, con reducciones del orden del $3 \%$ en la población general y del $61 \%$ entre los adolescentes y jóvenes.

En Suriname se aprecia un aumento de la mortalidad por caídas accidentales en la población general, si bien los valores de las tasas correspondientes no exceden a los de las de mortalidad por homicidio. A su vez, en este país llama la atención el hecho de que, en 1980, los principales incrementos de mortalidad por grupos de causas externas se ubiquen en los accidentes de tráfico y en los suicidios, lo cual sugiere posibles inconsistencias en la certificación de las causas externas de defunción.

En resumen, la reducción de la mortalidad por causas externas en Suriname puede ser atribuída a la caída de la mortalidad por accidentes de tráfico, tanto en la población general como entre los adolescentes y jóvenes, a lo cual se suma la disminución de la mortalidad por homicidio.

En Trinidad \& Tobago, las relaciones entre las magnitudes de las tasas de mortalidad originadas por los distintos grupos de causas externas revelan que la primera causa externa de muerte durante la mayor parte del período analizado correspondió a los accidentes de tráfico, si bien en los últimos años es sobrepasada por la segunda causa externa de defunción en Trinidad \& Tobago los suicidios, hecho que afecta no sólo a la población general, sino también al grupo de 10 a 24 años de edad. Otro punto relevante en este país estriba en las escasas diferencias entre las magnitudes de las tasas de mortalidad debidas a las tres principales causas externas de defunción al final del período, cuando la tercera causa, los homicidios, llega a igualar a la segunda.

La mortalidad por accidentes de tráfico presenta importantes reducciones entre 1979 y 1989 , del $48 \%$ en la población general y del $31 \%$ entre los adolescentes y jóvenes.

La mortalidad por suicidio, en cambio, se muestra notablemente ascendente en todos los grupos de edad, con incrementos de un $165 \%$ en la población general y de un $210 \%$ entre los adolescentes y jóvenes.

La mortalidad por homicidios muestra también tendencias crecientes y similares a las observadas para el grupo anterior de causas, con incrementos del $93 \%$ en la población general y del $232 \%$ entre los adolescentes y jóvenes, aumento que en este grupo de edad se concentra en los grupo de 10 a 14 anos y de 15 a 19 años.

La mortalidad por caídas accidentales se incrementó asímismo durante el período estudiado, especialmente entre los adolescentes y jóvenes.

En conclusión, se puede asegurar que la reducción de la mortalidad por causas externas en Trinidad \& Tabago se debió exclusivamente a la caída de la mortalidad por accidentes de tráfico, ya que todos los demás grupos de causas externas tendieron al ascenso. Hay que señalar también que se aprecia una reducción importante de la mortalidad por lesiones de causa externa ignorada, lo cual puede haber originado un aumento estadístico de las mortalidades por otras causas externas definidas. 
TABLA 11. Mortalidad* por Causas Externas, para Todas las Edades y en el Grupo de 10 a 24 Años de Edad, Segun Grupos de Causas. Brasil, Puerto Rico y Mexico, 1979-1986

\begin{tabular}{|c|c|c|c|c|c|c|c|c|c|c|c|c|c|c|c|}
\hline \multirow[b]{3}{*}{ Grupos de Causas y Año } & \multicolumn{15}{|c|}{ Grupos de Edad (años) } \\
\hline & \multicolumn{3}{|c|}{ Todas las Edades } & \multicolumn{3}{|c|}{$10-24$} & \multicolumn{3}{|c|}{$10-14$} & \multicolumn{3}{|c|}{$15-19$} & \multicolumn{3}{|c|}{$20-24$} \\
\hline & BRA & PUR 1 & MEX & BRA & A PUR & MEX & & PUR I & MEX & BRA & A PUR & MEX & & A PUR & MEX \\
\hline \multicolumn{16}{|l|}{1979} \\
\hline ACCIDENTE DE TRAFICO (1) & 17.57 & 15.90 & $\ldots$ & 13.59 & 13.81 & $\ldots$ & 7.37 & 3.54 & $\ldots$ & 12.82 & 16.86 & $\ldots$ & 22.10 & 22.53 & $\ldots$ \\
\hline SUICIDIO (2) & 2.94 & 8.63 & $\ldots$ & 2.64 & 4.71 & $\ldots$ & 0.52 & 0.59 & $\ldots$ & 2.92 & 5.62 & $\ldots$ & 4.90 & 8.60 & $\ldots$ \\
\hline HOMICIDIO Y OTRAS (3) & 9.44 & 15.43 & $\ldots$ & 8.74 & 16.95 & $\ldots$ & 0.98 & 1.18 & $\ldots$ & 8.09 & 15.09 & $\ldots$ & 19.05 & 38.35 & F... \\
\hline CAIDA ACCIDENTAL (4) & 1.65 & 4.31 & $\ldots$ & 0.60 & 1.36 & $\ldots$ & 0.31 & 0.00 & $\ldots$ & 0.48 & 1.18 & $\ldots$ & 1.09 & 3.23 & $\ldots$ \\
\hline LESIONES C. EXT. IGNORADA (5) & 11.38 & 4.53 & $\ldots$ & 9.68 & 2.51 & $\ldots$ & 3.98 & 1.47 & $\ldots$ & 10.29 & 1.78 & $\ldots$ & 15.92 & 24.66 & $\ldots$ \\
\hline RESTO CAUSAS EXTERNAS (6) & 12.04 & 11.52 & $\ldots$ & 11.25 & 10.04 & $\ldots$ & 7.02 & 6.49 & $\ldots$ & 12.57 & 15.09 & $\ldots$ & 14.84 & +8.24 & $\ldots$ \\
\hline \multicolumn{16}{|l|}{1980} \\
\hline ACCIDENTE DE TRAFICO (1) & 16.37 & 17.28 & $\ldots$ & 13.15 & 16.51 & $\ldots$ & 7.06 & 3.54 & $\ldots$ & 13.04 & 18.93 & $\ldots$ & 20.50 & 29.56 & $5 \quad \ldots$ \\
\hline SUICIDIO (2) & 3.21 & 9.11 & $\ldots$ & 2.69 & 5.26 & $\ldots$ & 0.42 & 0.59 & $\ldots$ & 3.07 & 5.92 & $\ldots$ & 4.96 & 10.22 & 2... \\
\hline HOMICIDIO Y OTRAS (3) & 11.47 & 15.07 & $\ldots$ & 11.27 & 15.88 & $\ldots$ & 0.93 & 0.88 & $\ldots$ & 11.14 & 18.05 & $\ldots$ & 23.67 & 31.75 & $\ldots$ \\
\hline CAIDA ACCIDENTAL (4) & 1.62 & 4.12 & $\ldots$ & 0.55 & 0.53 & $\ldots$ & 0.39 & 0.29 & $\ldots$ & 0.57 & 0.30 & $\ldots$ & 0.73 & 1.09 & $\ldots$ \\
\hline LESIONES C. EXT. IGNORADA (5) & 11.17 & 5.46 & $\ldots$ & 9.47 & 3.47 & $\ldots$ & 3.94 & 0.88 & $\ldots$ & 9.65 & 3.55 & $\ldots$ & 15.84 & 4.57 & $\ldots$ \\
\hline RESTO CAUSAS EXTERNAS (6) & 14.05 & 9.48 & $\ldots$ & 13.20 & 9.15 & $\ldots$ & 8.73 & 6.78 & $\ldots$ & 14.62 & 13.02 & $\ldots$ & 16.84 & +7.30 & $\ldots$ \\
\hline \multicolumn{16}{|l|}{1981} \\
\hline ACCIDENTE DE TRAFICO (1) & 15.44 & 15.87 & 24.17 & 12.78 & 15.10 & 19.88 & 6.83 & 4.73 & 9.30 & 13.03 & 17.11 & 20.14 & 19.36 & 525.56 & 35.01 \\
\hline SUICIDIO (2) & 3.27 & 9.36 & 1.66 & 3.09 & 3.27 & 1.89 & 0.52 & 0.00 & 0.27 & 3.55 & 4.42 & 2.15 & 5.53 & 5.93 & 3.96 \\
\hline HOMICIDIO Y OTRAS (3) & 12.26 & 16.80 & 17.47 & 12.01 & 18.90 & 14.00 & 1.06 & 1.48 & 2.45 & 11.53 & 21.24 & 14.33 & 25.24 & 437.78 & 30.47 \\
\hline CAIDA ACCIDENTAL (4) & 2.52 & 3.56 & 6.53 & 1.20 & 0.63 & 4.23 & 0.67 & 0.30 & 1.97 & 1.13 & 0.88 & 4.28 & 1.89 & 0.74 & 7.45 \\
\hline LESIONES C. EXT. IGNORADA (5) & 9.86 & 5.55 & 1.10 & 8.51 & 2.85 & 0.90 & 3.26 & 2.07 & 0.33 & 9.24 & 2.95 & 1.00 & 13.75 & 53.70 & 1.61 \\
\hline RESTO CAUSAS EXTERNAS (6) & 14.54 & 8.18 & 45.47 & 13.61 & 6.97 & 36.53 & 8.88 & 5.33 & 17.46 & 14.87 & 7.08 & 38.97 & 17.64 & 48.89 & 61.40 \\
\hline \multicolumn{16}{|l|}{1982} \\
\hline ACCIDENTE DE TRAFICO (1) & 16.36 & 15.03 & 21.56 & 13.74 & 14.60 & 17.90 & 7.07 & 5.06 & 8.87 & 14.41 & 17.65 & 17.97 & 20.53 & 22.68 & 30.98 \\
\hline SUICIDIO (2) & 3.09 & 9.26 & 1.61 & 2.74 & 3.81 & 1.75 & 0.48 & 0.30 & 0.32 & 2.87 & 2.06 & 1.94 & 5.15 & 10.41 & 3.62 \\
\hline HOMICIDIO Y OTRAS (3) & 12.25 & 15.96 & 18.03 & 11.70 & 16.08 & 13.81 & 1.09 & 0.89 & 2.19 & 11.23 & 17.06 & 13.18 & 24.23 & 33.83 & 31.52 \\
\hline CAIDA ACCIDENTAL (4) & 1.87 & 3.55 & 6.72 & 0.67 & 1.27 & 4.27 & 0.41 & 1.19 & 2.23 & 0.70 & 0.00 & 4.05 & 0.91 & 2.97 & 7.51 \\
\hline LESIONES C. EXT. IGNORADA (5) & 10.09 & 3.92 & 1.16 & 8.22 & 2.33 & 0.99 & 3.11 & 0.60 & 0.31 & 8.35 & 2.06 & 1.04 & 13.86 & 54.83 & 1.91 \\
\hline RESTO CAUSAS EXTERNAS (6) & 14.23 & 8.40 & 43.19 & 13.23 & 8.15 & 34.04 & 8.20 & 6.25 & 15.63 & 14.30 & 9.71 & 37.02 & 17.73 & 8.55 & 57.27 \\
\hline \multicolumn{16}{|l|}{1983} \\
\hline ACCIDENTE DE TRAFICO (1) & 15.47 & 16.41 & 18.83 & 12.78 & 14.16 & 14.00 & 6.50 & 5.09 & 6.65 & 12.99 & 12.02 & 13.90 & 19.51 & 28.04 & 24.78 \\
\hline SUICIDIO (2) & 3.53 & 10.10 & 1.37 & 2.97 & 4.02 & 1.38 & 0.54 & 0.30 & 0.28 & 3.27 & 2.05 & 1.59 & 5.33 & 11.07 & 2.72 \\
\hline HOMICIDIO Y OTRAS (3) & 13.42 & 13.33 & 16.80 & 12.97 & 13.95 & 12.81 & 1.24 & 1.50 & 2.00 & 13.50 & 11.73 & 12.26 & 25.42 & 232.10 & 29.19 \\
\hline CAIDA ACCIDENTAL (4) & 1.79 & 3.51 & 5.69 & 0.60 & 0.74 & 3.08 & 0.39 & 0.30 & 1.45 & 0.49 & 0.00 & 3.33 & 0.96 & 2.21 & 5.13 \\
\hline LESIONES C. EXT. IGNORADA (5) & 8.65 & 4.62 & 0.96 & 7.46 & 2.33 & 0.75 & 2.12 & 0.30 & 0.31 & 7.75 & 2.64 & 0.70 & 13.08 & 3.43 & 1.43 \\
\hline RESTO CAUSAS EXTERNAS (6) & 17.26 & 7.11 & 35.50 & 15.61 & 6.66 & 26.74 & 9.84 & 6.29 & 12.46 & 17.01 & 6.74 & 27.88 & 20.51 & 7.01 & 46.11 \\
\hline 1984 & & & & & & & & & & & & & & & \\
\hline ACCIDENTE DE TRAFICO (1) & 16.54 & 17.14 & $\ldots$ & 13.69 & 14.66 & $\ldots$ & 6.49 & 5.74 & $\ldots$ & 14.46 & 15.79 & $\ldots$ & 20.79 & 24.00 & ... \\
\hline SUICIDIO (2) & 3.34 & 9.20 & $\ldots$ & 2.61 & 3.06 & $\ldots$ & 0.47 & 0.30 & $\ldots$ & 2.66 & 3.22 & $\ldots$ & 4.92 & 6.18 & $\ldots$ \\
\hline HOMICIDIO Y OTRAS (3) & 14.90 & 14.75 & $\ldots$ & 15.06 & 14.14 & $\ldots$ & 1.20 & 0.30 & $\ldots$ & 15.89 & 19.96 & $\ldots$ & 29.40 & 27.27 & ... \\
\hline CAIDA ACCIDENTAL (4) & 1.56 & 3.65 & $\ldots$ & 0.43 & 0.74 & $\ldots$ & 0.26 & 0.00 & $\ldots$ & 0.47 & 0.58 & $\ldots$ & 0.58 & 1.82 & $\ldots$ \\
\hline LESIONES C. EXT. IGNORADA (5) & 9.68 & 4.81 & $\ldots$ & 8.47 & 2.43 & & 2.39 & 0.30 & & 8.41 & 3.22 & $\ldots$ & 15.21 & 4.00 & $\ldots$ \\
\hline RESTO CAUSAS EXTERNAS (6) & 16.09 & 8.58 & $\ldots$ & 14.85 & 8.12 & $\ldots$ & 9.07 & 5.74 & $\ldots$ & 16.70 & 8.48 & $\ldots$ & 19.29 & 10.55 & ... \\
\hline 1985 & & & & & & & & & & & & & & & \\
\hline ACCIDENTE DE TRAFICO (1) & 17.92 & 18.06 & 15.52 & 15.07 & 16.60 & 12.05 & 7.78 & 8.84 & 5.83 & 15.65 & 16.96 & 1.23 & 22.47 & 25.18 & 20.59 \\
\hline SUICIDIO (2) & 3.14 & 8.19 & 1.97 & 2.39 & 3.57 & 1.92 & 0.49 & 0.91 & 0.51 & 2.38 & 4.09 & 1.95 & 4.47 & 6.03 & 3.87 \\
\hline HOMICIDIO Y OTRAS (3) & 14.57 & 17.64 & 18.66 & 15.77 & 17.12 & 14.35 & 1.45 & 2.13 & 2.08 & 18.07 & 18.13 & 14.53 & 29.08 & 33.33 & 31.37 \\
\hline CAIDA ACCIDENTAL (4) & 1.81 & 4.17 & 4.79 & 0.51 & 0.21 & 2.37 & 0.33 & 0.00 & 1.20 & 0.50 & 0.29 & 2.51 & 0.70 & 0.35 & 3.84 \\
\hline LESIONES C. EXT. IGNORADA (5) & 10.07 & 4.54 & 2.75 & 8.82 & 1.37 & 1.93 & 2.50 & 0.30 & 0.78 & 8.91 & 1.17 & 2.00 & 15.64 & +2.84 & 3.46 \\
\hline RESTO CAUSAS EXTERNAS (6) & 15.82 & 12.09 & 36.53 & 14.87 & 9.35 & 26.57 & 9.28 & 7.01 & 13.63 & 16.77 & 9.65 & 28.46 & 19.05 & 511.70 & 42.46 \\
\hline 1986 & & & & & & & & & & & & & & & \\
\hline ACCIDENTE DE TRAFICO (1) & 21.35 & 18.65 & 15.13 & 18.14 & 16.60 & 11.23 & 8.55 & 7.38 & 5.99 & 18.87 & 15.88 & 10.84 & 27.94 & +27.65 & 18.81 \\
\hline SUICIDIO (2) & 3.11 & 9.36 & 2.13 & 2.51 & 2.30 & 2.01 & 0.41 & 0.31 & 0.45 & 2.79 & 0.88 & 2.31 & 4.53 & 6.14 & 3.77 \\
\hline HOMICIDIO Y OTRAS (3) & 14.79 & 21.82 & 19.46 & 16.58 & 20.88 & 15.60 & 1.75 & 2.46 & 2.36 & 19.12 & 23.82 & 16.09 & 30.35 & 537.88 & 32.97 \\
\hline CAIDA ACCIDENTAL (4) & 1.74 & 4.59 & 4.60 & 0.44 & 0.63 & 2.26 & 0.22 & 0.31 & 1.32 & 0.43 & 0.29 & 2.43 & 0.68 & 1.37 & 53.32 \\
\hline LESIONES C. EXT. IGNORADA (5) & 11.39 & 3.95 & 1.92 & 10.34 & 1.98 & 1.39 & 2.71 & 0.00 & 0.33 & 11.31 & 2.65 & 1.54 & 17.76 & 53.41 & 2.63 \\
\hline RESTO CAUSAS EXTERNAS (6) & 16.90 & 9.84 & 33.77 & 15.38 & 7.62 & 24.14 & 9.50 & 5.23 & 12.78 & 16.44 & 7.94 & 26.24 & 20.79 & 9.90 & 37.02 \\
\hline
\end{tabular}

* Tasas por 100.000 personas de cada grupo de edad

... Datos no disponibles.

Fuente: Sistema de Informacion Tecnica de la OPS.

(1) Códigos E810-E819, CIE IX; (2) Códigos E950-E959, CIE IX; (3) Códigos E960-969, E970-E978 Y E990-E999, CIE IX;

(4) Códigos E880-E888, CIE IX; (5) Códigos E980-E989, CIE IX; (6) Códigos E800-E807, E820-E879, E890-E949, CIE IX. 
TABLA 12. Mortalidad* por Causas Externas, para Todas las Edades y en el Grupo de 10 a 24 Años de Edad, Segun Grupos de Causas. Suriname, Trinidad \& Tobago, 1979-1989

\begin{tabular}{|c|c|c|c|c|c|c|c|c|c|c|}
\hline \multirow[b]{3}{*}{ Grupos de Causas y Año } & \multicolumn{10}{|c|}{ Grupos de Edad (años) } \\
\hline & \multirow{2}{*}{\multicolumn{2}{|c|}{ Todas las Edades }} & \multicolumn{2}{|c|}{$10-24$} & \multicolumn{2}{|c|}{$10-14$} & \multicolumn{2}{|c|}{$15-19$} & \multirow{2}{*}{\multicolumn{2}{|c|}{$\begin{array}{l}20-24 \\
\text { SURTRT }\end{array}$}} \\
\hline & & & SUR & TRT & SUR & TRT & SUR & TRT & & \\
\hline \multicolumn{11}{|l|}{1979} \\
\hline ACCIDENTE DE TRAFICO (1) & 17.09 & 19.91 & 10.94 & 13.66 & 6.00 & 6.45 & 10.87 & 12.78 & 18.75 & 22.94 \\
\hline SUICIDIO (2) & 13.96 & 5.16 & 15.63 & 4.92 & 4.00 & 0.00 & 19.57 & 5.26 & 28.13 & 10.09 \\
\hline HOMICIDIO Y OTRAS (3) & 5.70 & 4.79 & 5.47 & 3.01 & 0.00 & 0.81 & 6.52 & 1.50 & 12.50 & 7.34 \\
\hline CAIDA ACCIDENTAL (4) & 1.71 & 3.76 & 0.00 & 0.55 & 0.00 & 0.81 & 0.00 & 0.00 & 0.00 & 0.92 \\
\hline LESIONES C. EXT. IGNORADA (5) & 2.85 & 8.83 & 3.13 & 9.29 & 0.00 & 0.81 & 4.35 & 8.27 & 6.25 & 10.18 \\
\hline $\begin{array}{l}\text { RESTO CAUSAS EXTERNAS (6) } \\
\mathbf{1 9 8 0}\end{array}$ & 16.52 & 15.68 & 10.94 & 13.93 & 10.00 & 10.48 & 10.87 & 12.78 & 12.50 & 19.27 \\
\hline ACCIDENTE DE TRAFICO (1) & 29.46 & 18.48 & 29.58 & 16.53 & 12.05 & 4.92 & 23.26 & 14.18 & 54.90 & 31.86 \\
\hline SUICIDIO (2) & 25.89 & 3.97 & 22.86 & 3.52 & 8.03 & 0.82 & 27.13 & 3.73 & 33.78 & 6.19 \\
\hline HOMICIDIO Y OTRAS (3) & 8.48 & 2.13 & 6.72 & 1.63 & 0.00 & 0.00 & 11.63 & 1.49 & 8.45 & 3.54 \\
\hline CAIDA ACCIDENTAL (4) & 9.37 & 3.05 & 2.69 & 1.08 & 0.00 & 0.00 & 3.88 & 1.49 & 4.22 & 1.77 \\
\hline LESIONES C. EXT. IGNORADA (5) & 8.03 & 16.36 & 8.07 & 13.28 & 4.02 & 3.28 & 3.88 & 18.66 & 16.89 & 17.70 \\
\hline $\begin{array}{l}\text { RESTO CAUSAS EXTERNAS (6) } \\
1981\end{array}$ & 43.75 & 14.14 & 34.96 & 7.86 & 4.02 & 2.46 & 46.51 & 8.96 & 54.90 & 12.39 \\
\hline ACCIDENTE DE TRAFICO (1) & 15.54 & 14.47 & 10.53 & 11.08 & 4.08 & 0.83 & 10.42 & 15.79 & 19.44 & 16.24 \\
\hline SUICIDIO (2) & 14.69 & 5.28 & 12.03 & 5.95 & 0.00 & 0.83 & 22.92 & 7.52 & 13.89 & 9.40 \\
\hline HOMICIDIO Y OTRAS (3) & 4.52 & 3.28 & 3.01 & 2.16 & 0.00 & 0.00 & 6.25 & 1.50 & 2.78 & 5.13 \\
\hline CAIDA ACCIDENTAL (4) & 2.54 & 3.64 & 0.75 & 0.54 & 2.04 & 0.00 & 0.00 & 0.75 & 0.00 & 0.85 \\
\hline LESIONES C. EXT. IGNORADA (5) & 2.82 & 8.74 & 3.01 & 6.49 & 0.00 & 0.83 & 2.08 & 11.28 & 8.33 & 6.84 \\
\hline RESTO CAUSAS EXTERNAS (6) & 22.88 & 18.93 & 12.03 & 14.32 & 4.08 & 8.33 & 16.67 & 15.04 & 16.67 & 19.66 \\
\hline 1982 & 19.17 & 2109 & 1397 & 18.11 & 12.24 & 5.04 & 8.33 & 20.77 & 23.08 & 28.10 \\
\hline SUICIDIO (2) & 17.78 & 6.97 & 19.12 & 6.22 & 0.00 & 1.68 & 22.92 & 8.46 & 38.46 & 8.26 \\
\hline HOMICIDIO Y OTRAS (3) & 2.22 & 3.13 & 2.94 & 2.43 & 0.00 & 0.00 & 2.08 & 3.08 & 7.69 & 4.13 \\
\hline CAIDA ACCIDENTAL (4) & 3.06 & 6.17 & 0.74 & 0.81 & 0.00 & 0.84 & 0.00 & 0.77 & 2.56 & 0.83 \\
\hline LESIONES C. EXT. IGNORADA (5) & 5.56 & 4.83 & 1.47 & 4.05 & 2.04 & 0.00 & 0.00 & 6.92 & 2.56 & 4.96 \\
\hline $\begin{array}{l}\text { RESTO CAUSAS EXTERNAS (6) } \\
\mathbf{1 9 8 3}\end{array}$ & 28.89 & 23.24 & 16.91 & 14.05 & 14.29 & 4.20 & 18.75 & 23.08 & 17.95 & 14.05 \\
\hline ACCIDENTE DE TRAFICO (1) & 17.17 & 16.70 & 9.35 & 17.79 & 6.12 & 8.40 & 10.42 & 19.84 & 11.90 & 24.60 \\
\hline SUICIDIO (2) & 24.25 & 8.70 & 25.18 & 8.89 & 4.08 & 0.84 & 33.33 & 9.52 & 40.48 & 15.87 \\
\hline HOMICIDIO Y OTRAS (3) & 5.72 & 5.54 & 3.60 & 4.58 & 0.00 & 0.84 & 4.17 & 3.17 & 7.14 & 9.52 \\
\hline CAIDA ACCIDENTAL (4) & 2.45 & 3.78 & 0.00 & 0.81 & 0.00 & 0.84 & 0.00 & 0.79 & 0.00 & 0.79 \\
\hline LESIONES C. EXT. IGNORADA (5) & 2.72 & 2.28 & 0.00 & 1.62 & 0.00 & 1.68 & 0.00 & 0.79 & 0.00 & 2.38 \\
\hline $\begin{array}{l}\text { RESTO CAUSAS EXTERNAS (6) } \\
\mathbf{1 9 8 4}\end{array}$ & 23.71 & 22.41 & 15.11 & 19.14 & 12.24 & 13.45 & 20.83 & 20.63 & 11.90 & 23.02 \\
\hline ACCIDENTE DE TRAFICO (1) & 14.40 & 18.48 & 10.00 & 19.19 & 6.25 & 7.56 & 8.33 & 22.13 & 15.91 & 27.13 \\
\hline SUICIDIO (2) & 27.73 & 6.74 & 26.43 & 8.65 & 8.33 & 1.68 & 31.25 & 13.93 & 40.91 & 10.08 \\
\hline HOMICIDIO Y OTRAS (3) & 6.13 & 5.79 & 2.14 & 4.32 & 0.00 & 0.84 & 2.08 & 3.28 & 4.55 & 8.53 \\
\hline CAIDA ACCIDENTAL (4) & 2.13 & 4.06 & 0.00 & 2.16 & 0.00 & 0.00 & 0.00 & 0.00 & 0.00 & 6.20 \\
\hline LESIONES C. EXT. IGNORADA (5) & 3.47 & 6.48 & 3.57 & 4.86 & 0.00 & 2.52 & 0.00 & 3.28 & 11.36 & 8.53 \\
\hline RESTO CAUSAS EXTERNAS (6) & 24.80 & 17.44 & 6.43 & 15.41 & 10.42 & 11.76 & 4.17 & 13.93 & 4.55 & 20.16 \\
\hline 1985 & & & & & & & & & & \\
\hline ACCIDENTE DE TRAFICO (1) & 17.75 & 18.08 & 9.22 & 15.41 & 8.51 & 2.50 & 8.33 & 20.83 & 10.87 & 22.31 \\
\hline SUICIDIO (2) & 21.15 & 2.46 & 19.15 & 2.16 & 6.38 & 0.83 & 25.00 & 2.50 & 26.09 & 3.08 \\
\hline HOMICIDIO Y OTRAS (3) & 5.74 & 9.17 & 7.09 & 7.84 & 2.13 & 0.83 & 8.33 & 10.00 & 10.87 & 12.31 \\
\hline CAIDA ACCIDENTAL (4) & 3.39 & 4.67 & 0.00 & 0.54 & 0.00 & 0.00 & 0.00 & 0.00 & 0.00 & 1.54 \\
\hline LESIONES C. EXT. IGNORADA (5) & 4.44 & 11.63 & 2.84 & 6.76 & 6.38 & 0.00 & 0.00 & 6.67 & 2.17 & 13.08 \\
\hline $\begin{array}{l}\text { RESTO CAUSAS EXTERNAS (6) } \\
\mathbf{1 9 8 6}\end{array}$ & 16.97 & 13.41 & 3.55 & 8.38 & 2.13 & 4.17 & 4.17 & 8.33 & 4.35 & 12.31 \\
\hline ACCIDENTE DE TRAFICO (1) & 11.79 & 16.18 & 5.63 & 17.07 & 4.35 & 5.79 & 6.25 & 14.41 & 6.25 & 30.00 \\
\hline SUICIDIO (2) & 10.77 & 8.67 & 14.08 & 7.05 & 2.17 & 0.83 & 18.75 & 8.47 & 20.83 & 11.54 \\
\hline HOMICIDIO Y OTRAS (3) & 6.15 & 7.59 & 7.04 & 4.34 & 2.17 & 0.83 & 2.08 & 3.39 & 16.67 & 8.46 \\
\hline CAIDA ACCIDENTAL (4) & 1.28 & 2.84 & 0.00 & 0.81 & 0.00 & 0.00 & 0.00 & 0.85 & 0.00 & 1.54 \\
\hline LESIONES C. EXT. IGNORADA (5) & 6.57 & 6.59 & 7.04 & 2.71 & 2.17 & 0.00 & 6.25 & 1.69 & 12.50 & 6.15 \\
\hline $\begin{array}{l}\text { RESTO CAUSAS EXTERNAS (6) } \\
\mathbf{1 9 8 7}\end{array}$ & 11.03 & 14.93 & 3.52 & 8.67 & 0.00 & 1.65 & 10.42 & 11.02 & 0.00 & 13.08 \\
\hline ACCIDENTE DE TRAFICO (1) & 8.79 & 14.43 & 4.29 & 13.46 & 0.00 & 4.13 & 4.17 & 13.68 & 8.33 & 22.22 \\
\hline SUICIDIO (2) & 13.07 & 9.75 & 12.14 & 9.62 & 2.27 & 1.65 & 20.83 & 8.55 & 12.50 & 18.25 \\
\hline HOMICIDIO Y OTRAS (3) & 5.53 & 10.66 & 2.14 & 7.42 & 0.00 & 0.83 & 0.00 & 5.98 & 6.25 & 15.08 \\
\hline CAIDA ACCIDENTAL (4) & 2.76 & 3.28 & 0.00 & 0.55 & 0.00 & 0.00 & 0.00 & 0.85 & 0.00 & 0.79 \\
\hline LESIONES C. EXT. IGNORADA (5) & 6.28 & 4.84 & 7.14 & 2.20 & 0.00 & 0.00 & 8.33 & 0.00 & 12.50 & 6.35 \\
\hline RESTO CAUSAS EXTERNAS (6) & 12.06 & 14.02 & 10.71 & 10.71 & 4.55 & 2.48 & 2.08 & 9.40 & 25.00 & 19.84 \\
\hline 1988 & & & & & & & & & & \\
\hline ACCIDENTE DE TRAFICO (1) & $\ldots$ & 9.99 & $\ldots$ & 9.67 & $\ldots$ & 4.10 & ... & 12.82 & $\ldots$ & 12.20 \\
\hline SUICIDIO (2) & $\ldots$ & 13.22 & & 9.94 & & 3.28 & ... & 8.55 & $\ldots$ & 17.89 \\
\hline HOMICIDIO Y OTRAS (3) & $\ldots$ & 8.78 & & 5.52 & & 0.00 & $\ldots$ & 2.56 & $\ldots$ & 13.82 \\
\hline CAIDA ACCIDENTAL (4) & $\ldots$ & 3.38 & $\ldots$ & 1.38 & $\ldots$ & 0.00 & ... & 3.42 & $\ldots$ & 0.81 \\
\hline LESIONES C. EXT. IGNORADA (5) & $\ldots$ & 2.34 & $\ldots$ & 1.93 & $\ldots$ & 0.00 & $\ldots$ & 2.56 & $\ldots$ & 3.25 \\
\hline $\begin{array}{l}\text { RESTO CAUSAS EXTERNAS (6) } \\
\mathbf{1 9 8 9}\end{array}$ & $\ldots$ & 13.62 & $\ldots$ & 11.88 & $\ldots$ & 9.02 & ... & 12.82 & $\ldots$ & 13.82 \\
\hline $\begin{array}{l}1989 \\
\text { ACCIDENTE DE TRAFICO (1) }\end{array}$ & $\ldots$ & 10.30 & $\ldots$ & 9.42 & $\ldots$ & 4.03 & $\ldots$ & 9.32 & $\ldots$ & 15.13 \\
\hline SUICIDIO (2) & ... & 13.71 & ... & 15.24 & ... & 4.03 & ... & 18.64 & ... & 23.53 \\
\hline HOMICIDIO Y OTRAS (3) & $\ldots$ & 9.27 & $\ldots$ & 9.97 & $\ldots$ & 4.84 & $\ldots$ & 9.32 & ... & 15.97 \\
\hline CAIDA ACCIDENTAL (4) & $\ldots$ & 4.20 & & 0.83 & $\ldots$ & 0.81 & $\ldots$ & 1.69 & $\ldots$ & 0.00 \\
\hline LESIONES C. EXT. IGNORADA (5) & $\ldots$ & 3.33 & $\ldots$ & 2.22 & $\ldots$ & 1.61 & $\ldots$ & 1.69 & ... & 3.36 \\
\hline RESTO CAUSAS EXTERNAS (6) & $\ldots$ & 9.59 & $\ldots$ & 5.54 & $\ldots$ & 3.23 & $\ldots$ & 5.93 & $\ldots$ & 7.56 \\
\hline
\end{tabular}

* Tasas por 100.000 personas de cada grupo de edad...

Datos no disponibles.

Fuente: Sistema de Informacion Tecnica de la OPS

(1) Códigos E810-E819, CIE IX; (2) Códigos E950-E959, CIE IX; (3) Códigos E960-969, E970-E978 Y E990-E999, CIE IX;

(4) Códigos E880-E888, CIE IX; (5) Códigos E980-E989, CIE IX; (6) Códigos E800-E807, E820-E879, E890-E949, CIE IX. 


\section{H. Países del Cono Sur: Argentina, Chile y Uruguay (Tabla 13)}

En Argentina, la primera causa externa de defunción corresponde a los accidentes de tráfico, seguidos a muy corta distancia (diferencia relativa inferior a 0,5 ) por los suicidios. Las diferencias entre las magnitudes de las tasas de mortalidad por accidentes de tráfico y por suicidio tienden a desaparecer al final del período para la población general, por reducción de la mortalidad originada por el primero de estos grupos de causas y por aumento simultáneo de la mortalidad por suicidios. Entre los adolescentes y jóvenes no se aprecia este fenómeno, dado que, si bien al inicio del período la segunda causa externa de defunción de este grupo de edad es la misma que aparece en la población general, al final del mismo el segundo lugar ha sido ocupado por los homicidios, la magnitud de cuya tasa sobrepasa en alrededor de un 50\% a la de mortalidad por suicidio.

En el período mencionado, la mortalidad por accidentes de tráfico se redujo en un $31 \%$ para la población general y en un $27 \%$ para los adolescentes y jóvenes, con escasas diferencias entre los grupos de edad del grupo de 10 a 24 años.

La mortalidad por suicidio se incrementó ligeramente en la población general (8\%), mientras entre los adolescentes y jóvenes se mantuvo prácticamente estacionaria.

La mortalidad por homicidio, en cambio, mostró tendencias notablemente crecientes en todos los grupos de edad, elevándose en un $70 \%$ para la población general y en un $144 \%$ entre los adolescentes y jóvenes. En conclusión, la caída de la mortalidad por causas externas en Argentina se debió principalmente a la disminución de la mortalidad por accidentes de tráfico en todos los grupos de edad, ya que los demás grupos de causas externas de muerte mostraron tendencias más bien crecientes, especialmente los homicidios entre los adolescentes y jóvenes.

En Chile, dada la escasa calidad de los datos disponibles acerca de los grupos de causas externas de muerte en este país durante este período, se presenta la evolución de los tres principales grupos de causas externas de muerte, con base en información proveniente del Servicio Médico Legal chileno, el cual se hace cargo nominalmente de los peritajes tanatológicos de la totalidad de los fallecimientos por causas externas, si bien se estima que su cobertura real en este campo se acerca a sólo el $80 \%$ de las defunciones por estas causas.

La primera causa de muerte en Chile, durante el período analizado, fueron los accidentes de tráfico; la segunda, los suicidios. La tasa de mortalidad por accidentes casi duplicó a la registrada por suicidios - tanto en la población general como para los adolescentes —, y ésta presentó valores dos veces superiores a la tasa por homicidios.

La mortalidad por accidentes de tráfico se redujo en la población general y en los adolescentes y jóvenes; la mortalidad por suicidios aumentó en un $8 \%$ en la población general y se mantuvo casi constante entre los adolescentes y jóvenes; y la mortalidad por homicidios aumentó alrededor de $7 \%$ en la población general y en el grupo de 10 a 24 años.

Se puede concluír, por lo tanto, que salvedad hecha del comportamiento de otras causas externas de defunción y de que los factores que alteraron la confiabilidad de las estadísticas de causas externas de muerte en Chile se ubican preponderantemente en los procedimientos vinculados con la práctica forense, la reducción de la mortalidad por causas externas en Chile se debió básicamente a la caída de la mortalidad por accidentes de tráfico, ya que las otras dos causas externas relevantes muestran tendencias ascendentes.

En Uruguay, la principal causa externa de defunción correspondió a los accidentes de tráfico, seguida a muy corta distancia por los suicidios, los valores de cuyas tasas son muy similares a los de las de mortalidad por accidentes de tráfico. La tercera causa externa de muerte de los uruguayos está representada por las caídas accidentales, excepto en el grupo de 10 a 24 años, donde este lugar es ocupado por los homicidios. Los valores de las tasas de mortalidad por caídas accidentales y por homicidio son del orden de la mitad de los de las de la causa precedente en magnitud en cada caso. 
Yunes, J. \& Rajs, D.

TABLA 13. Mortalidad* por Causas Externas, para Todas las Edades y en el Grupo de 10 a 24 Años de Edad, Segun Grupos de Causas. Argentina, Chile y Uruguay, 1979-1990

\begin{tabular}{|c|c|c|c|c|c|c|c|c|c|c|c|c|c|c|c|}
\hline \multirow[b]{3}{*}{ Grupo de Causas y Año } & & & & & & & 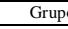 & os de Ed & dad (años & & & & & & \\
\hline & Toda & is las Ed. & dades & & $10-24$ & & & $10-14$ & & & $15-19$ & & & $20-24$ & \\
\hline & ARG & $\mathrm{CHI}$ & I URU & ARG & $\mathrm{CHI}$ & URU & ARG & $\mathrm{CHI}$ & URU & ARG & $\mathrm{CH}$ & HI URU & ARG & $\mathrm{CH}$ & HI URU \\
\hline 1979 & & & & & & & & & & & & & & & \\
\hline ACCIDENTE DE TRAFICO (1) & 14.15 & ... & ... & 10.93 & ... & ... & 5.54 & $\ldots$ & ... & 11.83 & ... & $\ldots$ & 15.77 & ... & ... \\
\hline $\begin{array}{l}\text { SUICIDIO (2) } \\
\text { SUT (1) }\end{array}$ & 6.59 & -... & ... & 3.85 & ... & ... & 0.99 & $\cdots$ & ... & 4.65 & ?... & ... & 6.10 & ... & ... \\
\hline HOMICIDIO Y OTRAS (3) & 3.89 & $\ldots$ & $\ldots$ & 3.02 & $\ldots$ & $\ldots$ & 0.87 & $\ldots$ & $\ldots$ & 3.23 & $\ldots$ & $\ldots$ & 5.12 & $\ldots$ & $\ldots$ \\
\hline CAIDA ACCIDENTAL (4) & 4.93 & ... & ... & 1.48 & $\cdots$ & $\cdots$ & 0.83 & ... & $\cdots$ & 1.03 & ... & ... & 2.65 & ... & ... \\
\hline LESIONES C. EXT. IGNORADA (5) & 6.05 & ... & $\ldots$ & 4.51 & $\ldots$ & $\ldots$ & 1.36 & $\ldots$ & $\ldots$ & 4.47 & $\ldots$ & $\ldots$ & 7.91 & $\ldots$ & $\ldots$ \\
\hline RESTO CAUSAS EXTERNAS (6) & 23.40 & $\ldots$ & $\cdots$ & 17.25 & $\cdots$ & $\cdots$ & 10.54 & $\ldots$ & $\ldots$ & 19.66 & $\ldots$ & $\ldots$ & 21.95 & $\ldots$ & $\ldots$ \\
\hline 1980 & 1340 & 1285 & & 1033 & 877 & 1227 & & 499 & 373 & 1148 & 745 & & & & \\
\hline $\begin{array}{l}\text { ACCIDENTE DE TRAFICO (1) } \\
\text { SUICIDIO (2) }\end{array}$ & $\begin{array}{c}13.40 \\
7.03\end{array}$ & $\begin{array}{l}12.85 \\
4.85\end{array}$ & 92.18 & $\begin{array}{l}10.31 \\
3.85\end{array}$ & 4.50 & $\begin{array}{l}12.27 \\
6.35\end{array}$ & $\begin{array}{l}4.85 \\
0.94\end{array}$ & 0.24 & $\begin{array}{l}3.73 \\
1.24\end{array}$ & $\begin{array}{l}11.48 \\
4.67\end{array}$ & 5.07 & $\begin{array}{l}14.23 \\
569\end{array}$ & 15.01 & 14.44 & 19.31 \\
\hline HOMICIDIO Y OTRAS (3) & 3.47 & 2.57 & 2.61 & 2.62 & 1.71 & 2.12 & 0.53 & 0.40 & 0.41 & 2.23 & 1.35 & 2.44 & 5.28 & 3.63 & $\begin{array}{l}12.61 \\
3.60\end{array}$ \\
\hline CAIDA ACCIDENTAL (4) & 4.75 & 4.29 & 5.01 & 1.40 & 1.43 & 0.99 & 0.37 & 0.87 & 0.00 & 1.41 & 0.95 & 1.22 & 2.51 & 2.63 & 1.80 \\
\hline LESIONES C. EXT. IGNORADA (5) & 0.00 & 37.98 & 0.07 & 0.00 & 25.74 & 0.00 & 0.00 & 12.20 & 0.00 & 0.00 & 26.86 & 0.00 & 0.00 & 39.96 & 0.00 \\
\hline RESTO CAUSAS EXTERNAS (6) & 23.99 & 15.88 & 33.46 & 17.12 & 5.85 & 21.16 & 10.67 & 2.54 & 11.62 & 19.57 & 5.86 & 27.24 & 21.57 & 9.63 & 24.77 \\
\hline 1981 & & & & & & & & & & & & & & & \\
\hline ACCIDENTE DE TRAFICO (1) & 13.08 & 12.77 & 12.75 & 9.97 & 8.42 & 12.92 & 5.20 & 5.49 & 3.29 & 11.25 & 6.06 & 13.11 & 13.89 & 14.30 & 23.11 \\
\hline SUICIDIO (2) & 7.73 & 5.76 & 9.14 & 4.11 & 4.70 & 3.93 & 0.88 & 0.64 & 0.00 & 4.22 & 5.91 & 3.28 & 7.54 & 7.86 & 8.89 \\
\hline HOMICIDIO Y OTRAS (3) & 3.84 & 3.04 & 3.20 & 2.68 & 2.35 & 2.53 & 0.64 & 0.08 & 0.41 & 2.51 & 1.97 & 2.46 & 5.08 & 5.30 & 4.89 \\
\hline CAIDA ACCIDENTAL (4) & 4.77 & 4.48 & 5.15 & 1.02 & 1.56 & 0.98 & 0.60 & 1.27 & 0.00 & 0.94 & 1.10 & 0.41 & 1.58 & 2.38 & 2.67 \\
\hline LESIONES C. EXT. IGNORADA (5) & 0.00 & 35.60 & 0.00 & 0.00 & 24.15 & 0.00 & 0.00 & 10.34 & 0.00 & 0.00 & 25.35 & 0.00 & 0.00 & 38.13 & 0.00 \\
\hline RESTO CAUSAS EXTERNAS (6) & 25.03 & 16.41 & 31.33 & 18.67 & 5.22 & 18.82 & 12.04 & 3.10 & 11.93 & 20.24 & 5.20 & 21.72 & 24.32 & 7.59 & 23.11 \\
\hline 1982 & & & & & & & & & & & & & & & \\
\hline ACCIDENTE DE TRAFICO (1) & 11.89 & $\ldots$ & 10.91 & 9.25 & $\ldots$ & 11.20 & 4.03 & $\ldots$ & 4.47 & 10.12 & 12.50 & $\ldots$ & 14.19 & ... & 17.11 \\
\hline SUICIDIO (2) & 6.97 & ... & 10.91 & 3.62 & ... & 3.22 & 0.59 & ... & 0.41 & 4.23 & $\ldots$ & 2.08 & 6.37 & $\ldots$ & 7.46 \\
\hline HOMICIDIO Y OTRAS (3) & 4.53 & $\cdots$ & 3.15 & 3.73 & $\cdots$ & 1.68 & 1.10 & ... & 0.00 & 3.73 & $\cdots$ & 2.92 & 6.68 & $\cdots$ & $\begin{array}{l}.40 \\
2.19\end{array}$ \\
\hline CAIDA ACCIDENTAL (4) & 4.39 & $\ldots$ & 4.37 & 0.94 & $\ldots$ & 0.84 & 0.43 & $\ldots$ & 0.41 & 0.97 & $\ldots$ & 1.25 & 1.48 & ... & 0.88 \\
\hline LESIONES C. EXT. IGNORADA (5) & 3.66 & $\cdots$ & 0.00 & 2.43 & $\cdots$ & 0.00 & 1.13 & $\cdots$ & 0.00 & 2.67 & '... & 0.00 & 3.62 & ... & 0.00 \\
\hline $\begin{array}{l}\text { RESTO CAUSAS EXTERNAS (6) } \\
\mathbf{1 9 8 3}\end{array}$ & 22.06 & $\ldots$ & 36.08 & 15.12 & $\ldots$ & 21.85 & 9.12 & $\ldots$ & 10.57 & 18.08 & $\ldots$ & 25.00 & 18.77 & $\ldots$ & 30.70 \\
\hline ACCIDENTE DE TRAFICO (1) & 11.98 & $\ldots$ & 9.96 & 9.41 & $\ldots$ & 5.71 & 5.08 & $\ldots$ & 1.19 & 9.53 & $\ldots$ & 5.08 & 14.21 & $\ldots$ & 11.30 \\
\hline SUICIDIO (2) & 6.36 & $\ldots$ & 10.97 & 3.27 & $\ldots$ & 3.34 & 0.46 & $\ldots$ & 0.40 & 4.28 & ... & 4.66 & 5.43 & ... & 5.22 \\
\hline HOMICIDIO Y OTRAS (3) & 4.50 & ... & 2.32 & 3.34 & $\cdots$ & 2.23 & 0.61 & $\cdots$ & 0.40 & 3.44 & ... & 0.85 & 6.35 & ... & 5.65 \\
\hline CAIDA ACCIDENTAL (4) & 4.60 & $\ldots$ & 4.81 & 0.77 & $\ldots$ & 0.70 & 0.46 & $\ldots$ & 0.00 & 0.59 & $\ldots$ & 1.27 & 1.30 & $\ldots$ & 0.87 \\
\hline LESIONES C. EXT. IGNORADA (5) & 4.24 & $\ldots$ & 0.20 & 2.85 & & 0.00 & 1.37 & & 0.00 & 2.90 & $\ldots$ & 0.00 & 4.48 & & 0.00 \\
\hline $\begin{array}{l}\text { RESTO CAUSAS EXTERNAS (6) } \\
1984\end{array}$ & 22.70 & $\ldots$ & 30.09 & 16.47 & $\ldots$ & 17.41 & 10.84 & $\ldots$ & 8.33 & 18.98 & $\ldots$ & 24.58 & 20.30 & $\ldots$ & 20.00 \\
\hline ACCIDENTE DE TRAFICO (1) & 11.32 & 7.32 & 9.00 & 8.82 & 4.42 & 7.52 & 4.83 & 1.76 & 2.71 & 9.71 & 4.46 & 7.26 & 12.55 & 7.10 & 12.99 \\
\hline SUICIDIO (2) & 6.33 & 6.18 & 11.17 & 2.90 & 5.25 & 3.90 & 0.59 & 0.88 & 0.78 & 3.44 & 5.65 & 5.98 & 5.02 & 9.31 & 5.19 \\
\hline HOMICIDIO Y OTRAS (3) & 5.26 & 3.25 & 2.54 & 4.64 & 2.30 & 1.67 & 0.56 & 0.48 & 0.39 & 5.64 & 2.15 & 1.71 & 8.35 & 4.33 & 3.03 \\
\hline CAIDA ACCIDENTAL (4) & 4.37 & 4.98 & 4.92 & 0.85 & 1.74 & 0.70 & 0.52 & 0.96 & 0.00 & 1.04 & 1.67 & 0.00 & 1.04 & 2.61 & 2.16 \\
\hline LESIONES C. EXT. IGNORADA (5) & 3.53 & 35.83 & 0.13 & 2.83 & 23.09 & 0.00 & 1.41 & 8.87 & 0.00 & 2.86 & 21.48 & 0.00 & 4.46 & 39.27 & 0.00 \\
\hline RESTO CAUSAS EXTERNAS (6) & 23.04 & 19.82 & 25.22 & 15.59 & 5.65 & 16.16 & 9.76 & 2.96 & 10.08 & 18.13 & 4.22 & 15.81 & 19.73 & 9.88 & 22.94 \\
\hline $\begin{array}{l}1985 \\
\text { ACCIDENTE DE TRAFICO (1) }\end{array}$ & 880 & 643 & 8.31 & 6.88 & 4.28 & 850 & & 209 & 227 & 6.42 & 304 & 1068 & 1059 & 7.72 & 13.42 \\
\hline $\begin{array}{l}\text { ACCIDENTE DE TRAFICO (1) } \\
\text { SUICIDIO (2) }\end{array}$ & $\begin{array}{l}8.80 \\
6.75-15 x-10\end{array}$ & $\begin{array}{l}6.43 \\
5.63\end{array}$ & $\begin{array}{l}8.31 \\
9.57\end{array}$ & $\begin{array}{l}6.88 \\
3.42\end{array}$ & 4.55 & $\begin{array}{l}8.50 \\
3.29\end{array}$ & $\begin{array}{l}4.18 \\
0.97\end{array}$ & $\begin{array}{l}2.09 \\
0.80\end{array}$ & 1.14 & $\begin{array}{l}6.42 \\
3.64\end{array}$ & $\begin{array}{l}3.04 \\
5.04\end{array}$ & $\begin{array}{l}1.68 \\
2.56\end{array}$ & 6.12 & 7.80 & $\begin{array}{l}13.42 \\
6.49\end{array}$ \\
\hline HOMICIDIO Y OTRAS (3) & 5.82 & 3.19 & 2.83 & 5.71 & 2.43 & 1.65 & 0.76 & 0.32 & 0.76 & 5.97 & 1.68 & 0.85 & 11.37 & 5.31 & 3.46 \\
\hline CAIDA ACCIDENTAL (4) & 3.71 & 4.23 & 5.02 & 0.65 & 1.28 & 1.10 & 0.58 & 0.56 & 1.14 & 0.37 & 0.88 & 0.00 & 1.03 & 2.41 & 2.16 \\
\hline LESIONES C. EXT. IGNORADA (5) & 3.78 & 38.15 & 0.03 & 2.76 & 26.11 & 0.00 & 1.15 & 12.06 & 0.00 & 3.68 & 24.94 & 0.00 & 3.70 & 41.35 & 0.00 \\
\hline RESTO CAUSAS EXTERNAS (6) & 20.18 & 16.68 & 25.03 & 14.29 & 4.52 & 17.01 & 8.50 & 1.61 & 15.91 & 17.37 & 5.12 & 15.81 & 17.96 & 6.84 & 19.48 \\
\hline $\begin{array}{l}\mathbf{1 9 8 6} \\
\text { ACCIDENTE DE TRAFICO (1) }\end{array}$ & 10.10 & 6.46 & 9.45 & 8.26 & 4.39 & 8.56 & 4.84 & 2.27 & 560 & 7.94 & 4.89 & 7.59 & 1280 & 5.99 & 12.99 \\
\hline SUICIDIO (2) & 7.53 & 5.31 & 8.76 & 3.99 & 4.18 & 4.35 & 0.63 & 0.89 & 0.75 & 4.33 & 4.49 & 3.80 & 7.75 & 7.10 & 9.09 \\
\hline HOMICIDIO Y OTRAS (3) & 6.52 & 3.05 & 3.04 & 6.55 & 2.60 & 1.77 & 1.46 & 0.41 & 0.37 & 7.46 & 2.00 & 2.53 & 11.82 & 5.35 & 2.60 \\
\hline CAIDA ACCIDENTAL (4) & 3.58 & 3.09 & 5.02 & 0.53 & 0.75 & 0.82 & 0.28 & 0.32 & 0.37 & 0.48 & 0.56 & 1.27 & 0.90 & 1.36 & 0.87 \\
\hline LESIONES C. EXT. IGNORADA (5) & 3.84 & 35.52 & 0.03 & 2.82 & 24.79 & 0.00 & 1.29 & 9.18 & 0.00 & 3.93 & 25.16 & 0.00 & 3.51 & 39.74 & 0.00 \\
\hline RESTO CAUSAS EXTERNAS (6) & 22.67 & 17.93 & 30.04 & 15.09 & 5.95 & 17.53 & 9.23 & 31.17 & 10.45 & 18.32 & 5.53 & 18.99 & 18.84 & 9.10 & 24.24 \\
\hline 1987 & & & & & & & & & & & & & & & \\
\hline ACCIDENTE DE TRAFICO (1) & 9.94 & 7.01 & 9.53 & 7.45 & 5.33 & 8.47 & 4.10 & 3.05 & 3.28 & 8.36 & 4.65 & 9.92 & 10.68 & 8.22 & 13.16 \\
\hline SUICIDIO (2) & 7.49 & 5.53 & 8.54 & 3.82 & 4.33 & 3.63 & 0.98 & 0.58 & 0.73 & 4.51 & 4.41 & 3.31 & 6.68 & 7.90 & 7.46 \\
\hline HOMICIDIO Y OTRAS (3) & 6.12 & 2.73 & 3.15 & 6.63 & 2.05 & 2.96 & 1.28 & 0.08 & 1.09 & 8.56 & 2.01 & 2.89 & 11.32 & 3.99 & 5.26 \\
\hline CAIDA ACCIDENTAL (4) & 3.58 & 2.82 & 6.21 & 0.46 & 0.59 & 1.08 & 0.13 & 0.08 & 0.36 & 0.63 & 0.64 & 0.83 & 0.68 & 1.04 & 2.19 \\
\hline LESIONES C. EXT. IGNORADA (5) & 5.55 & 34.54 & 0.03 & 4.49 & 24.18 & 0.00 & 1.41 & 10.53 & 0.00 & 6.12 & 21.99 & 0.00 & $\begin{array}{l}0.00 \\
6.60\end{array}$ & $\begin{array}{l}1.04 \\
39.58\end{array}$ & 0.00 \\
\hline RESTO CAUSAS EXTERNAS (6) & 21.16 & 14.40 & 32.75 & 12.95 & 4.17 & 20.16 & 7.50 & 1.81 & 13.50 & 15.58 & 3.93 & 21.07 & 16.98 & 6.70 & 27.19 \\
\hline 1988 & & & & & & & & & & & & & & & \\
\hline ACCIDENTE DE TRAFICO (1) & 9.64 & $\ldots$ & 12.35 & 7.47 & $\ldots$ & 9.85 & 4.23 & $\ldots$ & 5.05 & 8.12 & ... & 9.68 & 10.97 & ... & 15.93 \\
\hline SUICIDIO (2) & 7.59 & $\ldots$ & 8.79 & 4.23 & $\ldots$ & 4.79 & 0.94 & $\ldots$ & 0.72 & 5.09 & $\ldots$ & 5.65 & 7.55 & $\ldots$ & 8.85 \\
\hline HOMICIDIO Y OTRAS (3) & 6.39 & ... & 3.43 & 6.82 & $\cdots$ & 2.26 & 1.14 & $\cdots$ & 1.08 & 9.15 & ... & 1.61 & 11.60 & $\cdots$ & $\begin{array}{l}8.03 \\
4.42\end{array}$ \\
\hline CAIDA ACCIDENTAL (4) & 3.61 & $\ldots$ & 5.46 & 0.37 & $\ldots$ & 1.73 & 0.16 & $\ldots$ & 1.08 & 0.42 & $\ldots$ & 2.02 & 0.59 & $\ldots$ & 2.21 \\
\hline LESIONES C. EXT. IGNORADA (5) & 5.70 & ... & 0.00 & 4.07 & $\cdots$ & 0.00 & 1.34 & $\cdots$ & 0.00 & 5.70 & ... & 0.00 & 5.82 & ... & 0.00 \\
\hline $\begin{array}{l}\text { RESTO CAUSAS EXTERNAS (6) } \\
1989\end{array}$ & 21.90 & ... & 27.94 & 13.43 & $\ldots$ & 19.71 & 8.04 & $\ldots$ & 8.66 & 16.46 & $\ldots$ & 25.00 & 17.08 & $\ldots$ & 27.43 \\
\hline ACCIDENTE DE TRAFICO (1) & 9.72 & $\ldots$ & 15.50 & 7.90 & $\ldots$ & 11.71 & 4.18 & $\ldots$ & 5.73 & 8.53 & $\ldots$ & 14.51 & 12.09 & $\ldots$ & 15.93 \\
\hline SUICIDIO (2) & 7.15 & ... & 11.21 & 3.54 & ... & 6.05 & 0.76 & $\ldots$ & 0.72 & 4.06 & ... & 9.80 & 6.63 & $\ldots$ & 8.41 \\
\hline OY OTRAS (3) & 6.63 & $\ldots$ & 4.65 & 7.38 & & 3.6 & 1.0 & & 1.08 & 9.72 & $\ldots$ & 3.14 & 13.13 & & 7.52 \\
\hline CAIDA ACCIDENTAL (4) & 3.92 & ... & 5.43 & 0.52 & $\cdots$ & 0.9 & 0.32 & $\cdots$ & 0.00 & 0.56 & $\cdots$ & 0.00 & 0.75 & $\ldots$ & 3.10 \\
\hline LEIONES C. EXT. IGNORADA (5) & 6.10 & ... & 0.19 & 5.01 & $\ldots$ & 0.00 & 1.81 & ... & 0.00 & 7.08 & ... & 0.00 & 6.92 & ... & 0.00 \\
\hline RESTO CAUSAS EXTERNAS (6) & 21.19 & ... & 27.36 & 13.50 & $\ldots$ & 23.03 & 8.24 & $\ldots$ & 10.39 & 16.24 & $\ldots$ & 30.59 & 17.34 & $\ldots$ & 30.09 \\
\hline & & & & & & & & & & & & & & & \\
\hline NTE DE TH & $\ldots$ & $\ldots$ & 12 & ... & $\ldots$ & 9.4 & $\ldots$ & $\ldots$ & 1.7 & $\ldots$ & $\ldots$ & 11.15 & $\ldots$ & $\ldots$ & 16.74 \\
\hline SUICIDIO (2) & -... & ... & 10.31 & ... & $\cdots$ & 6.01 & ... & $\cdots$ & 2.15 & $\ldots$ & ... & 6.15 & ... & $\cdots$ & 10.57 \\
\hline HOMICICDIO Y OTRAS (3) & $\ldots$ & $\ldots$ & 4.40 & ... & ... & 3.13 & $\ldots$ & $\ldots$ & 0.72 & $\ldots$ & ... & 3.46 & $\ldots$ & ... & 5.73 \\
\hline CAIDA ACIDENTAL (4) & $\ldots$ & $\ldots$ & 4.98 & $\ldots$ & $\ldots$ & 0.52 & $\ldots$ & $\ldots$ & 0.00 & $\ldots$ & $\ldots$ & 0.77 & $\ldots$ & $\ldots$ & 0.88 \\
\hline LESIONES C.EXT.IGNORADA (5) & & $\ldots$ & 0.03 & & & 0.00 & $\ldots$ & & 0.00 & $\ldots$ & $\ldots$ & 0.00 & $\ldots$ & & 0.00 \\
\hline RESTO CAUSAS EXTERNAS (6) & $\cdots$ & $\cdots$ & 29.90 & $\cdots$ & ... & 18.80 & $\ldots$ & $\cdots$ & 12.19 & ... & $\cdots$ & 24.62 & ... & $\cdots$ & 20.26 \\
\hline
\end{tabular}

* Tasas por 100.000 personas de cada grupo de edad Fuente: Sistema de Informacion Tecnica de la OPS

... Datos no disponibles.

(1) Códigos E810-E819, CIE IX; (2) Códigos E950-E959, CIE IX; (3) Códigos E960-969, E970-E978 Y E990-E999, CIE IX;

(4) Códigos E880-E888, CIE IX; (5) Códigos E980-E989, CIE IX; (6) Códigos E800-E807, E820-E879, E890-E949, CIE IX. 
La mortalidad por accidentes de tráfico se mantiene prácticamente invariable en la población general (aumenta en un 0,2\%), pero decrece en un $23 \%$ entre los adolescentes y jóvenes, concentrándose esta reducción en el subgrupo de 10 a 14 años (52\% de reducción).

La mortalidad por suicidio creció en un $8 \%$ en la población general, pero se redujo en un $53 \%$ en el grupo de 10 a 24 años, si bien en los grupos de edad de este último conjunto las variaciones son bastante disímiles (incrementos del 73\% en el subgrupo de 10 a 14 años y del $8 \%$ en el de 15 a 19 años, y caída del $16 \%$ en el subgrupo de 20 a 24 años).

La mortalidad por homicidios, si bien de menor magnitud que las anteriores, creció en un $68 \%$ entre 1980 y 1990 en la población general y en un $48 \%$ en el grupo de 10 a 24 años de edad.

La mortalidad por caídas accidentales, la tercera causa externa de muerte en Uruguay, muestra un pequeño decenso, del $6 \%$, en el período (47\% de reducción en el grupo de 10 a 24 años). Sin embargo, las pendientes de las curvas de evolución de la mortalidad debida a este grupo de causas son, en general, positivas y mínimas, dando lugar a un comportamiento más bien estacionario de este fenómeno.

En conclusión, la ligera reducción de la mortalidad por causas externas en Uruguay se explica principalmente por la moderada disminución de la mortalidad por accidentes de tráfico en el grupo de 10 a 24 años, ya que todos los demás grupos de causas crecen o se mantienen estacionarios.

\section{DISCUSION Y CONCLUSIONES}

\section{Comportamiento de la Tendencia de la Mortalidad por Causas Externas en la Región de las Américas}

Las descripciones realizadas anteriormente permiten formular ciertas conclusiones muy generales, que conciernen en especial a los países de cuya información de mortalidad por causas externas y por grupos de estas causas se pudo disponer. De hecho, sólo 15 países de la Región proporcionaron datos suficientes para satisfacer los requisitos mínimos de análisis de estadística fijados para este trabajo.

En relación con lo observado en estos 15 países, que representan al $87 \%$ de la población de la Región, se puede afirmar que, en general, la mortalidad por causas externas tendió a decaer en las Américas entre 1979 y 1990, dado que en nueve de estas naciones las tendencias del indicador son descendentes en todos los grupos de edad (Argentina, Canadá, Costa Rica, Chile, EE.UU. de Norteamérica, México, Suriname, Trinidad \& Tobago y Venezuela) y que en tres más, sea para la población general (Uruguay), sea para el grupo de 10 a 24 años (Panamá y Puerto Rico), se verifica también un movimiento decreciente. Sólo tres países de este conglomerado muestran tendencias francamente crecientes de su mortalidad por causas externas en todos los grupos de edad y en el grupo de 10-24 años (Brasil, Colombia y Cuba), mientras en otros dos (Panamá y Puerto Rico) tales movimientos se aprecian en la población general y en uno (Uruguay) afectan sólo al grupo de 10 a 24 años de edad. Además, salvo en los tres primeros, las velocidades de incremento calculadas son exiguas.

El comportamiento del fenómeno por grupos de edad y sexo y por grupos de causas externas permite anotar también algunas observaciones relevantes:

a. La interpretación de las series cronológicas y de los coeficientes de variación de período presentados debe tomar en cuenta la extensión de cada uno de los lapsos y las magnitudes de las tasas originarias en el cálculo. Así, por ejemplo, conviene recordar que las variaciones de período mayores o menores se ven influídas en cierta medida por la extensión del mismo, además de que las tasas muy bajas, que han resultado de exiguos números de defunciones, acusan variaciones porcentuales importantes que, a veces, corresponden a incrementos o decrementos numéricamente despreciables de la cantidad de decesos. 
Este fenómeno se observó frecuentemente en las mortalidades por grupos de causas externas en el subgrupo de 10 a 14 años en casi todos los países.

De igual manera, las velocidades de variación anual de estos indicadores dependen de la magnitud inicial de la tasa en cuestión, hecho que también se expresó constantemente en este estudio, sobre todo en relación con tasas muy elevadas o muy bajas. Así, por ejemplo, se calculó ritmos de reducción mayores para las tasas de mayor magnitud al inicio de la serie, mientras aquéllas que eran originalmente más bajas, mostraron mayor resistencia al descenso.

b. Respecto a la distribución por sexo, si bien existe una tendencia a la equiparación, los hombres continúan presentando un riesgo mayor de morir por causas externas.

c. Si se clasifica a los países de la Región según la magnitud de la mortalidad por causas externas que los afectó durante el período del estudio y si se los ordena según los rangos de variación máxima observados en sus tasas de mortalidad por causas externas, se confirma la configuración de tres grupos de naciones, según las magnitudes alcanzadas por este indicador.

El primer grupo, de los países de elevada mortalidad por causas externas entre 1979 y 1989, está constituído por Colombia, Cuba, Chile, México y Suriname, naciones en las que se llegó a máximos de 114 a 125 defunciones por 100.000 habitantes, mientras los mínimos rara vez bajaron de 65 decesos por 100.000 personas en ese período. En la población de 10 a 24 años de edad, las mortalidades oscilaron en estos países entre las 43 y las 105 muertes por 100.000 adolescentes y jóvenes.

El segundo grupo, de mortalidad de nivel intermedio, está conformado por Brasil, Canadá, EE.UU. de Norteamérica, Puerto Rico y Venezuela, países en que los máximos de la mortalidad por causas externas en el período oscilaron entre 66 y 74 defunciones por 100.000 habitantes, mientras los mínimos no fueron nunca inferiores a 51 muertes por 100.000. En el grupo de 10 a 24 años de edad de estos países, se conserva una proporcionalidad similar a la observada en el caso anterior, con mortalidades máximas por causas externas que fluctuaron entre las $45 \mathrm{y}$ las 69 defunciones por $100.000 \mathrm{y}$ con valores mínimos de entre 32 y 57 decesos por 100.000 mil adolescentes y jóvenes.

El tercer grupo, de moderada mortalidad, incluye a Argentina, Costa Rica, Panamá, Trinidad \& Tobago y Uruguay, países donde la mortalidad máxima por causas externas fluctuó entre las 51 y las 65 defunciones por 100.000 habitantes, mientras la mínima fue siempre inferior a 50 decesos por 100.000. En estos países se mantuvo igualmente la proporcionalidad observada en el grupo anterior en la mortalidad del grupo de 10 a 24 años de edad, oscilando sus valores máximos entre las 45 y las 55 defunciones por 100.000 adolescentes y jóvenes, mientras los mínimos llegaron hasta 25 decesos por 100.000 .

De las tablas presentadas en este trabajo se puede deducir las diferencias con que la problemática planteada por las causas externas incide sobre la mortalidad de las poblaciones de cada país. Así, por ejemplo, resulta evidente que, a pesar de sus tendencias decrecientes, la mortalidad por accidentes de tráfico es un grave problema en Brasil, Canadá, EE.UU. de Norteamérica y Venezuela, países donde además afecta fuertemente a la población de 10 a 24 años de edad, independientemente de que en la mayoría de ellos tienda al descenso.

De igual forma, se puede concluír que la mortalidad por suicidio constituye motivo de preocupación en Argentina, Canadá, los EE.UU. de Norteamérica, Suriname, Trinidad \& Tobago, y Uruguay, si bien generalmente es más elevada en la población general que entre los adolescentes y jóvenes. Por su parte, la mortalidad por homicidios o lesiones intencionales infligidas por otros es particularmente alarmante en Colombia, Brasil, México, Panamá, Puerto Rico y Venezuela, especialmente por sus expresiones entre los adolescentes y jóvenes.

Por último, en relación con el comportamiento global de los tres grupos de 
causas externas (accidentes de tráfico, suicidio y homicidio), hay que señalar claramente que el único que muestra tendencias inequívocas al descenso en la mayoría de los países de la Región es el de la mortalidad por accidentes de tráfico, ya que la mortalidad provocada por lesiones intencionales de toda índole parece propende al aumento en ellos, afectando de manera muy preocupante a los adolescentes y jóvenes, y en particular, al subgrupo de 15 a 19 años de edad.

\section{El Papel del Sector Salud en la Prevención} de la Mortalidad Debida a Causas Violentas

Los dados demonstrados en este documento constituyen base suficiente para otorgar a las actividades destinadas a su prevención un sitial preponderante entre los objetivos de salud que deberán ser cumplidos en esta década. Para prevenir la mortalidad por causas externas implica al menos considerar tres niveles de acción:

Prevención de la Incidencia de Hechos Violentos y de la Ocurrencia de Lesiones a Través de Medidas de Promoción de la Salud

\section{Factores Psicosociales y Violencia}

El uso de la fuerza física o de cualquier otro procedimiento con el propósito de producir daño a los demás es quizás uno de los mayores retos con los que se enfrenta la Salud Pública moderna.

Las consecuencias devastadoras de las guerras vividas en la Región en la última década son conocidas. A fines de 1987, la guerra de Nicaragua había causado el cierre del $25 \%$ de los establecimientos de salud. El embargo comercial inducía carencia de productos básicos y farmacéuticos y deterioro de los recursos para la salud. $\mathrm{Su}$ reconstrucción costaría dos veces el presupuesto anual de salud. Además, un $0,2 \%$ de la población había muerto en acciones de guerra (Garfield, 1989). En El Salvador, la guerra provocó el desplazamiento de casi un tercio de la población. La probabilidad de morir de estos desplazados era más de tres veces mayor que la de la población general del país (Lundgren \& Lang, 1989). En Panamá, la mortalidad por causas externas aumentó abruptamente en 1989, a expensas de los grupos de causas externas denominados "Lesiones Resultantes de Operaciones de Guerra" e "Intervención Legal".

En otros países de la Región, la violencia ha adoptado formas menos visibles, pero igualmente perniciosas. La injusticia, en sus múltiples formas, parece estar en el origen del problema de la violencia. Gran parte de la injusticia que padecen las sociedades de las Américas es de tipo social y, en períodos recientes, la violencia adquirió en muchas de estas sociedades un carácter político (Ugalde, 1989), habiéndose organizado también institucionalmente, con lo cual la tortura y el terror se convirtieron, durante las décadas pasadas, en hechos cotidianos y tristemente comunes.

El incremento generalizado de la mortalidad por lesiones intencionales en la Región debe ser relacionado con "la agudización de las desigualdades económico-sociales, con los efectos directos e indirectos de la crisis económica, con la intensificación de conflictos bélicos internos o estimulados desde el exterior y con el incremento de la circulación y del consumo de drogas" (OPS, 1990).

Factores económicos y sociales diversos han incidido además en la difusión del consumo de una variedad de agentes psicoactivos, especialmente entre los adolescentes y los jóvenes, cuyos efectos se suman a los ya conocidos daños resultantes de la ingestión de alcohol.

El consumo per cápita de alcohol absoluto ha tendido a aumentar en la Región. Los últimos datos disponibles para algunos países, correspondientes al segundo quinquenio de la década de 80, dejan ver que, en el lapso del decenio anterior a esa fecha, este indicador creció en cerca de un $7 \%$ en Colombia y Chile, en un $11 \%$ en México, en un $16 \%$ en Panamá, y en un $31 \%$ en Brasil, para mencionar sólo algunos de los países de elevada mortalidad por causas externas. En varias de estas naciones (Chile, México, Panamá, Puerto Rico), el riesgo relativo de morir por 
cirrosis hepática es cuatro a seis veces mayor que en Canadá (Peruga, 1989).

Respecto al consumo y al abuso de las demás sustancias psicoactivas, las de mayor prevalencia de uso en la Región son las benzodiazepinas, los barbitúricos y la Cannabis sativa. En algunos países del Área Andina y en América del Norte hay que añadir el consumo de las diversas formas de cocaína y en esta última sub-región, el de heroína.

La prevalencia de uso de fármacos de propiedades sedantes ha sido medida en diversos estudios durante la década pasada. La prevalencia del consumo de fármacos sedantes osciló entre un $7,2 \%$ en una muestra de 20.000 estudiantes en Brasil y un 19,6\% en una muestra de población tomada en Perú (Peruga, 1989).

En Chile, las ventas de fármacos presentan tendencias crecientes, especialmente en lo que se refiere al consumo de tranquilizantes (Larraín, 1987). Una encuesta acerca del consumo de benzodiazepinas en la Provincia de Santiago, aplicada a una muestra de la población de 15 años y más, demostró una prevalencia global de uso de estos fármacos de un 42,9\% (Busto, 1992).

Según algunos estudios, el porcentaje de individuos que ha consumido Cannabis por lo menos alguna vez en su vida fluctúa entre el $21,2 \%$ y el $38,8 \%$, en los países industrializados, y entre el $6 \%$ y el $11 \%$, en los países en desarrollo. Entre los jóvenes, la prevalencia osciló entre 3,2\% en México y el $40 \%$ en Chile (Murelle et al., 1989).

El consumo de cocaína es tradicional en algunas zonas del Área Andina. Bolivia, Colombia, Ecuador y Perú son los mayores productores de hoja de coca en todo el mundo. Estudios fotogramétricos realizados en esta área demuestran que existen unas 60.000 hectáreas dedicadas al cultivo del arbusto de la coca, estimándose el volumen de la producción de hojas de coca en 118 mil toneladas métricas anuales. La mayor parte de la cocaína elaborada en esa sub-región es exportada a los países industrializados, donde la prevalencia de uso de este alcaloide ha sido estimada en cifras que oscilan entre el $4 \%$ y el 16,8\% de los estudiantes de educación secundaria. En América Latina, la prevalencia de consumo de cocaína varía entre el 1,4\% y el 6,7\% de la población de 12 a 45 años, según diversos estudios (OPS, 1990). Sin embargo, una encuesta de prevalencia realizada en mayores de 10 años en cuatro ciudades de Chile (Arica, Iquique, fronterizas con países productores de coca y Santiago y Valparaíso) en 1991 (Pemjean, 1991) reveló que el $25 \%$ de los entrevistados había consumido cocaína al menos una vez durante el año anterior al momento de la entrevista.

Aparte de las sustancias mencionadas, los grupos juveniles marginales de muchas urbes latinoamericanas y caribeñas consumen inhalantes (solventes industriales, nitrato de amilo y pegamentos). En Chile y en México se ha detectado prevalencias de uso de estas sustancias de entre el $3 \%$ y el $4,4 \%$ de los estudiantes de la Educación Media, respectivamente.

Pese a la gravedad de los fenómenos descritos, los programas de prevención de las adicciones en los países de la Región son aún incipientes y adolecen de limitaciones conceptuales y técnicas, que les restan posibilidades de eficacia.

Por otra parte, excepto para el caso de las relaciones entre consumo de alcohol, nivel de alcoholemia e incidencia de accidentes del tránsito de vehículos a motor, no se dispone de estudios suficientes, en la Región, que permitan precisar las repercusiones del uso y del abuso de diversas drogas sobre la ocurrencia de hechos violentos. Incluso frente a los accidentes del tránsito es inusual aún en la mayoría de los países de la Región, que se verifique la presencia de alcaloides $\mathrm{u}$ otros tóxicos diferentes del alcohol en el torrente circulatorio de los conductores.

\section{Prevención de la Violencia y de las Lesiones Debidas a Hechos Violentos, por Medio de Medidas de Protección Específica. Responsabilidades del Sector Salud}

El deterioramiento de los indicadores de la salud, generado por la acción de las causas externas, es susceptible de una identificación muy precisa de sus factores de riesgo, frente a los cuales es perfectamente posible adoptar medidas preventivas idóneas. 
La atención de los lesionados y de los discapacitados por accidentes de tráfico y del trabajo representa una pesada carga para los Servicios de Salud y para las instituciones de Seguridad Social. Las causas determinantes y condicionantes de estos eventos son conocidas, además de no existir latencia entre la aplicación de las medidas preventivas y la reducción de la incidencia del fenómeno, a diferencia de lo que ocurre con muchas enfermedades crónicas no transmisibles. "De aquí que se pueda afirmar que cualquier progreso en la disminución del número y de la gravedad de los accidentes mejoraría significativamente las condiciones de salud de la población de la Región, en especial de la de adolescentes y jóvenes y liberaría de inmediato a los servicios asistenciales de una demanda impostergable, compleja y de alto costo" (Yunes \& Rajs, s/d).

La reducción de la accidentabilidad solamente será lograda con el enfoque intersectorial y con la participación social efectiva.

Por otra parte, es fundamental mejorar la capacidad de los servicios de salud para asistir a los lesionados dado que una atención oportuna y eficiente reduce la letalidad, disminuye los tiempos de tratamiento y limita la extensión de las secuelas.

El sector salud en este campo no puede continuar restringuiéndose en los estrechos límites de la atención y del registro de los casos, sino que requiere de la adopción de un rol más activo en distintas esferas, entre las que se puede mencionar a las siguientes:

\section{a. Prevención de Accidentes del Trabajo}

El sector debe participar, en conjunto con las organizaciones laborales, en el diseño de funciones y de puestos de trabajo, en la vigilancia del cumplimiento de normas saludables en relación con la duración, ritmo, grado de demanda psicofisiológica y control de riesgos específicos de la jornada laboral y en el desarrollo de programas de educación y capacitación de los trabajadores, que les permitan elevar su capacidad de control sobre los riesgos vinculados al proceso específico de trabajo en que se desempeñan. Para orientar mejor los programas de prevención sería importante que las estadísticas oficiales registrasen las defunciones por causas externas causadas por accidentes de trabajo. La Clasificación Internacional de Enfermedades no posibilita esta especificación.

\section{b. Desarrollo de Programas de Seguridad Vial y Prevención de Accidentes del Tráfico}

Además de la ejecución de programas intersectoriales de educación dirigidos tanto a los grupos de riesgo como a la población general, éstos deben contemplar la implantación de normas relativas a la seguridad de la estructura y de la señalización de las vías de comunicación por tierra y al control del estado mecánico y de dotación de los vehículos terrestres, acuáticos y aéreos.

En lo que respecta al tránsito terrestre, el sector salud debe llamar la atención sobre la totalidad del problema, no reduciéndolo sólo a las actividades educativas, ya que muchas de ellas no tendrán efecto alguno, mientras no se otorgue facilidades y no se establezca normas para el mantenimiento y para la dotación de mecanismos de protección a los vehículos de carga y de transporte de pasajeros (uso de cinturones de seguridad y otros dispositivos protectores, restricción de los límites de carga aceptables y otros) y para la disposición de carreteras idóneas para el tránsito de vehículos.

A su vez, las medidas de seguridad vial deben tomar en cuenta las particularidades biopsíquicas de ciertos grupos de mayor riesgo, como los adolescentes y jóvenes, como también la educación de los conductores y de los trabajadores del transporte, con el fin de controlar los riesgos provenientes de las conductas humanas.

\section{c. Lucha en Contra del Consumo de Alcohol y de Sustancias Psicoactivas}

La difusión de contenidos educativos acerca de los riesgos derivados del consumo de 
alcohol y de las demás sustancias psicoactivas será eficaz en la medida en que se acompañe de la adopción de otras medidas de política social y económica, que favorezcan el pleno desarrollo de las potencialidades humanas y garanticen la estabilidad laboral, familiar y comunitaria.

El sector salud puede contribuír a la formulación de políticas y de estrategias de control y de eliminación de las adicciones y del consumo excesivo de diversas drogas, aportando conocimientos epidemiológicos acerca de sus orígenes económico-sociales, incluyendo los que atañen al narcotráfico y acerca de sus efectos sobre las poblaciones involucradas [en Chile se ha constatado recientemente la existencia de un "foco epidémico" de consumo de derivados de la cocaína en las ciudades de Arica e Iquique, fuertemente afectadas por el tráfico de drogas ilícitas (Pemjean, 1991). Al parecer, fenómenos similares han sido detectados en otros países de la región donde se ha incrementado este comercio], con el fin de que éstos sirvan de fundamento para la reorientación de las medidas preventivas, superando los estrechos marcos jurídicos y policiales en que habitualmente son mantenidas.

Pueden ser consideradas como premisas para el éxito de los programas de salud destinados a la prevención del consumo y de la adicción a sustancias psicoactivas, las siguientes:

- Que éstos sean estrictamente orientados por objetivos de salud, excluyendo expresamente cualquier otra finalidad;

- Que se basen en una estrategia de democratización del conocimiento científico sobre la salud, compartiendo con la población los datos objetivos disponibles acerca de la nocividad de diversos agentes químicos y de los riesgos de accidentabilidad relacionados con el consumo mínimo o excesivo de los mismos y eliminando toda tendencia a culpabilizar a los adictos;

- Para el caso del consumo de sustancias psicoactivas ilegales, que hagan evidencia pública de la total prescindencia del sector salud en los asuntos policiales o judiciales relacionados con el narcotráfico;

- Que incluyan la supresión definitiva y rigurosa de la publicidad de las sustancias nocivas para la salud legalmente comercializadas (tabaco, alcohol y medicamentos) como medio de contribuír a la prevención de las adicciones antes del ingreso a la edad adulta, dado que el agregado de advertencias acerca de los posibles daños que sufrirá quien consuma determinados productos, una vez que éstos han sido publicitados, parece insuficiente para frenar la difusión de esas prácticas.

\section{d. Prevención de la Violencia en las Relaciones Intrafamiliares, Comunitarias, Sociales y Políticas}

La participación del sector salud en la adopción de medidas de prevención de la mortalidad por causas violentas y de promoción de cambios en las normas de convivencia, a través de la educación y de una legislación social amplia, que aborde el conjunto de las mismas, debe ser entendida como un proceso que integre a diversos actores sociales en el desarrollo de estrategias conducentes a la humanización de todas las formas de conflicto social.

Esto implica, en primer lugar, reconocer la existencia y establecer la magnitud y los factores determinantes de las distintas formas de violencia familiar, étnica, laboral, delictual, estatal y política que se manifiestan hoy en nuestras sociedades, enfatizando en aquéllas peor estudiadas, como la que afecta a mujeres, ancianos y niños al interior de sus hogares. Requiere, a su vez, no sólo de la participación social e intersectorial, sino del concurso de varias áreas especializadas de los Servicios de Salud, entre las que cobran especial importancia las relacionadas con la Salud Psicológica y con la Rehabilitación.

La eliminación de las discriminaciones por sexo, edad, raza, religión, posición económica o política u otras características individuales es otro campo en el que debe hacerse presente el sector salud, destacando la incidencia de las desigualdades sociales sobre los problemas de salud. 
Prevención de las Complicaciones de las Lesiones Resultantes de Hechos Violentos a Través del Tratamiento Oportuno e Eficaz

Es fundamental la adopción de por lo menos las siguientes medidas:

- Educación masiva de la población en el cuidado inicial del traumatizado;

- Creación de mecanismos de atención de urgencia en el sitio de la ocurrencia y de un sistema de transporte suficiente y oportuno;

- Definición de la participación de los establecimientos de todos los niveles de la atención en el sub-sistema, especificando el alcance de sus capacidades resolutivas en relación con la atención de lesionados;

- Eliminación de toda barrera económica o geográfica para el acceso a la atención profesional de los pacientes que han sufrido traumatismos;

- Instauración de un sistema de vigilancia epidemiológica de los accidentes y de las demás violencias y de mecanismos de evaluación periódica del funcionamiento y de los logros del sub-sistema;

- Formulación e implantación de normas clínicas para el tratamiento de lesionados en todos los niveles de la atención;

- Implantación de una red de servicios de emergencia, dotada de recursos para la atención de lesionados de diversa gravedad;

- Creación o integración de los servicios de rehabilitación al sub-sistema;

- Capacitación del personal profesional y auxiliar de los servicios de salud en los aspectos clínicos y epidemiológicos correspondientes, considerando que actualmente son escasas las instituciones de formación de profesionales de la salud que incluyen en sus planes de estudios esta temática.

\section{RESUMEN}

YUNES, J. \& RAJS, D. Tendencia de la Mortalidad por Causas Violentas en la Población General y Entre los Adolescentes y Jóvenes de la Región de las Américas. Cad. Saúde Públ., Rio de Janeiro, 10 (suplemento 1): 88-125, 1994.

Se analiza la tendencia de la mortalidad por causas externas y grupo de causas en 15 países, durante el período de 1979 a 1990. Se demuestra que en nueve países (Argentina, Canadá, Costa Rica, Chile, EE.UU. de Norteamérica, México, Suriname, Trinidad \& Tobago y Venezuela) la tendencia de la mortalidad es descendiente en todos los grupos de edad estudiados y que en tres más, sea para la población general (Uruguay), sea para el grupo de 10 a 24 años (Panamá y Puerto Rico), se observa tambien una tendencia decreciente. Solo tres países (Brasil, Colombia y Cuba) muestran tendencias francamente crecientes de su mortalidad en todos los grupos de edad, mientras en otros dos (Panamá y Puerto Rico), tales movimientos se aprecian en la población en general y en uno (Uruguay), afectan solo al grupo de 10 a 24 años de edad.

La mortalidad por causas externas segun grupo de edad se concentra frecuentemente en el grupo de los adolescentes y jóvenes y las tendencias de la mortalidad por sexo, aunque predomine en el sexo masculino, las diferencias tienden a disminuir. Segun la magnitud de la mortalidad por causas externas se configuran tres grupos de países, de acuerdo a las tasas alcanzadas por este indicador: países de elevada mortalidad (Colombia, Cuba, Chile, México y Suriname); países de nivel intermedio (Brasil, Canadá, EE.UU. de Norteamérica, Puerto Rico y Venezuela); y países de moderada mortalidad (Argentina, Costa Rica, Panamá, Trinidad \& Tobago y Uruguay). En relación a los grupos de causas externas resulta evidente que, a pesar de sus tendencias decrecientes, la mortalidad por accidentes de tráfico continúa siendo un grave problema en Brasil, Canadá, EE.UU. y Venezuela. La mortalidad por suicidio sigue siendo motivo de preocupación en Canadá, EE.UU., Suriname, Trinidad \& Tobago, Argentina y Uruguay. 
En relación a la mortalidad por homicidio, ésta es particularmente alarmante en Brasil, Colombia, México, Panamá, Puerto Rico y Venezuela, especialmente por sus expresiones entre los adolescentes y jóvenes. En relación al comportamiento global de los tres grupos de causas externas (accidentes de tráfico, suicidio y homicidio) se observa claramente que el único que muestra tendencias inequívocas al descenso en la mayoría de los países de la Región de las Américas es el de los accidentes de tráfico, mientras que la mortalidad provocada por homicidio y suicidio en algunos tienden al aumento, afectando de manera muy preocupante a los adolescentes y jóvenes y, en particular, al grupo de 15 a 19 años de edad. El trabajo tambien propone cual debería ser el papel del sector salud en la prevención de la mortalidad debida a causas violentas.

Palabras Clave: Violencia; Mortalidad; Adolescentes; Epidemiología

\section{REFERENCIAS}

ANZOLA-PÉREZ, E. \& BANGDIWALA, S., 1991. La Cambiante Estructura de las Muertes por Accidentes y Violencias en América Latina. Seminario sobre Causas y Prevención de la Mortalidad de los Adultos en los Países en Desarrollo, 07 a 11 de outubro, Santiago de Chile: Celade/IUSSP/OPS. (Mimeo.)

AALUND, O., DANIELSEN, L. \& SANNHUEZA, R. O., 1990. Injuries due to deliberate violence in Chile. Forensic Science International, 46: 189-202.

BUSTO, M. A., 1992. BDZ: La Tranquila Adicción de Santiago. Santiago de Chile: Corporación de Salud y Políticas Sociales (Corsaps). (Cuaderno de Trabajo, 2)

CANO, G. E., 1989. Análisis Situacional de la Salud del Adulto en las Américas. Programa de Salud del Adulto. Informe de Consultoría, abril. Washington, D.C: OPS. (Mimeo.)

CEPALC (Comisión Económica para América Latina y el Caribe), 1989. Balance Preliminar de la Economía de América Latina y el Caribe 1989. Santiago de Chile: Cepalc. (Mimeo.) , 1990. Transformación Productiva con

Equidad. La Tarea Prioritaria del Desarrollo de América Latina y el Caribe en los Años Noventa. Santiago de Chile: Cepalc. (Mimeo.)
, 1991. Balance Preliminar de la Economía de América Latina y el Caribe 1991. Santiago de Chile: Cepalc. (Mimeo.)

DANIELSEN, L.; AALUND, O.; MAZZA, P. H. \& KATZ, G., 1989. Injuries due to deliberate violence in areas of Argentina. II. Lesions. Copenhagen study group. Forensic Science International, 42: 165-175.

FRANCO, A. S., 1990. La violencia: un problema de salud pública que se agrava en la Región. Boletín Epidemiológico OPS, 11: 01-07.

GARCIA, N., 1992. Políticas de Ajuste y Mercado de Trabajo. Seminario Latinoamericano: Ajuste, Políticas Sociales y Condiciones de Vida. X Asamblea General de la Asociación Latinoamericana de Organizaciones de Promoción (ALOP). Santiago de Chile: Cepalc. (Mimeo.)

GARFIELD, R. M., 1989. War-related changes in health and health services in Nicaragua. Social Science and Medicine, 28: 669-676.

HÍJAR MEDINA, M. C., 1986. Mortalidad por accidentes, violencias y envenenamientos en el Distrito Federal, de 1980 a 1982. Salud Pública de México, 28: 413-437.

LARRAÍN, C., 1987. La Industria Farmacéutica en Santiago: 1968-1985. Antecedentes Económicos. Santiago de Chile: Colegio Médico de Chile, Departamento de Salud Pública, Consejo Regional Santiago.

LUNDGREN, R. J. \& LANG, R., 1989. There is no sea, only fish: Effects of United States policy on the health of the displaced in El Salvador. Social Science and Medicine, 28: 697-706.

MELLO JORGE, M. H. \& BERNARDES MARQUES, M., 1985. Violent childhood deaths in Brazil. Bulletin of Pan American Health Organization, 19: 288-299.

MINAYO, M. C. S., 1990. Bibliografia Comentada da Produção Científica Brasileira sobre Violência e Saúde. Rio de Janeiro: Escola Nacional de Saúde Pública, Fiocruz. (Coleção Panorama ENSP, 2)

MURELLE, L.; ESCALONA, R. \& FLORENZANO, R., 1989. Perfiles Epidemiológicos Nacionales sobre Consumo de Alcohol y Otras Drogas en América Latina. Informe del Grupo Asesor de Epidemiología de la Farmacodependencia. Chappel Hill, North Carolina: OPS. (Mimeo.)

OPS (Organización Panamericana de la Salud), 1990. Las Condiciones de Salud en las Américas. Edición de 1990. Vol. I, Washington, D.C.: OPS. (Publicación Científica, 524) , 1993. Violencia y Salud - Doc. CE 111/19, junio-julio. Washington, D.C.: Consejo Ejecutivo/OPS. 
PEMJEAN, A., 1991. Prevalencia de Patrones de Consumo de Drogas en Población General

Urbana (Encuesta de Drogas en Población General: Arica, Iquique, Valparaíso, Santiago). Santiago de Chile: Ministerio de Salud, Unidad de Salud Mental. (Mimeo.)

PERUGA, A., 1989. La Salud de los Adultos en las Américas: Factores de Riesgo y Condiciones de Salud. Informe de Consultoría, Programa de Salud del Adulto, abril. Washington, D.C: OPS. (Mimeo.)

RAJS, D. \& SANDOVAL, H., 1992. La Salud del Adulto en las Américas. Programa Regional de Promoción de la Salud. Washington, D.C.: OPS. (Mimeo.)

SÁEZ, A. \& RAJS, D., 1992. Mortalidad por Causas Externas en la Región Metropolitana de Chile. Santiago de Chile: Grupo de Investigación y Capacitación en Medicina Social (GICAMS), Servicio Médico Legal de Chile. (Mimeo.)

TOKMAN, V., 1992. Producto, Desocupación, Salario Mínimo y Sector Informal. Conferencia de Prensa, Santiago de Chile, 8 de Mayo. (Mimeo.)
UGALDE, A., 1989. Towards an epidemiology of political violence in the third world. Social Science and Medicine, 28: 633-642.

U. S. DEPARTMENT OF HEALTH \& HUMAN SERVICES, 1991. Position Papers from The Third National Injury Control Conference, Denver, Colorado, april 22-25. Atlanta: Public Health Service, Centers for Disease Control, National Center for Environmental Health and Injury Control, Division of Injury Control in conjunction with National Institute for Occupational Safety and Health, National Highway Traffic Safety Administration.

YUNES, J., 1993. Mortalidad por causas violentas en la región de las Américas. Boletin de la Oficina Sanitaria Panamericana, 114: 302-316.

YUNES J. \& RAJS, D., (s/d). Mortalidad por Causas Violentas entre los Adolescentes y los Jóvenes de la Región de las Américas, United States. Washington, D.C.: OPS. (no prelo) 